\title{
RELAÇŌES ENTRE OS SOLOS E ELEMENTOS DA PAISAGEM NA ZONA DO BAIXO RIO DO PEIXE (REGIÃO CONCHAS-ANHEMBI, S.P.)
}

CARLOS ROBERTO ESPINDOLA

Orientador: GERALDO VICTORINO DE FRANÇA

\begin{abstract}
Dissertação apresentada à Escola Superior de Agricultura "Luiz de Queiroz", da Universidade de São Paulo, para obtenção do título de Mestre em Solos e Nutrição de Plantas.
\end{abstract}

PIRACICABA

Estado de São Paulo - Brasil

Novembro, 1977 
À memória de

TANCREDO ESPINDOLA FILHO,

meu pai e incentivador

\section{Para}

CLARA, RODRIGO, CAROLINA E FILIFE,

que compensam qualquer esforço

Ao amingo

JOSÉ FEREIRA DE QUEIRUZ NETO,

a quem devoto particular adni ração e estina. 
Diversas são as pessoas e insitituições que, de uma forna ou de outra, prestaram seu inestimável apoio no de senvolvimento dessa pesquisa, aos quais o autor consigna seus agradecimentos.

Ao Oricntador, Dr. Geraldo Victorino de França, a quem muito devo em minha fornação científica, peio apoio amigo e confiança em mim depositada.

Ao Dr. Gilberto José Garcia, junto a quem tive a honra de iniciar parte do presente trabalho.

fio Dr. Hélcio Rocha Galhego, compantieiro incansável e constancie no decorrer das análises de laboratório e da elaboração dessa Dissertação.

Ao Dr. José fereira de Oueiroz Neto, pelas sugestões oferecidas e também nor uma grande parcela de minha formação na docência e pesquisa.

A Dra. Wolmar npparecida Carvalho, pelo auxílio na execução da triangulação radial.

A equipe de pesquisadores e técnicos da office de la Recherche Scjentirique et Technique Durre nier (ORSTOM)- França, pelos magnificos momentus passados nessa Instituição de alto gatarito internacional, onde cinco meses podem re presentar muitos anos na vida profissional de um pesquisador. Agradecimentos particulares aos Drs. 1. Segalen, D. Dabin, M. Lamouroux, Minta, com quem tivemos maior contato, e aos técnicos F. Fusil, M. Koukoui, D. Rambaud, pela genilileza, de dicação e solicitude disponsadas, no auxilio das determinações mineralógicas.

À Fundação de Ampero à resquisa do Estado de São Paulo (FAPESF), pela possibilidade de estágio na ORSTom, onde, além da execucão do plano de pescuisa a ela proposto,pu de desenvolver peralelamente as análises mineralógicas do pre 
sente trabalho.

Aos Drs. Antonio Evaldo Klar, pelo auxilio no re sumo em Inglês, e Bário Raimundo Cirne, pelas sugestões com ralação à parte gráíca.

Ao SI. Francisco llartins Filho, pela solicitude e presteza na datilorrafia do trabalho.

Aqueles que, direta ou Indiretamente, contribuiram para a realizaça desta pesquisa. 
Fágina

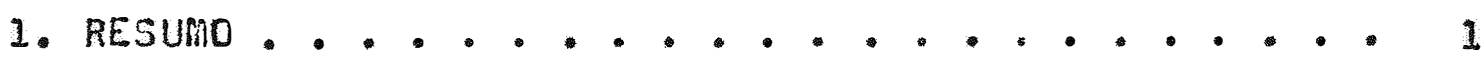

2. Introduç̃o . . . . . . . . . . . . 3

3. REVISÃ́ dA LITERATURA . . . . . . . . . . 5

4. MATERIAIS E mÉtodos . . . . . . . . . 22

4.1. Descrição do meio físico . . . . . . 22

4.1.1. Região de estudo ........ 22

4.1.2. Clima ......... 22

4.1.3. Geologia .......... 23

4.1.4. Solos e relevo ........... 23

4.1.5. Vegetação........... 28

4.2. Estudo das redes de drenagem......... 28

4.3. Estudo dos solos e das alterações ..... 30

4.3.1. Amostragen e preparo do material para análise......... 30

4.3.2. Análise granulométrica . . . . . 32

4.3.3. Análise química do solo ..... 32

4.3.4. Análises mineralógicas ..... . 33

5. RESULTAdOS E diSCUSSÑo . . . . . . . . 35

5.1. Análises morfológicas, granulométricas e quínicas ................ 35 
vi.

Rágina

5.1.1. Descrições morfológicas ....... 35

3.1.2. Análises granulométricas e quínicas dos perfis.................. 40

5.1.3. Comentários sobre os resultados morfológicos, físicos e químicos. . . . . . 43

5.2. Análises mineralógicas .......... 4 49

6.2.1. Dirração de raios $x$ e análise térmica dí ferencial . . . . . . . . 49

5.2.2. Microscopia eletrônica . . . . . . 62

5.2.3. Confronto entre os resultados mineralógi $\cos . . . . . . .662$

5.3. Análise da rede de drenagen e da evolucão do re lêvo................. 71

5.4. Quadro analílico da evolução da paisagem . . 87

6. conclusões . . . . . . . . . . . . . . . 94

7. SUMmRY . . . . . . . . . . . . . 9 97

๑. LiteratuRA citada . . . . . . . . . . . 99 


\section{LISTA DE ILUSTRACÕ̃ES}

TABELA

Página

1 - Resultados das análises granulonétricas dos perfis................. . 41

2 - Resultados das análises químicas dos porfis. 42

3 - Valores de densidade de drenagem (Dd) e frequência de rios (FI), por repetjcão...... 84

4 - Análise de variâncja e teste de Tukey. . . 84

\section{FIGURA}

1 - Mapa geolágico simplificado do centro-leste do Estado de São Paulo (SDAREs, 1975). . . .. 24

2 - Perfil geológico, Rodovia Marechal Rondon (SP) Grupo São Bento, seção-tjpo da Formação Piranbóla (SOARES, 1975). . . . . . . . . 25

3 - Esquema de localização da região, apresentando as três áreas estudadas . . . . . . . 27

4 - Folha topográfica de uma parcela da ragião de estudo (FUNDASño IEGE, 1970). . . . .. 29

5 - Difratogramas de amostras da área A (JUQUIRATI $\mathrm{BA}) . . . . . . . . . . . .51$

6 - Termogramas de argilas dos perfis estudados. 52

7 - Difratogranas da rocha integral e da argila de la extraída (Perfil Liar/2). . . . . . 55 
FIGURA

B - Difratogramas de amostras da área B (FIRAliBólA . . . . . . . 57

9 - Difratogramas de amostras da área c (ANHEliBI). ............... 59

20 - Micrografia eletrônica da argila extráda da rocha do perfil Liar/2. . . . ... 63

11 - Viicrografia eletrônica da aruila da onosira PVA $\times$ Liar - B/C. .........

12 - lijerograria eletrônica da argila da amostra $\mathrm{RLV} / 1$ - $\mathrm{B}_{1} \ldots \ldots$. . . . . . . . 64

13 - Microcrafia elotrônica da argila extraída da rocha do perfil Li/l ....... 64

14 - Evolução das "cabeceiras de erosão" na área A - Decento 1962/1972......... 73

15 - Evolução das "cabeceiras de erosão" na área B-Dacênio 1962/1972. . . . . . .

16 - Evolução das "cabeceiras de erosão da área. C - Decênio 1562/1972. . . . . . . 75

17 - Perfil topocráfico esquemático, ao longo da rodovia de acesso a Anhembi, a partir da fia rechal Rondon. . . . . . . . 78

18 - Amostras circulares $\left(10 \mathrm{~km}^{2}\right)$ da rede de dre nagen da área $A$ (JURuiratiba). ......

19 - Amosiras circulares $\left(10 \mathrm{~km}^{2}\right)$ da rede de dre nagem da área B (PIRAmé́í)........ 
FIGURA

Página

20 - Anostras circulares $\left(10 \mathrm{~km}^{2}\right)$ da rede de dre nagem da área C (ANHEMBI)....... 83 
1. RESUMO

E estudada uma região situada entre os munićźpios de Concines e finhembi, Estado de São faulo, que revela a presença de três distiintas áreas, com relação à distrübuição dos solos e variações do rolevo. Na área i (Juquiratiba) pre domina o Litossulo - fase substrato arenito calcário, sob um relevo fortemente ondulado; na B (Pirambóia) ocorre o Regosso 10 "intergrade" para Latoss lo Vermelho fmaralo (RLV), sob re lovo suavenente onduldo, e na $C$ (hnhembi) domina o podzólico Vernelho imarolo - variacão Laras, sob relevo ondulado. fireni tos da Formação Pirambóia (fiesozóico) são os materiais que o. correm por execlência, com presença secundária da formaça Es trada Nova (Paleozóico).

Com o intuito de estabelecer as relações entre os solos e a paisagem, procedeu-se. ao estudo fotointerpretatz vo das redes de drenagen de cada área (h, B e C) e do grau de evolução dos perfis, por internédio de descriçöes mor foló 1 cas, análises písicas e químicas de robina e análises mineralópicas (difração de rałos $x$, análise térmica diforencial e nicruscopia eletrônica).

Un alto grau de evoluço foi verificado nos per fis da área B, em oposicão aos Litossolos da área fi, com ní- 
vel intermediário de alteração para os Podzólicos, que dominam na área $C$, en runção da profundidade, índice de saturação de bases, atividade do complexo trocável, tipos de argilas e mobilidade das fracões finas. A montriorilonitu predomina nos meios coninantes (Litossolos a outros solos pouco espessos), alterando-se para caulinita nos perîs nais evoluidos e ben drenados.

As 7 amostras circulares de $10 \mathrm{~km}^{2}$, tonadas 20 acaso, en cada área nosiraram diferenças significatives entre as densidedes de drenagem (Dd) e as frequências de rios ( $F I$ ) de cada ume, com os seguintes valores médios, respectivamente: $A=3,02$ e 11,50; $B=1,62$ e 4,10; $C=2,61$ e 0,76, refletindo as distintas relações infiltroção/deflúvio en cada uma delas e, portanto, diferentes resistências à erosão.

Ao lado dos processos erosivos atuais, observados ao longo das vertentes e nas planicies aluviais, tais mecanismos violentos ocorrentes en outros períodos, ao longo do quaternáicio, foran os responsáveis pelo desmantelanento da su perfície de erosão anirga aí instalada (Neogênica), fropician do a formacão de solos jovens em vertentes (Litossulos e podzólicos), correspondentes a uma superfície geomorfólogica ten tativamente dalada no Pleistoceno Superior. Nas áreas onde o relevo não ofereceu condições pera tais ocorrências, permaneceram solos anticos (RLV), possivelmente com contribuicões de materiais velhos e pobres à montante, nas quais o cerrado, ve getação característica dessas formações arenosas espessas, mantido, testemunhando climas meis secos ao longo do quaterná rio; esta seria a outra superfície característica da reg̃ião estudada, correlacionada ao pliompleistoceno.

Os múltipilos aspecios analisados mostram que as diversidades verificadas são explicadas com base nas variações do material de origeri, nas idades e posições topográricas dos perfis. 


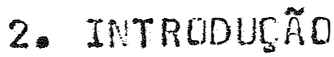

A presença de diferentes pormações supewiciais, ou de distintas unidades de solos, dispostas om áreas contí guas, de Iitologia semelhante e em comparimentos topográficos distintos, tem levado o pescuisador a supor diferentes graus de altonacão para os perfis correspondentes.

Entretanto, ao considerar tal hipótese como ves dadeira, sua curiosidade cientîica não the permice deter-se apenas na sua comprovação. Uma vez que os perfis guardan, entre si, estreitas relações genéticas en dilerentes unidades do relevo, ele se questiona a respeitio do caráter dessas diversidades fisiogrépicas, na tentativa de reconstituir a história evolutiva da paisagen, que está associada, em suma, à prólicia gênese dos perfis.

Porém, a que grau diforentes unidades de solos poderiarn corasponder a distintas "categorias de relevo"? A resposta para tal questão pode ser obtida, a uma larga extensão, por intermédio das características dos padrões de drena gem (sobretudo as quantitativas) de cada compartimento, de per si.

A partir de uha pesquisa inicial, aponas com o intuito precípuo de se estabelocen, por fotoincerpretacão, as peculieridades das redes de drenagen on três áreas contiguas, 
visondo à distinção de distintas categorias de solos, foi que surgiu a idéia de realizacão do presente trabalho, dentro do espiritu des indegações anteriormonte apresentadas.

Tais áreas estão situadas numa região compreendicle entre os fiunicipios de Anhembi e Conchas, Sp, grosso modo numa faixa de terras entre os rios con essas nesmas deng minações e entre o Tietê e a Rodovia Marechal Rondon, com amm plo predomínio de materiais da Formação Piranbóia.

Por intcrnédio da caracterização da rode de dre nagem, a fornecer informes sobre o relevo das áreas, ao lado do estudo do grau de evoluçẽo atingido pelus perfic de solos (descricões moriológicas, análises de rotina e análises minem ralógicas), pretende-se, pois, estabelecer courelacõos entre a natureza dos solos e a sua distribuição na peisagen, permitindo o diagnóstico das prováveis supeificies genoriológicas ai existientes e a tentativa de datação relativa das mesmas, propiciando methor compreensão dos aspectos relativos à gênese dos poritis. 


\section{REVISR̃O DA LITERATURA}

Dusante muito tempo os estudos pedosenéticos vi nham sendo iratados num seniido "verticalista", numa importação para os trópicos da netodologia de trabalino próprio das regiöes de clima temperado, onde a última glaciacão é um marco inicial do desenvolvimento de um número muito grande de so Los, portsnte de nesma idade, e muito jovens (SEGALEN, 1974): com o tempo, verificou-se que determinedas caracterísicas se riam dificilmento atribuivois a desenvolvinento unicamente vertical do pertil, e a idéie de quo os solos podian ser muito velhos tomou seu rumo. Desta roma, não se pode efetuar in terpretagões de perfis apenas com base en processos "lineared" ou tradicjonais, como aftrma OUEAROZ RETO (1975).

A prosonga de "stone-lines" a deciezinadas profundidades do hento de intemrerismo, indicativa de que o nate rial acina da mesma é de nawureza transportada (RUHE, 2956), foi una importente constatação nesse sentido. A Corisç̃̃o DE Solrs (1060) comonta que a rolacão entre o desenvolvimento do relovo e a idade dos solos é, de fato, a relação entre a his tória da erosão e sedinentarão e a idade do solo em un determinado lugar: se não ocorre erosão ou sedimentação mercante em uma detexininada área, por un longo período de telupo, relen vos e solus velhos são encontrados, ao passo que se bais even 
tos são relativanente recentes, relevos e solos jovens, ou re lativamente jovens, são encontrados.

Entritetanto, nem mesmo solos jovens, como os Litossolos, estão livres de descontinuidades entre o solo 0 a rocha subjacente, hercadas pelas "stone-1ines", enquanto que os solos com e textural frequentemente são formados por uma nistura de materiajs alóctones e autócnes sotopostos, os o latossólico são, via de regra, originários de materiais carac teristicamentie alúctones (comISSÃC DE SOLos, 1062). 0 pré-intemperismo e arrastamento podem promover una mistura de mate riais de oxigon de diferente natureza (UILLIERS, 1965 ).

Camadas arenosas supericiais, especjlmente no Podzólico Vermelho Amarelo, podem ser resulibado de coluvionanentio, en periodos recentes, ao lonco das vertentes (ROTTA, 1975). Uma das evidências desse prucesso é a presenga de bandas onduladas, de conetituição diferente da massa do norizon te de perda, onde ela se encontra (fUEIGUZ NETO, 1973). f natureza coluvial do horizonte $n$, repousando solre um $B$ fóssil, tem sido hencionada pelos pesquisadores (FNEADO e RARZANI, 1973: CARUALHO, 1976), Psequentemente associada às "stone-1ines": porem estias poden não ocurate se por ocasião dos prom cessos de retrabalhanento a massa transportade for pobre em naterial detritico CTOsseiro (BIGAFELLA et alii, 1965). Tam bem a presença de cascalhos juntamente com o material pedogeneizado é indicativa daquele processo (DUEIROZ NETO, 1975).

Esse grande increnento de argila no horizonte $B$, en relação ao A arenoso, tem sido motivo de um número muito crande de pesquisas, e a sua atribuiça meis segura a procesw sos puramonive mecânicos - Eluviação/iluviação, ou argiluviação (BRATELLI, 1973), ocorre nos solos onde essa concentração da prarão fina se dá nas pertes inibuediárias do perpil (SIhonsCl, 1949: ficCALLEE, 1959\%; tal hocanismo é perfeitamente distinto da podzolização, onde a migração de argila é acompanhada de intensa decomposição da fração nineral, pela ação e- 
nércica de ácidos orgânicos (GERAstrov, 1960).

$$
\text { AEREU (1976) roleciona "stone-lines" a. fases }
$$

mais secas de alternâncias clináticas ocorridas ao longo do nuatornánio en diversas regiões do mindo (CHATELIN, 1067: mi SUI, 1969; HERUIEU, 1970) e, perticulornente, ne nossa região (MODENESI, 1974), conforme pormenorizados estudos levados a feito na Depressão Periférica paulista (AB! SAEER, 1969a e 1969b; VENTEADO, 1969; QUEIROZ NETO, 1969).

- Plioceno no Brasil é considerado como um pé rfodo de címa semi-árido, onde houve a possibilidade de se 2 laborar un nível aplainado por pediplanação, que serve como ponto de partida para a datação rolativa dos acontiecimentos veríficados ne Quaternário, a paruir do sou entalhamento pelos cursos d'água (rENTEAdo, 1974). Fara ChristofOLTTI a PEN TEADC (1970) acontecimentos pós-Terciários seriam responsáveis peja nacro-compartimentação inicial na Depressão Periférica , onde puílodos hais secos favorecen a pediplanação, con a formação da superfície denominada Neogênica, por liartonNe (1243); as alturnancias seces e úmidas do quaternário, que PENTEAdo (1969) considerou como tendo sido em número de quatorze (osci leções de clina seco para úmido), tenderiam a promover o nive lanento dos cimos dos principajs interilúvios na Depressão Pe rị̂érica.

Essas oscilações clináticas en uni longo período de tempo tenden a abrandar o eîeito da superimposicão de caractures de pedogeneses sucessivas, como verificou FAUCK (1964) no estudo de detorninados Solos fracamente Ferralíbicos da hfrica.

Determinado matorial exposto às intempéries durente tempo muito prolongado deve apresentar um grau de alteração superior àquele sumetido às mesnes ações, durante tempo inrouior ( ULIRnz NETO, 1971) . A latolização - processo de intempexismo intenso - expressa em um perfil, pode termse rea lizado em un outro solo primitivo, que forreceu os produtos 
de erosão para a constituição daquele (comissño DE SpLos, 1962).

Solos velhos, como são nowhalmente os Latossolos, resultan de processos heis anitigos, e a cada episódio ocorrido devem perder elementos a degradar-se nats (nUExRoz NE TO, 1976), como se observa ao longo dessas antigas superfícies de erosão Terciárias ou do Quaternário Infexior (GUEIROz NETO, 1975).

Ds solus estão expostos às condicões as mais va riadas no tewo e no espaço, cada perîl representrando uma história particular, sujeita a episódios comuns e recebendo a influência de seus vizinhos, mas tendo pontos de lartida en é pocas diversas (QUETROZ NETO, 1976). Assim, um Litossolo näo representa necessarianente um solo no inżcio de sua formação, podendo ser resultado da renoção de cariadas de solos formados, em que a situação atual do relevo é una barreira pera o acúmu 30 de materiel edafizado, para o aumento de espessura (minRCOS e KINJ0, 1967).

Areas poden ser rejuvenecidas pela erosão dos antigos solos latossólicos (queInOZ NETO, 1970a), propiciando a formação do perfis de diferente natureza, cono os Litossolos, onde os elevados teores de silte são indicativos de seu pequeno estágio de maturidade (UAN WAMEEKE, 2967: CORISSAO DE SOLOS, 1962: SEGRLEN, 1974); nesses, os altos teores de maté ria orgânica chegam a ser una carccterísiica diagnóstica (miAR cos e KINJO, 1957), e esse conteúdo elevado de carbono eśtá relacionado à meior atividade das argilas (UUEIRUZ HETO,1975). Além disso, nesses porfis rejuvenescidos, os va lores de saturação en bases são mais elevados do que nos som los mais anticos, a indicar o nenor grau de alteração (GAMBLE e DANIELS, 1974), caráter associado, naturalmento, à menor profundidade dos perfis. Processo também atribuido a tempos mais recentes é a migração vertical de partícules finas, na constituição do horizonte argílico dos solos com $B$ textural 
(QUEIROZ NETO, 1975), com empobrecimento dos horizontes super ficiais en argila, onde é tambén usual o arraste obliquo dessas.partículas, ao Iono da vertente (LAMOUROUX, 1972; SEGALEN, 1974); esses colúvios poden ser nuito espessos, ou mesm. desaparecer, em encostas mais. İngremes, por efeit. ...erosivo (QUEIROZ NETO, e CASTRO, 1974).

Nos solos com B latossólico a argila floculada (CONIISSÃD DE SOLOS, 1960) \& um caráter tomado como um "envelhecimento" dessa fração e de sua estabilidade, como tem sido verificado en superfícies geomorfolónicas antigas (aUEIROZ. NE TO, 1975). Por vezes, os solos dessas superfícies são arenosos, considerados como "solos com E latossólico arenosos". as sim designados na rogião de são Podro (Coumaro et alii,1975).

Tais solos de textura grosseira, classificados como Recossolos ou Regossolos intergrade, foran colocados na oateguria dos "solos pouco desenvolvidos" rela Comissño DE SO LoS (1960), no Estado de São Pauro, para os quais admitiu-se que tais materiais arenosos, pobres en argilas, ou em minerais primários que pssam ser transformados em arqilas, não mostram na sequência de alteração nem a fase podzólica bem de senvolvida, nem a litossólica, mantendomse regossólicos.

Assin, o termo Regossolo foi reservado, nos tra balhos subsequentes de levantamento, a solos com minerais alteráveis (pouco desenvolvidos), utilizando-se pera os anterio res outras desi nações, como Areias Acidas Vermelhas e Amarelas, do "Delineamento Esquenático dos Solos do orasil" (CAMAR GO e BENNEMA, 1966), a exemplo de solos similares da África, denominados "psanno-ferralíticos" (BOTELHO DA COOTA et alii, 1964; ROOSE E CHEROUX, 1966; CHATELIN, 1972).

hNTUNES et alii (1971) verificaram que a maioIia dos solos do Estado do Es áxito Santo são desenvolvidos a pertir de materiais de origen pseudomatóctones, seguidos pelos alóctones, e raramente autóctones. Nos podzólicos a latos 
solos derivados de sedinentos Terciários e nuaternários a natureza é sehpre alóctone, e quanclo a fonte é contituída por rochas básicas, ácidas e intermediárias o naterial de origem é pseudomautóctone; apenas os Litossolos podem se oricinar de materieis autóctones..

A idéia de sequência evolutiva defondida pola Comissino DE SOLOS (1960), na qual os Litossolos dariam oitgem aos solos com $\theta$ textural, e estes aos solos con latossólico, tern sido, por vezes, contestada, como atesta o trabalho de EENEEMn et alii. (1970), ao verificarem que as caracteristi cas genéticas dos Ultissolos e Oxissolos do Bresil polem ser thmọdas como independentes, um perpil não se ortuinando do ou tro.

BENEEmin et alii (1962) conentan que a dictribuj cão dos Latossolos esteja correlacionada a antigas superificies de erasão, oxiginadas no Terciário ou Quaternário, sobre as quais intensas forças erosivas operaram, a diferentes momentos da escala geoló:ica do tempo, en diversos pontos da paisa gem, com diferentes intensidades nas variadas regiões, produzindo una grande diversidade de feições geomorfoló icas. BEIN ROTH et alii (1974) apresentan um esquema evolutivo semelhante de sulos e paisagem, a partir do entalhamento de una supes fície de uxissolos, con a consequente formação de ultissolos e Incaptissolos, associados a exposiçoses rochosas, em posições de vertenties.

Para HiCK (1972) determinadas caracteristicas hoje observadas poden ser devidas a reaçõs irreversiveas ocorridas no passado. Assin, a parsistencia do cerrado nas con dições úmidas atuais, amplanente favoráveis a veçetacõos mais densas (plorestais), estaria ligada a éreas de solos antigos, onde a sobriedade do relevo não possibilitou o rejuvenescimen to dos solos, com remoção erosiva de seu capeamentio de solos pobres (CRISTOFOLETTI, 1968). Paleoclimas úmiclos seriam res ponsáveis por vegetação do tipo flowestal, com atividade ero- 
siva reduzida ao mínimo e máxina evolução pedogenética, o con trário ocorrendo sob condicões de aridez (JESCUf, 1060).

Estudos procedidos por DINS FERREIRR e QUETROZ NETO (1974) na região da Serra do Linoeiro, SF, hostram a ocorrência de materiais nais antigos no reverso de Serra, cuja gênese é romontada ao Terciário. Sedimentos arenosos espessos, dispostos no plató de Santo Inácio (Regossolo "intergrade" pa ra Latossolo Vermelho Amarelo - fase arenosa), estarian corre lacionados à Neogênica, correspondente à superfície interplam nálłica majs antiga da Depressão Periférica (Plio-pleistoceno). Outras formacõos superîiciais aparccen en posição de entalhamento menos pronunciado, a 40-50 metros abaixo da anterior, do rinal do Neogeno, correspondentes às Culinas do Sistema Peixe-Eonito, apresentando ainda solos análogos aos da $\underline{y}$ nidade anterior e também Podzólico Vermelho Amerelo - variação Laras e Litossolos; as denais fornaçôs conresponden l.nitidam mente a colúvios de vertentes, mais recenties ffleistoceno e Holuceno), coni predomínio de podźólicos e Ljtossolos.

Em outra área próxima, na recião de são fedro, COITARD et alii (1975) realizarala estudos serielhantes, identi ficando a superficie mais antiga a 900-960 netros de altitude, reletiva ao plató acima da cuesta, com vestícios de couraças, ferruginosas, atribuida ao Terciário e referida is Cristas fié dias de MRTONNE (1945). Abaixo da cuesta ocorrem testemunhos da Neogênica desmentelada por processos erosivos, a revelar nessa área, 4 nítidos estágjos quaternários de elaboração do relevo; nos locais rejuvenescidos ocorre especialmente o Podzólico Vermelho Amarelo - varieção Laras, e na superficie Neo gênica solos com B latossólico arenosos.

AE' SABER (1969a) comenta que a Depressão Periférica é un compartinento topográfico de o igen pernanentemen te denudacional; nos perźodus de transição cinática é que os processos exosivos apresentan máxima atividade agressiva, a produzir ravinamentos ativos e fortes descarnementos nas ver- 
tentes mais vigorosas (AB MAEER, 2972). Tantén no Lasto peulista o desmentelanento de superificie de apjanamontc antiga pelos cursos d'ácua é la processo evidento (AEREU, 1076).

As "cabeceiras de erosão" (Afilnhl e Alij, 1272) iestienunhar ações orosivas regressivas, cujas partes hais recuadas e mrnos atin idas conserval: usualunte hateriais mais ajteradus e espessus (CUEIROZ [ETO, 1275). fio 20i\% das vosso rocas, de ocorrâncie generalizade nesse região, e eir ...franca expansão, (ROCHA PIEDADE st alif, 1976), cariadas argilosas d'é espessura varic da estão rolacionadas ao Tercíáio (FAIVA l'ETTG a Pncoili, 1072).

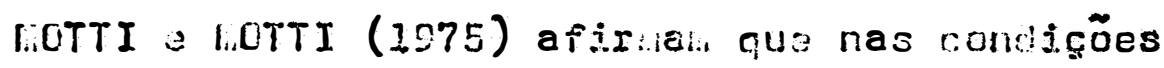

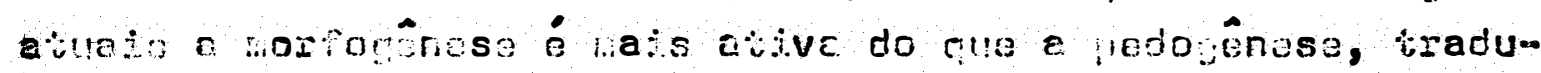
zita: a) pola erosão dos solos soliro as uncostas mais ingrewes; b) pelo remanejanonto en outros setoras dos interflú-

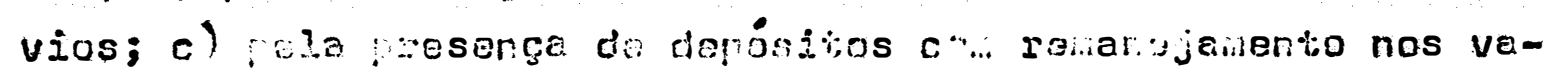
les.

Para SCARES (1573) e AZOLIN et alfi (1075) a re

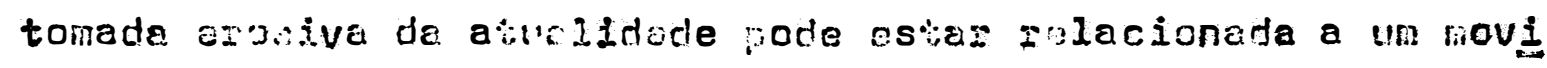
mento eplrogenético positivo, mutso lento e a jindu en impul-

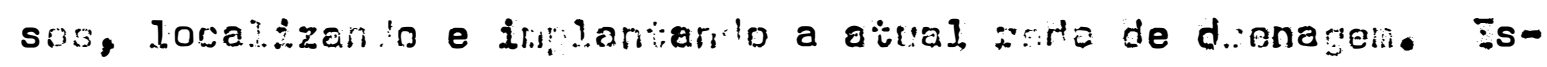
sas a Hirlas vão doserntnar o caráter policíclico do relevo,

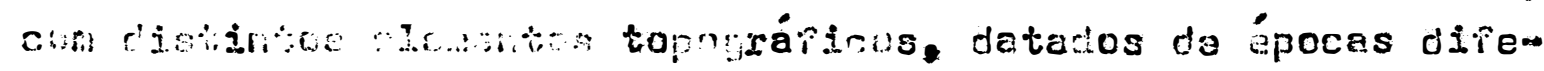
rentes, iunclo como princfpals causas as idificecoōes do nível de has o as alionnancias clináticas do quaternário (FENTEADO, 1974).

A ané..ise da redo do drenagen pode evidenciar direntes con osicões morfo-estruturis dos conpartimentos $\mathrm{B}$ xistentes (noneu, 1975), a a esindo do sol descnvalvinanto e expansão possicilita eluciciar e exilicar as romas de relevo en seu conjunto, sendo que a noriolo ia recional pode ser con siderade cono conseçuência direta das adaptações do sistena de drenagen (CIRTSTIFLLETTI e ARANA, 1975). 
Nesse tipo de estudo, ADOLLA (1.073) considera que a romaçäo de meandros, for un rio, ao lonco des planícres aluviats, b́ inticativa do estágio de naturidade do rolevo: a divagação do leito ao longo da ampla planície aluvial, coli a ocortoncia de neandros ai andonadoe e incxistricia de rá Fidos sugere une evolução para o estágio do senilidada, dentro da idéía de un relevo policíclico. Ainda dentro desce con ceito, inck (1972) tona cono superíficie final una topografia equili: rada, ou con tend laia ao equilílio, con eficiente re noção de detritos, associada à vedinentação en posição de sopé.

Tamién PENTEAdo (1974) adnitse que o meandro 'de um io seja una forma indjcativa de um estado de equilínio, muito comumente observado en determinados rios, cono certos trechos do Tieté, podendo ser resuriado de iudangas cjimáticas, pele clteração carga/détito dos xios, elsmonto causal de meandros a andonados.

O estudo solxe o desenvolvinento de sistemas hi drogáíicos o suas bacios de drenagen tem sido efetuado, via de rogra, com base no clássico irabalino de hopror (1945), que ressalia a jiportância da restictincia do solo face a essespro cessus do exosão hícrica, tendo alo rroposto ínicics quentita ívos para expressar o trau de dosenvolvinentio da rede de dre nagen, cono a densidado de drenagem (Dd) a a requêneia de rios $(F x)$, evitando a sujotividada dos caractioses puramente descritivos. En geval, ostudes dessa natureza levan en conta as diversas ordens de ramificação da rode hidrográíca, sendo fuito usual o sistona no qual os irjuvitérios não ramifićados, correspondem a somentios de la. ordan a o rio mincipal recebendo a orden nais elevada, critério esso se uido pos un núme ro muito grande de autoxes, dentre os quais STRAHLER (1957).

AUDI (1972) comenta que, dentise os nábodos da rojointerpretação do solos fundamantados na caractexização dos elewantos da paisagen, najs acessiveis à observação por fotom 
graijas aéreas, a drenasen e as característices exusivas são os aspectos hais inportantes en qualouer nétudo de trabalno.

Couto, entretanto, a FRACA ( 2568 ) a primazia de adatar a técnica de fobointerprotaça da redes de drenagem al licada ao estudo de solos, en nossu meio, lavando en conta que ruando ales são seneliantes, sous adröes tantén o são (FROST, 1950); até en;ão, tal técnica de trajaliro era pra ticanento do ânito da Gevlonia ou da seonompolonia. Elo ana. lisou áros con dirorontes unidados do solos, ori inados do produtos de altejação do arenitc fotucatu: Rerossolo "intes crade" (Rt V/RLV), Larossolo Voxiselho Anarelo - Pase aronosa -

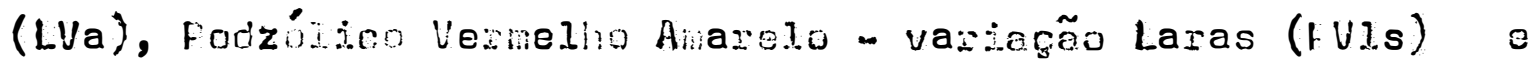
Litossolo (Li), encontrando Dd Crescenties no sentido: RPV/RLV - LVa - PUls - Li. Comentou o autos que hateziais do texturas semelhantes e depositiados pelo mesmo agence de transporte por dem oxi inar solos distintos, cujas diferencas vão se refle-

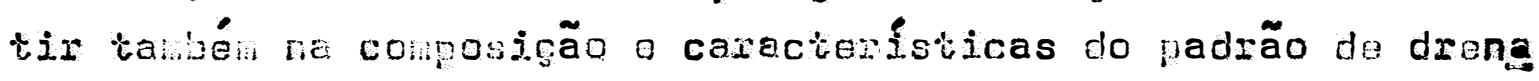
gen.

LUEDER (1059) assevera, com base nos estudos de HoRTon (1245), que as características da rode de drenacen são una consequêneia da relação entre infiltração e dếlívio que, logicamente, dejonden estraitamente da natweza to solo a das condiçõs locais. Os valores do Dd estão relacionados pirincin palmente con a resistência à exosão dos nateriais presenties, diminuilido à medicla que aruela aumenta (RAY, lrs3); anbora ha ja muitas exceções, este autor airima que arenitos de granula çäo grosseira tenden a apresentar redes de drenageti nenos ram mípicadas do que áreas de folhajhos e oubras rochas similares, de ranulação ïina. Observações semelinanties são fornectidas pur RICCI a PETRI (1965), consideranto a presença de hateriais in permeáveis, cone ar ila e folinolio a determinadas profundidades.

Outro aspecto diretanente relacionado aos mecam nismas de infiliração e deríúvio a a wajor eu menor unifosni- 
dade texiuraz do Hexil de solo, tendo KOFFlER (1976) : levado en conia ese caracien ística, ao ana isax os jnitices quanitita tivos das redes de drenagen de solos tíicos da revião noroes to do Estiado de São Faulo.

\section{Latossolos de texiuras sensivelmente djetintias}

podou revelar rades de drenagen muito somelhartes (DUMAR,

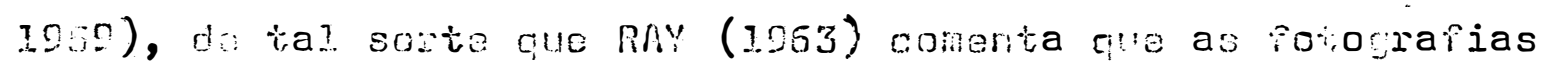
aéreas revelan a dronaceli efetiva do perfil. Diferenças entre os índicos de drenacer de três Latossolos estudados por Squzh (1975) são atribuidas às diversisdactes de rotevo, ấtetando a dinâmica da água.

Além do relevo, a natureza do sulstrato é outro fatas que pernite exilicar as diferenças entro os purits do solos con texural (Podzólico Vernelho Alarelo), ori inários de arenitos da difosentes fomaçoes (UAsques FllHo, 1972). Fa ra os Litiossolos os valores de Dd \& Fs são sempre elevados, mesio sen se considerar a natureza do sul strato rochoso, como se verifica a partir dos resultados bitidos por FRANÇA (158) MirRCHETTI (1969) a FRETRE (1977), a realcár a importância do relevo na individualizacão dos solos.

Ao lado do outros atrinntios ecoló ticos, PENTEADO (1974) comentia que o relevo conanda a circulação de água nos solos e os efe íos da lixiviação e acumulação absoluta, le vando os fedóloros à noção de "catena", rofecen\% d̀ diferenciacão dos solos sesundo as condiçães tuporsárices, sob as meshas condiços anientiais. A evolução dos solos a a evolu-

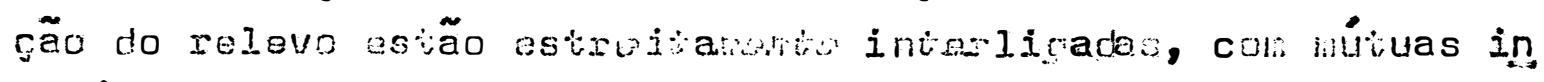
fluências a todo o instiantie (RLELLAM, 1971).

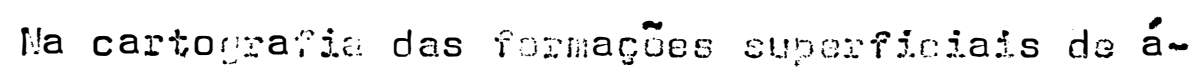
reas tralicais, onde o esiudo da evolução do relevo é de pri-

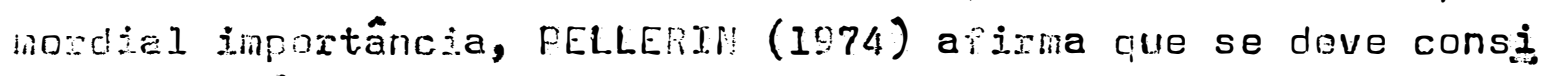
devar também os tipos de ar ilas nas direrentes posições da pajsaçeli, a pexhitir a definição do crau de altoração das diversas formações. 
A presença de peuris apresenuando d diferentes

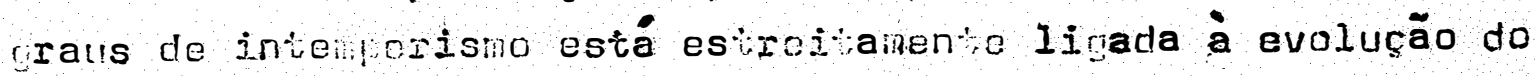
Ielevo; disuintos estácios de alteração, por vezes ousundosde um nesta poocess, corresponden a enilidados geonorfolósjcas bem derinidas (nUETROZ Reto, 1970a).

O direcionamento da esquisa para se estaivelecer o conjuntio de Penônonos e processas faleoclitáticos, responsáveis fela faisagon atual, está no estudo de detalhes das formas de relevo, ronaçõos superificiais e paloossolos, grau de alio:arão dos solos, e talvez das rochas (quevroz into, $19700\}$.

Há uma conplexidade nuito grande en se definir a contriluição da pedocênese atual nas diflenten reciões ta zona inturtiofical, quepodo aparecer nos sedinentos hais recen tres: ala se traduz, pur exonjo, por una evoluçăo irequentenentie dól ill (sulos pouco ovolufios) ou por una evolução ráijda (hidronoxila e halomorfia), narcando os úlitinos sodinentos derositados (PIAS, 1970).

São nomalmenio considerados como produtos fi nais do intenperisino, en sulos con avançado estägio de altera ção, a caulinita acompanharla_de óxidos e hidróxidos, son boas condições de drena en (JACKSON e BHEillan, 15.33), condiçöes es sas coninecidas cono "jntrormi erismo latossólico" (COMISsĩo DE SULCS, 1062), "alteração ferral "'ica" (DELUIGNE, 196ij) ou "in temporisuo latexitico (UILLTERS, 2965 ).

Pela Iixiviação quase que to al de bases, acom panha por perdas constantes de sílica, que o processo pres supōe, iem sido anplanente relatado que a caulinita pode dessilicatłzar-se e dar forliação à rijosita (fion'IZ e JACKSON, 1057; CARVILLHO, 1970; ANDRADE, 1971). RiILLOT (1964) afirma que apones sol intensa lixiviação a jibbsita se foma a par. ¿ir da caulinita, pela esta ilidade desta, e MAIGNIEN (1966) reafirna tal condição, comentando que tal processo élimitado, năo podendo explicer sua presença en crandes quantidades. 
Entretanto, a origen da gibbsita ten sido atribulida também a parír da alteração direta dos ninerais prináIioo (KELLER, 1964), podendo ser un dos primeiros inerais se cundários individualizados nessos ostácios inicicis de altera cão, sob boas condições de drenagem (fiELFI e LEVI, 2971).

De qualquer forma, originada por um ou por outro processo, parece realmente estabelecicio que a sua permanência requer boas condições de drenagen (nOHR e VAN EAREN. , 1954 ; SEGALEN, 1974 ).

A não ocorrência de gibbsita em solos considera dos bem intemperizados pode ser explicada for un estado de atividade dos íns no solo, tal que seja correspondente à raixa de estabilidade da caulinita, garanitida pela lenta dissoly ção de ruartzo (LEI SCH, 1975): tamiém GOEDERT et alii (1975) apresentan explicação semelhante, e FnuCK (1972) relata que abaixo de un certo linite de quartzo a gibbsicização ocorre bruscamente.

CADY (1960) comenta que en solos altamente inteliperizados não ocorre una nítida sequenctia de altieração dos minerais ao zongo da profundidado do perifil, observando-se, en geral, o nifido predomínio de apenas um mineral.

Contudo, para una mesta precipitação pluviométrica, a drenagem pode variar com a posição do perfil na paisagem, interferindo sobre os processos de alteração (DELVIGNE, 1965).

PEDRO (1969) demonstra que a natureza das alteraçōes depende, sobretudo, da drenagen, associada ao iipo de rocha, podendo ser alfítica, monossialficica e bissialítica, em funcão daqueles fatores.

A ilita, nineral amplamente relatado cono impor tanto conponente das rochas sedinentares (RIVIĚRE, 1952; MIL LOT, 1952; LUCAS, 1962), apresenta comportamento oposto ao da 
veriniculita, iace às condicões de drenagen, scricla a primeira

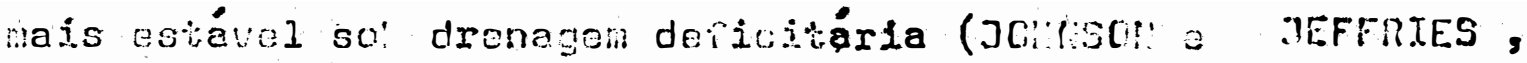

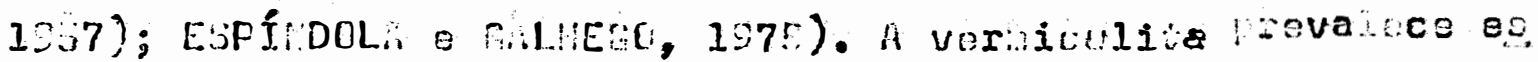
pectalmoro sos hoas condiçōes de drenaren (hILLT, 1064), a

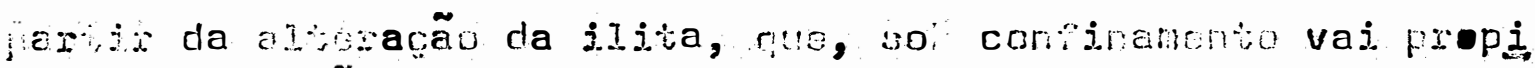
ciar a mocão de montiorilonita, cono ol servada for La ou. Roux (1072) en libotibos de alteração de aronitos.

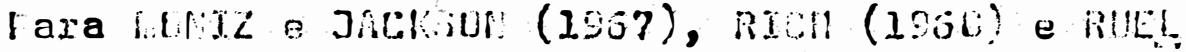

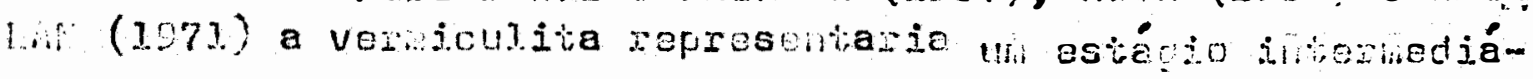

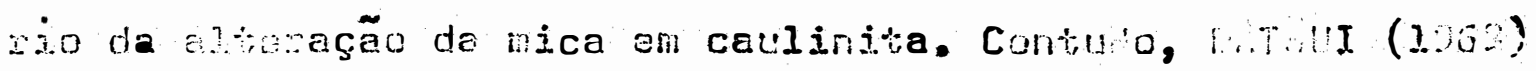
"exificou que, sot condiceos rortohente jjxiviaries, fons alu nínio são froquentomente removidos da escrutura rios eristais e tixados nus espacos interlanalares dos inorais, formando A1 - vorniculita ou 19 - nothorilontia; no pleossolos por Ele esturiados os minerejo doninantes na fra äo ar ila foran o

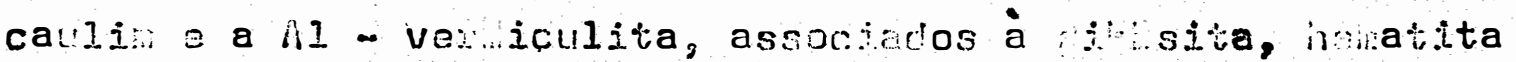

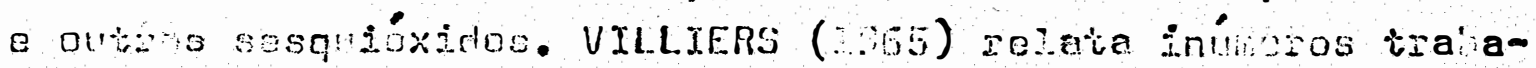

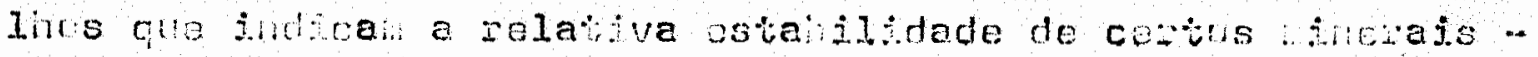

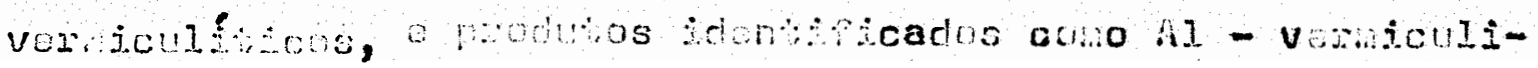
ta ocorati en solos altanme intumerizados da África, pare. condo ser ias restetentes do ruo o sistoma caulin-haloisita.

Nitca o vermiculita buli sido encontradas en produtos de albesacão "in situ" de arenjio sobucatu (DI.s FERREI

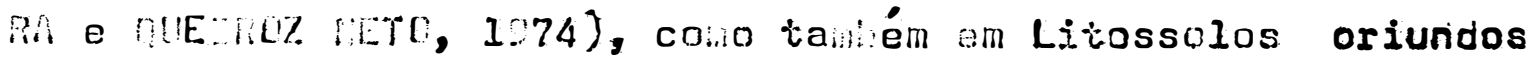

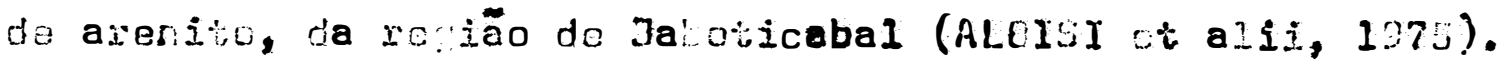

No Bauru, a atapu. tia, nisera? rarai hto obtontrado en condi çôes iropicats (a não ser on cundicoos espectos), ten sico relatada cowo inportante componente, juntainnto con a montho-

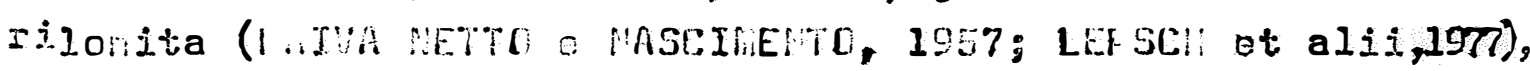
cono trabén a mica, cuja alteração prepicia a ra: ação da caụ linita (Chrualio, 1975). llo cotucatu ráctes iluvial e lacustrre, cor. cirantação calcária, a montuorilonita é un dos nrinm

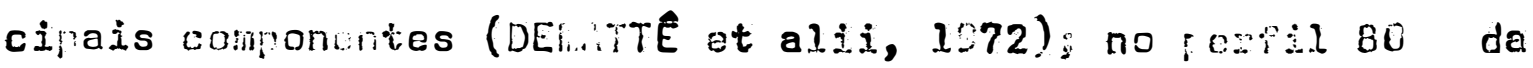
conISSÑO DE SOLOS (1960) - Litosst lo - Pase su strato arenito 
calcáxio (cotrada Conchas Juquji:atiba) a rracão ar gila aprem senta donśnio de quartzo, o en menor protorão ninerais $2: 1$ (noutinorilonóide).

As condiçoes para a formaça do nortmonilonita contrastan con aquelas recossárias à gênese de caulinita. 0 sistona quínico na qual ela se rina é caractostzado pela al.. ta relaçã Si:Al e relativa al undâncía de lig, Fe, Ca, lla e $K$

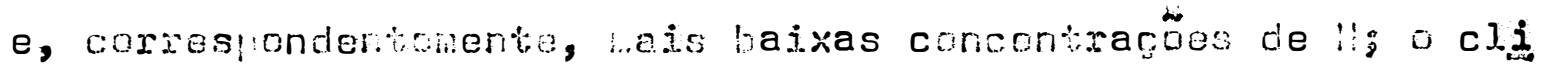
ma (macro e micro) de amiente de interiberismo e a ciciencia da drenagem são tão importantes cono o materia? original (KEL LER, 1064).

OCUUIER et alii ( 1970 ) tamén constataxan as. condiçós ropícias à hontuorjton ta em rejo confinante, cuja Cornacão veñ acen uar ainda hajs essa laixa condição de drena gen, con "invasão" da laisacen à uontante por aquele mineral. Fośn a sua natureza é transíýria, com sondioncia à alüeracão on caulinita (FAfUET, 1970). H.MTERS a BLEEKER (1S70) verifjcarail rue, hesmo sol niá, dronaesii, en solos calcários ricos en bases e sf́líca, al guma nontmovilonita se transioma en caulinita: de nanejra sinilen, hestio sol as con djecões ejtáticas do Rio srando do Sul, favcrévois áquele m1nesal, a cau?inita assume importância nas zones sechoriolóotcas de naing lixiviagão (conchlues e nortz, 107\%).

Sua ocorrêncie en solos brasileiroe está sempre rulacionada a condições larticularos e espocf́ftcas locais, co nu, por excmono, aquelas chicontradas no pantanal de lato nros

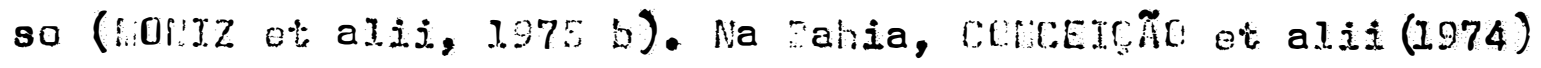
descreven a porsiatincia da montmorilontra en solos. jovens, pouco espessos ( 30 a $100 \mathrm{~cm}$ ), cono testemunho de dim peŕído clinático nais árido do que o atual. RI ET:0 (1974), támbém naquele Estiado, atril ui a sua presença tanto à rucha-nãe, rica en elonentos alcalinos e alcalinomterrosos, como ao conjun to de fateres poconenéticos, subressaindo-se o clina como pator importartio, tendo tanbón invocado ocorrencia de oscilacóas 
clinávicas ao lon co do nuacernário, incluanciondo a pedogêne-

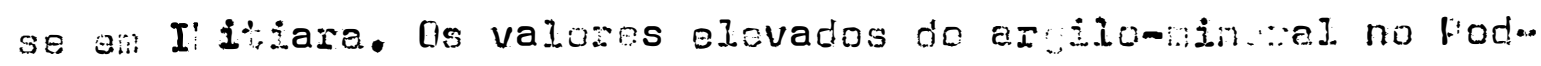
zólico Vernelino Auerolo .. varioção laca a no flogossolo . "in tororade" para fodzólsco Verinelho Anarsa, da rewäc do Pira-

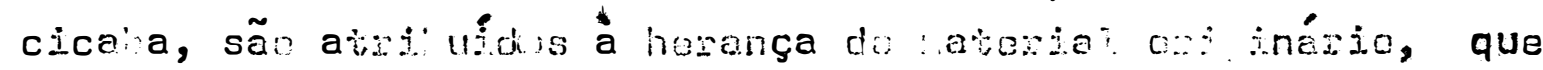

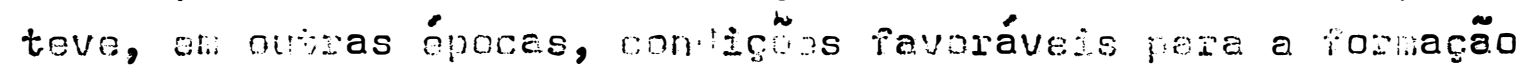
da montworilonitia (DEGATTE et alii, 1072).

Enyretanto, alón da eftctencia wajor au wnos da drena on, fLLI e LEVI (1971) ressaltan a importâncie de natu

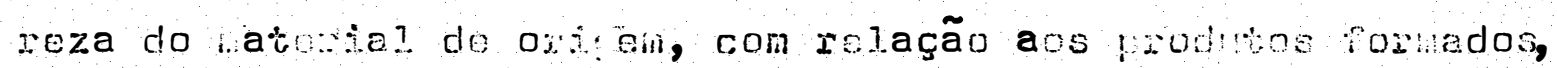

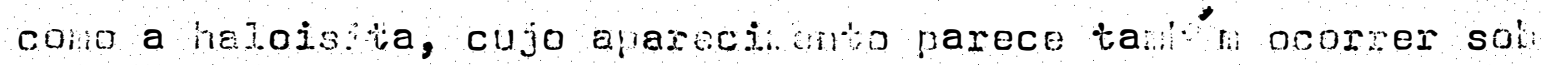
condiços lais continadas, a partir do intewotisto de felds. patos.

CERRJ a LLOISI (1075) fizeran sent Thanto consta tação, ó sorvanro oue para a sua cóneso há niccessirade de so-

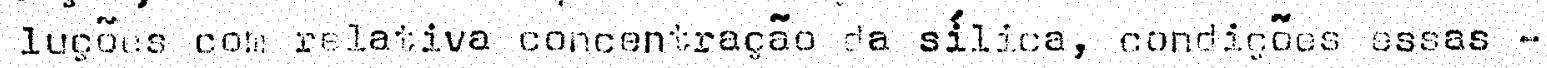

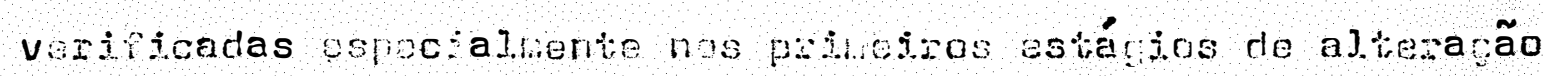
dos minoxais. Os autores conentan gue a halojstia a a notaha-

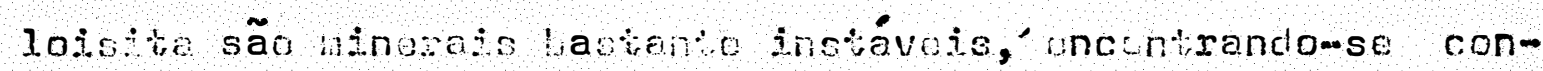
contiados nos hortzontes próxinos à rocha, e desararecentonos níveis naśo próxinos à superfície.

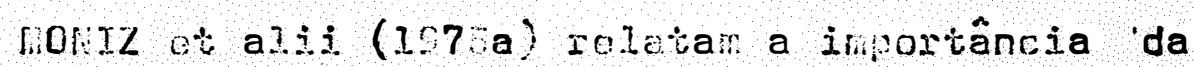
a croscopia eletróntica no lesfotto reconhecinento dos minerais halots fucos, uala vez que cerca de 40 \% de caulinitia são suticiantes para asceras $6 \mathbf{t}$ de haloivita, na ilsura de amhos (Thloley et alii, 1963). Utilizenco-se dosta técnica nicroscó ica, CERAT e ALCTSI (1275) di servaran formas variáveis de haloisitia o fetahaloistita: cohl relação à caulintita quando suas partículas sấ l.aijores $(* 0,5 \mu)$ as plaquetas são mais regulartiente liexafonais, ao passo que as t.rnoses $( \pm 0,1 \mu)$ apresentan forkes hexa onats irrecurlases, as yazes com bordos arrecondados e corruf́dos.

STEFFERMNA o IIILLT (1068) ve:.ifica:am que a haloisita o a netalaloisitie são ilportantes componoltes de so 


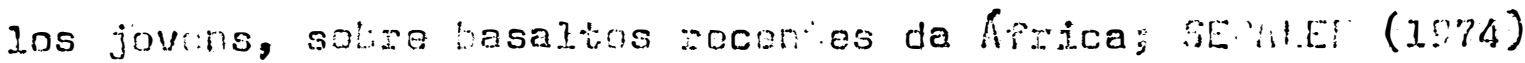

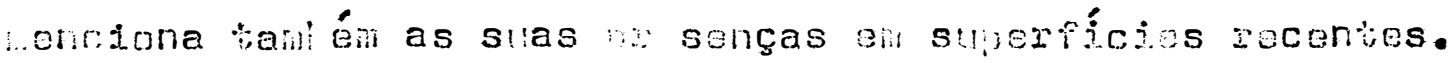


4. VATERTITS E VÉTtIDOS

4.1. Descricão do nejo físico

4.1.1. Rorião de estudo

A área da sstudo ssiá struada na sagião centro- Ieste do Estado de São Fauto, sul-rocião nédio Tiotâ, abranGunto crita extensão dos lunicírios de Anhanti o Conchas, a. proximadanente entro as latitudes $22^{\circ} 45^{\prime}-23^{\circ} 001 \mathrm{~S}$ a as lonGitudes $48^{\circ} \mathrm{Cr}^{2}$ - $48^{\circ} 2 \mathrm{~J}^{\prime} \mathrm{W}$, na província reomorfoló jca da Depressão roiférica, conforne divisão de ALlEIDA (164).

\subsubsection{Clima}

De acordo con SETLER (1066), o til o clinático é - Cua, dofinjo cono clima hesotíxinto de invesno seco, en que a temperatura média do mês nais frio é infer $10 \mathrm{r}$ a $10^{\circ} \mathrm{C}$, e a do mês inais quente uitira assa $22^{\circ} \mathrm{C}$. A ter paratua nédia anual está ontre 20 e $21^{\circ} \mathrm{C}$ (SECRETARIA DA AGRXCULTURA, 1974): as precintiacoes hédias anuais de Anhenti a Conches são, respectivanente, 1.250 e $1.131 \mathrm{~mm}$ de chuva (SECRETARTh DOS SERUTCQ i E or mas (UtLACAS, 1072 ). 


\subsubsection{Gedogia}

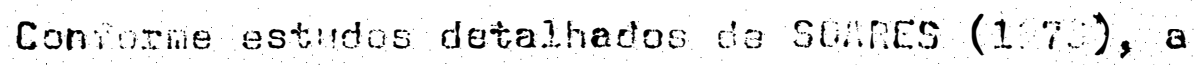

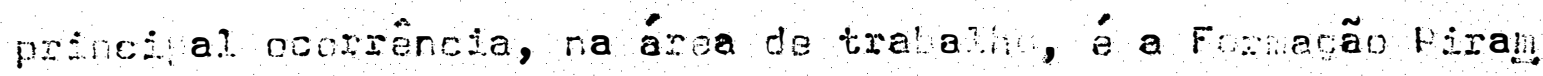

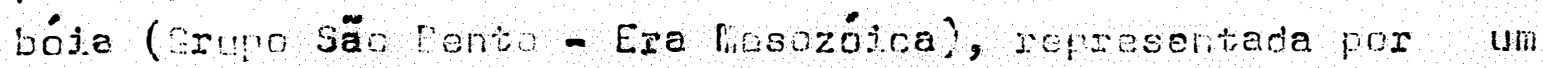
racote de ar nitho te granulaçá variáven, solre una discordância esculjida io Vermiano (Funacão Estrada lova - Grupo Passe Dots - Era fateuzóical, nutbo e fouco stlko-arctoosos, con estradijcacão cruzada planar a acanalada, e Manomparale la, com variação cíclica do $14+$ olocia na vortical, intercalan do lenitos aronosos.

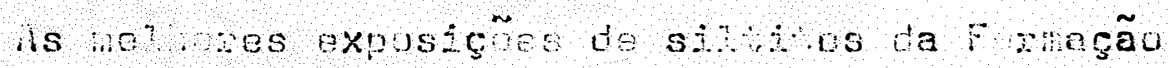
Estrada lova, dentro de ároa a oposta, a azecon has prexillida des de Anhent i, na lacià do Ráleirão dos Renédios, fn cortes da es rada que lí a aq ela cidade an atrro Lojtado. Assin co no olseivara sflipes (3.075), nossa zona de contato des lojie ma

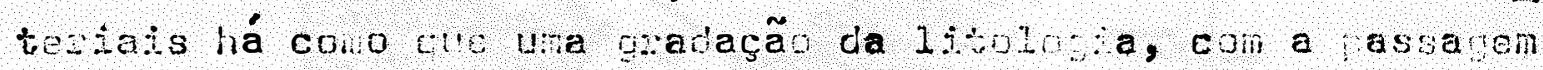

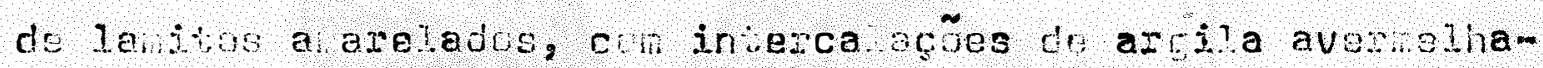
da e sititito (Estrada liova) a sjitito arenoso o ax nito wutbo

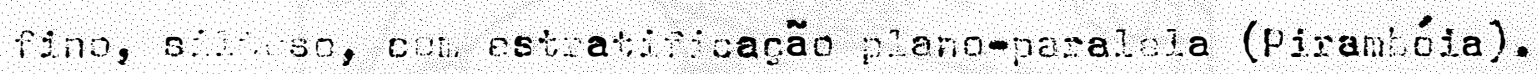

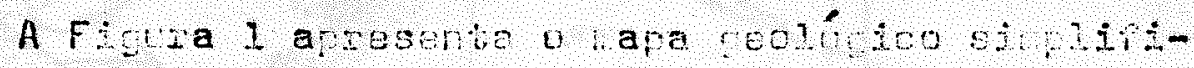
cado da reciãa cen'ro-1este pacljsia (ommis, 1:75), o o perfil geolósica ac longa da Roricuia lamecial Rondon (Figura 2),

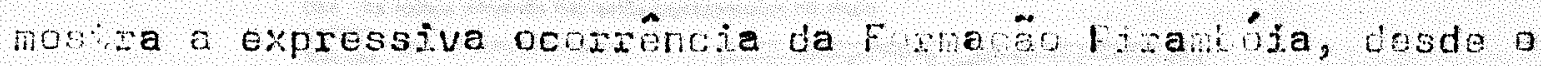
seu topo, ha Serra de or,lcati, até a sua hase, nas cercanias de Conches. De espocial interesse, darla à sua prcixinitade da

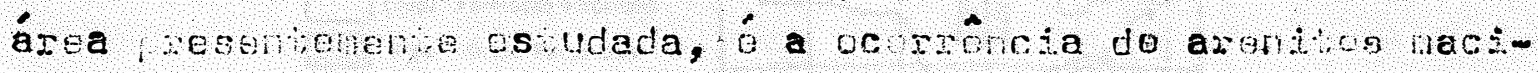
cos do Cenoź́ico, nas imedieg̃es do Distrtio de Firai óia, a cotas entro 520 a 640 hetros, selarados do arontio sitiatificado por con toweradoc e cascaihos.

\subsubsection{Solos e relovo}

1 crcorrendorso a resião de estivo ditaliadanente, fode-se visterizar a presenģa de três árcas distintas,com 


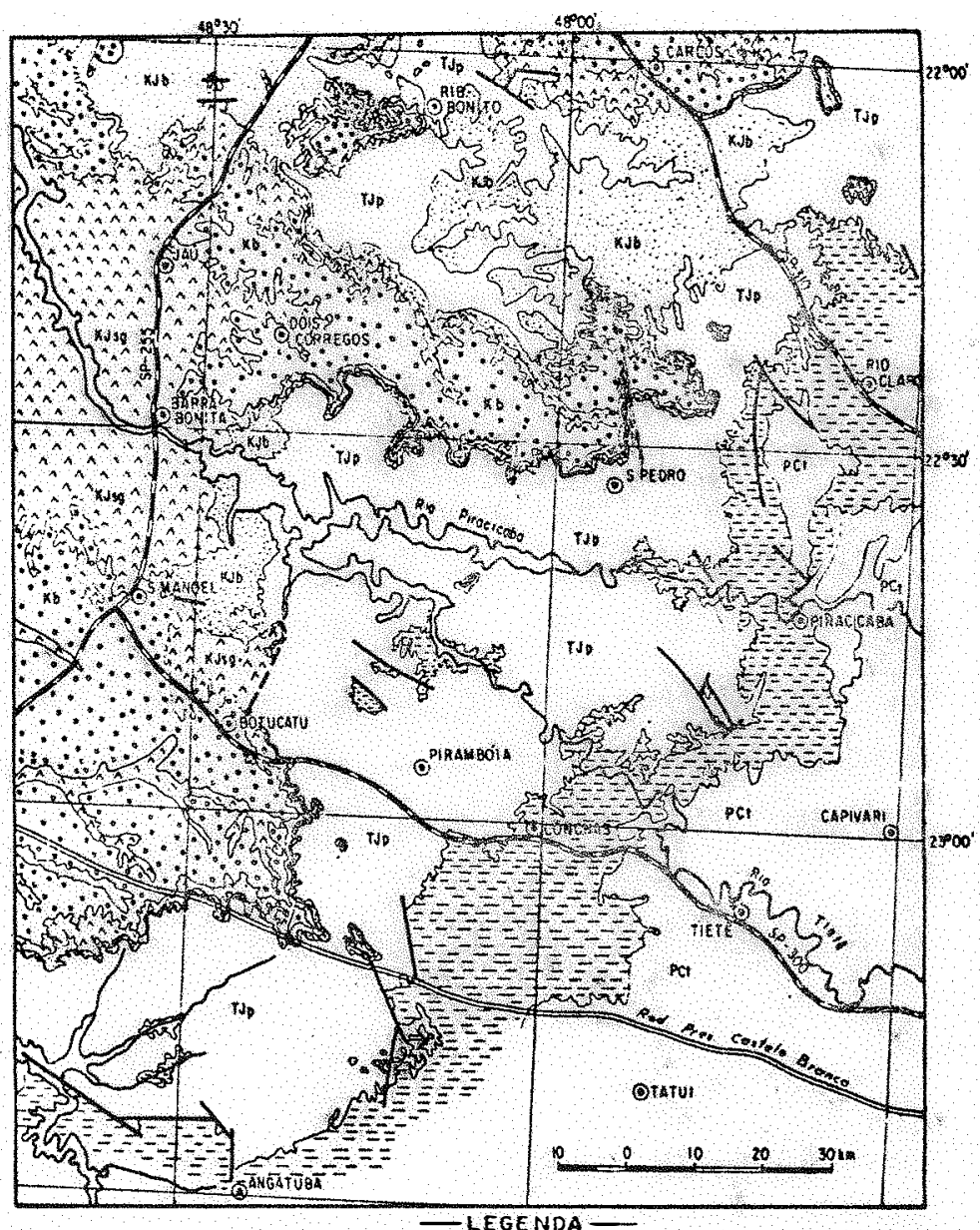

Obs As rochos intrusivas nơo es tão representadas no mapo

$\because \because$ (kb) formocõo Bouru

An (KJsg) Formaçōo Serra Geral

(KJb) Formogõo Botucótu

$\square$ (TJP) formacōo Pirombobio

E Pod Grupo Posso Dois

$P C_{\text {I }}(P C+)$ Grupo Tubaröo

Foino

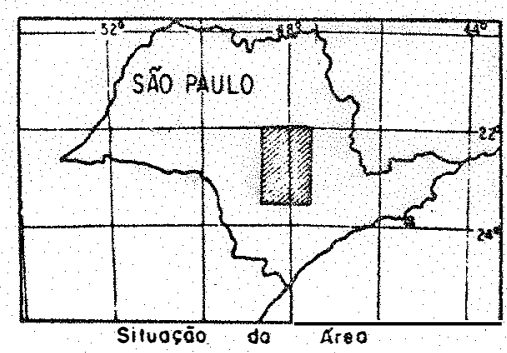

FIG. I Mapa geológico simplificaco do centro-leste do Estado de São Paulo (SOARES, 1975). 


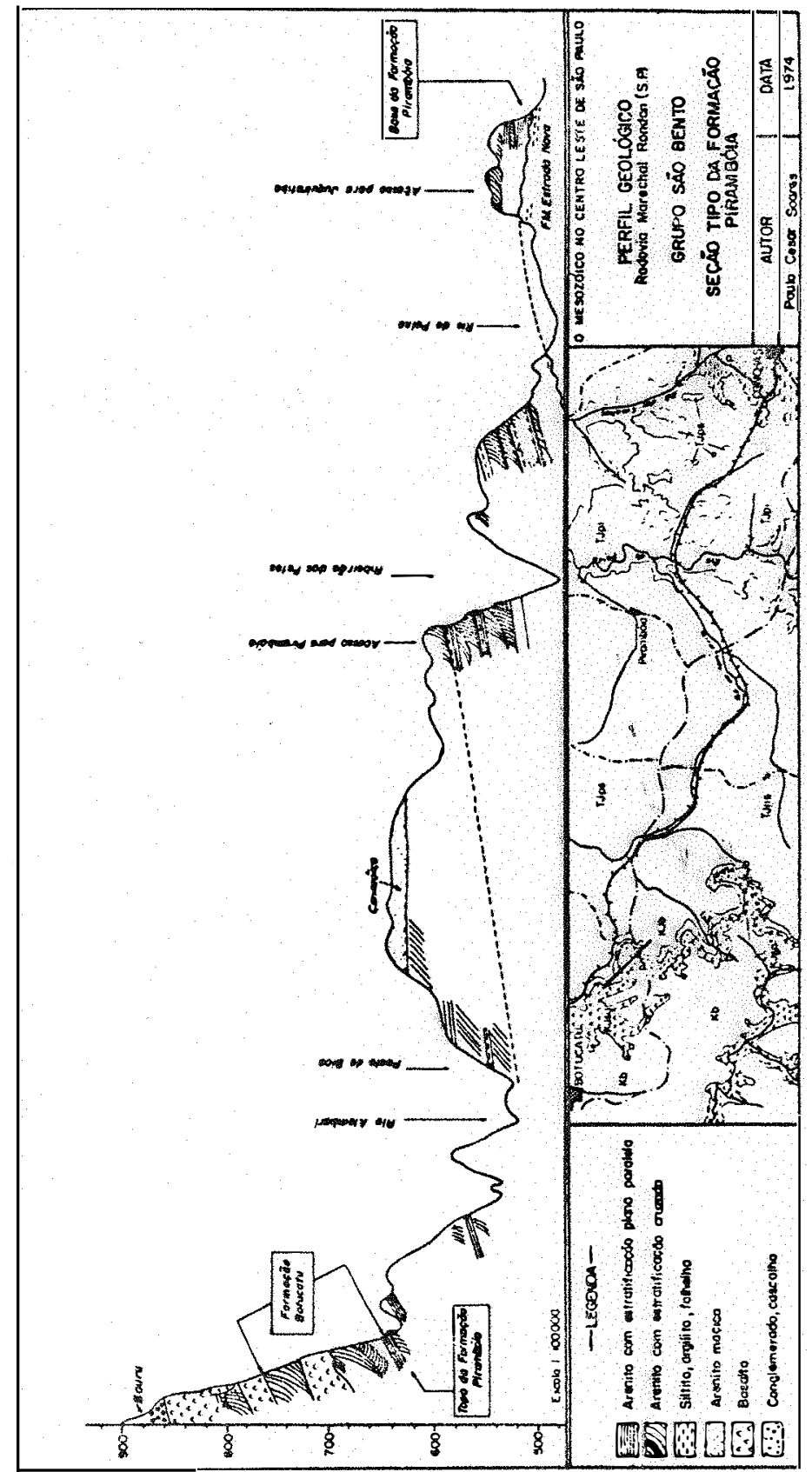

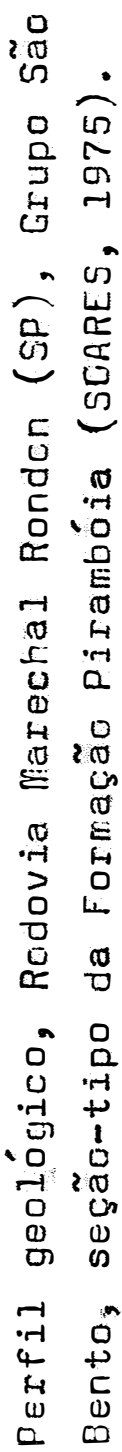

I

$N$

$\stackrel{\oplus}{\dot{\omega}}$ 
relação às ascrotecoños solos x relevo, benco stido as mesmas desinedas $A, r$ e c, cuja locajização es uenáuica é a:rosenta da na Fisura 3 .

e) Aroa A: Iróxina a Conchas, nas Lnediaróes da Rodovia lie

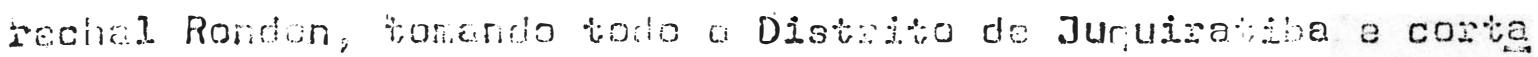
da pelo Rio Sol ado; compende parto de lacio do Rio do Poixe e parte da do Bto de Conches. li relovo é bastante n vinen tado (ondulado a Pmbinonite ondurado), com frodonínto da uni-

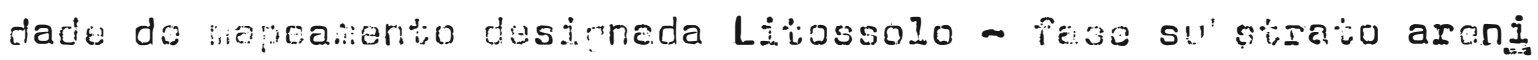

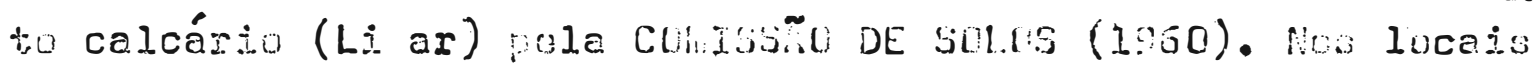
de rejevo wajs sueve, entise os int rílúvios ou os divisores de a va, a solo so tonna nato ustesco, caractorizado pelo Gran

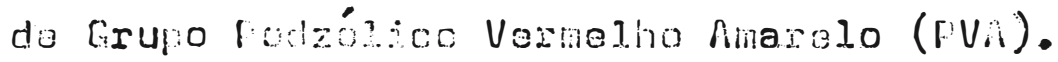

b) Írea es sivuada no Distrito de pirambía, acompanhando longa cxtehsão do Rio do Faixo, oujus pinctiats tibutários

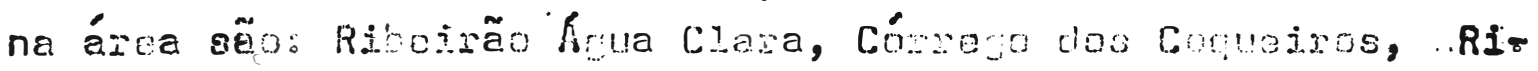
beirão Ruva do Rrejão, Córseco da lientioca, Ribeirão Marra-

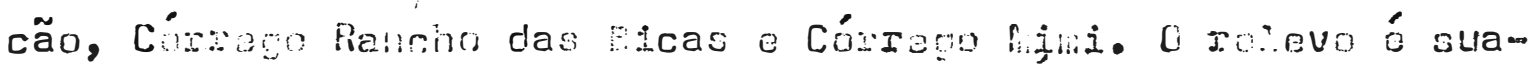

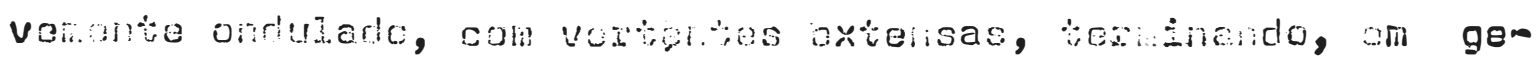

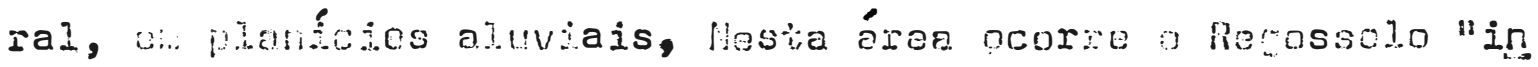
torgrado" fara Láuscojo Vesmetho (BLV).

c) Aroa C: localizada nas proxintiaces de finiont, especial

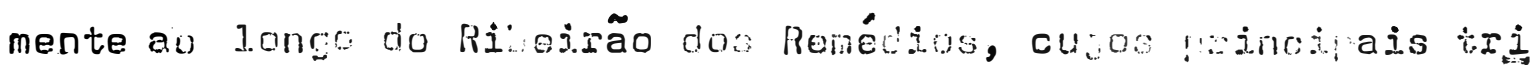

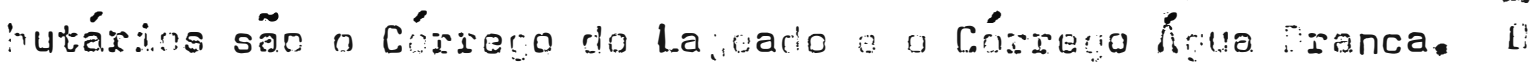

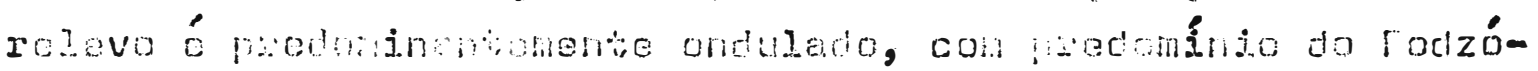

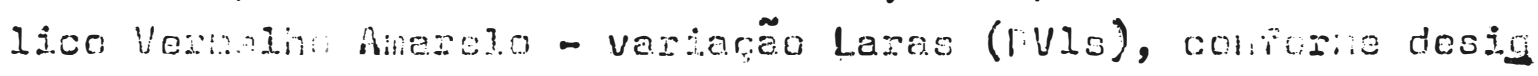

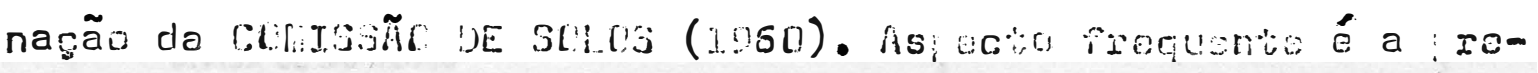
senca de "stone-lines", ox vezes cescolnetras de 30 ch de es pessura, a prindtades variéveis, brenvatas em exposições

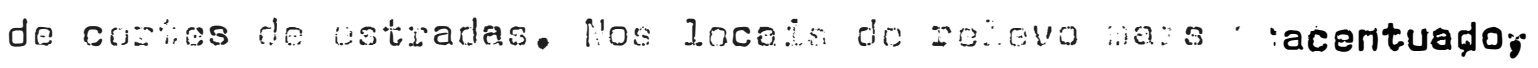
nowinalmente emvertintes de cuxta oxtensao, ocorrem solos pou co espossos - Litossolos, en ceral com uma canada superficial arenosa, fastante escurectida por natéria orgânica. 


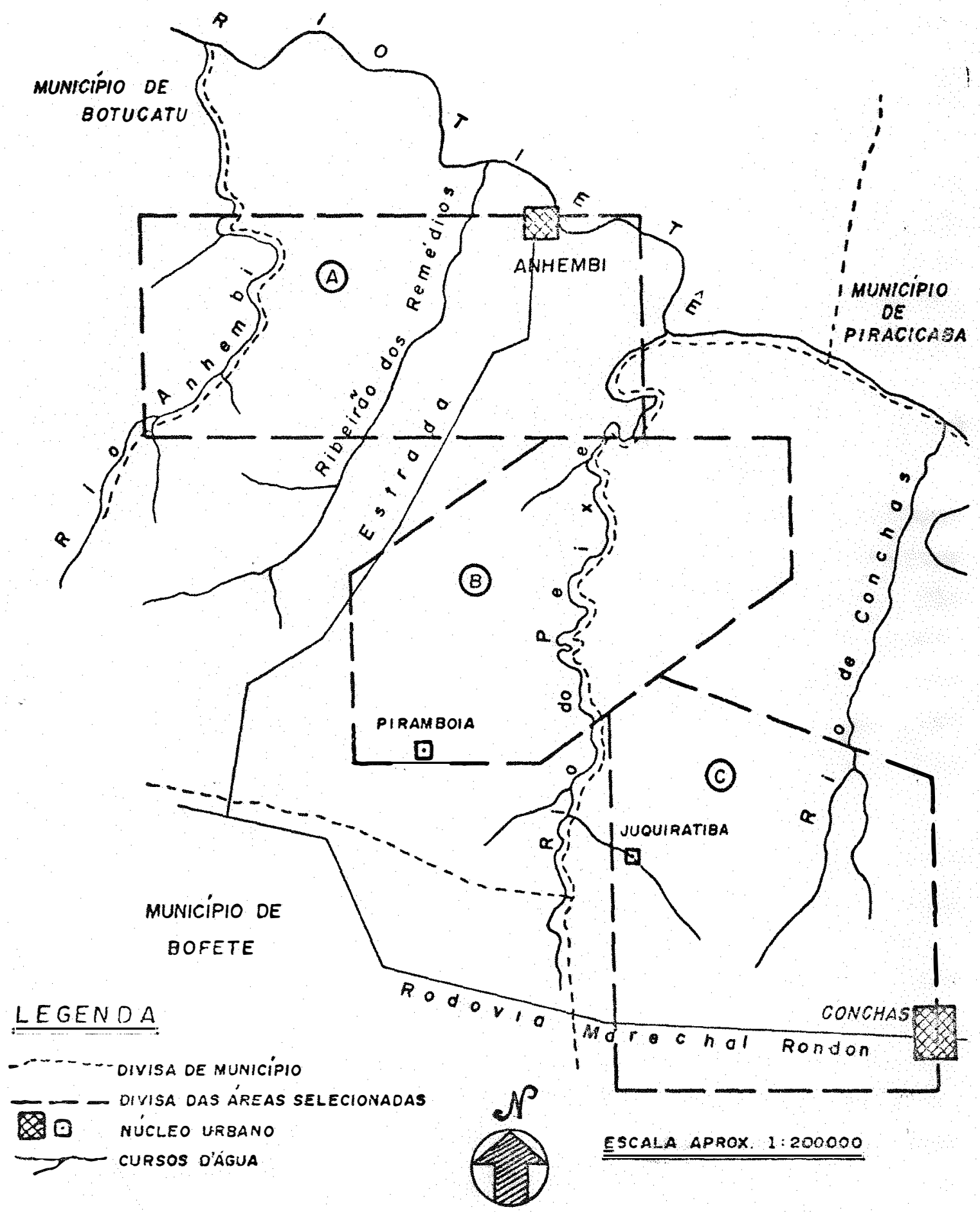

FIG.3 - Esquemo de locolizóçao do região,opresentondo os tres áreas estudadas. 
Nla área como un sodo as a títudes estão en torm no de 600 o 440 metros, com predonínio antre 600 e 540 wetros: áreas de chas 60u m ocorrem isoladas, colio no airro" hua Clara, róximo a Firanóia, o na estrada de acesso a linhembi, a portili da liarechas Rondon, são observados valores nais olem vados. As nonures coţas ucorren, natura mente, nas imediaçũes

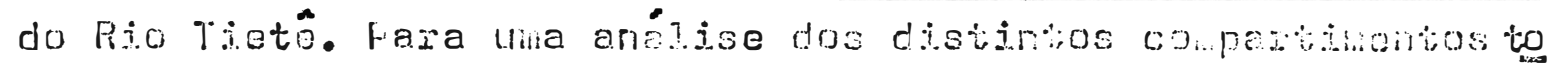
porráicos existontes, eventualnente corselacionáveis a super.

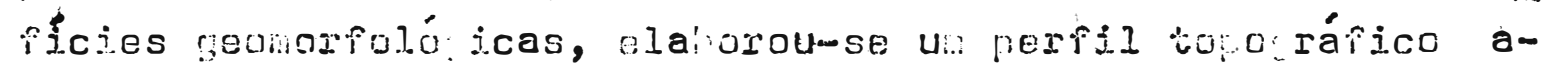
companhando a menoionada via de acesso, a partiz da folha topomáfica de hnhemi (FUfDACinc I EE, 2970), apresontado na Fi

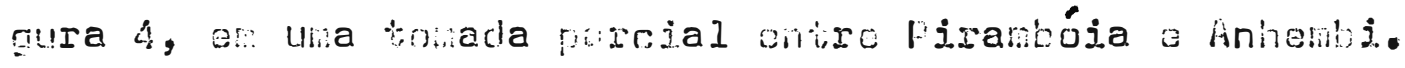

\subsubsection{Verctação}

Nas áraas A (Juquiratiba) o C (Anhemi $i$ ) a vego-

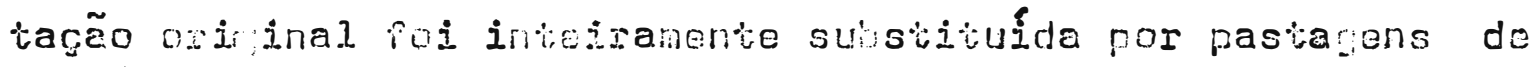

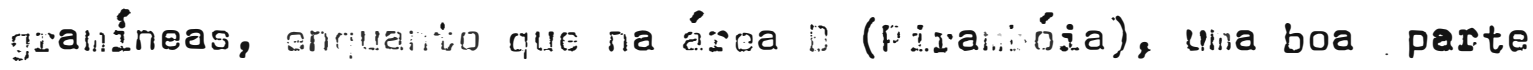
apresenta-se ainda rovestida da ve etação natural do cerredo, con parcelas teoledas roplasestadas con élcalsitio a asinda por cões ponco expessives com pastagens.

\subsection{Estur's das zodes de drenazen}

A pertiz das otogratas ás.as verticais de

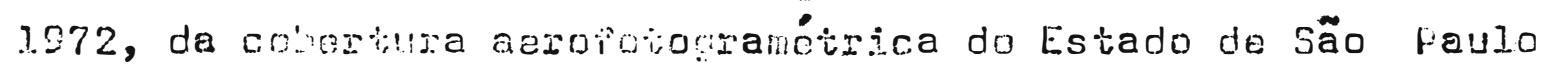
(na escala andoxinada do $1: 25000$ ), mocedeumse a exame interpretativo, coi alixilio de lii asturescórjo de espelhos UTLD - STl; conieccionollose, assin, o Mepe bésico da redo de drenargin, col. correção das distorgoos, por internédio do neto

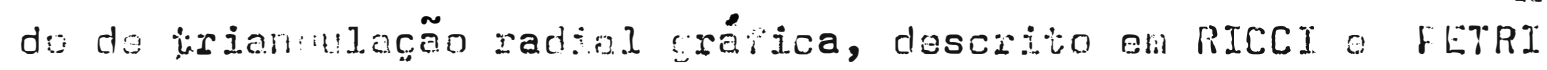
$(1965)$.

A rede de drenagen assin olvida conpreende canto os ranais resuluentes, colio so benjoxáros, tendome adota do, para e estı do de sua composção, a oxderi de ramîicação u 




FIG. 4 Folha topográfica de uma parcela da regiãode estudo (FUNDAÇÃO IBGE, 1970). 
tilizada por GTRAHLR (1957). Hor internédio do anosiras circulares de $10 \mathrm{~km}^{2}$ (RAY e FISCHER, 1250), Poran procedidos esi. cudos comparativos das áreas A, $B$ e C, através dos índjces: .. densidade de drenagen. (Dd) e frequência de rios (Fr), proposLas por honton (2945).

A Dd é representada pela relação entre o compri. mento total de secmontos de rios e a área consideroda, anquan to que a Fr corresponde à relação sntre o núnaro total de seg ar ríos a a área.

A análice comparativa dos resultadoe ofticios fot procedida medianto o delineamonto experinental de parcelas in teiranente casualjzadas, consiojindo de 3 cratanentos (áreas A, o C), com 7 rapeticues (7 amoetras circulares de $10 \mathrm{~km}^{2}$ en cada área considorada). Os dados coran sulnetidos à análin se de vartancia e as nédias do tratanentos conparadas pelo teste de Tukey, cujo processamento é exposto en FInETEL Co. IES (1.070).

Empreendeumse ainda un estudo superticial sotre a evolução de erosão, ou das"cabeceiras de erosão" (aiaral e AUDI, 1972), pelo exane conarativo das fotorrafias aéreas de 1952 e 1072, nas seguinies bacias de cada área: Córrego da Di visa e Córrego Daniel Lejte (Área A), Ribeirão Darracão e Ri. betrão Ácua do Erejão (Area ), Córrego do lajeado e Córrego Áua Branca (área C).

4.3. Estudo dos solos e dos alteracões

4.3.1. Amocitragen e proparo dỏ naterial para análise

En locatis representativeo dos princtpais solos ocorrentes en cada área foran che uadas as descrições morioló gicas dos periis, segundo as normas do SUTL SURUEY GTAFF(1951)

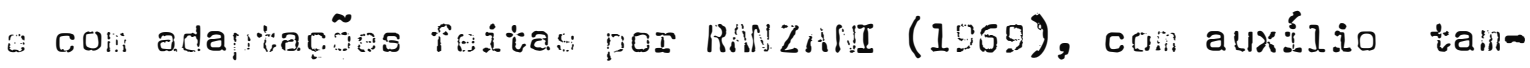
Lérin da carta de cores de fiurisell; as amostras coletadas dosho rizontes forali levadas ao la!rratorto o .. laraclas conforme as 


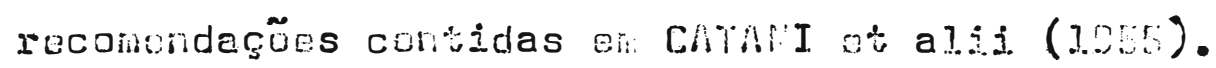

As dest naçõce convenctunete dy forpts a oves localszacões romen as seguinties:

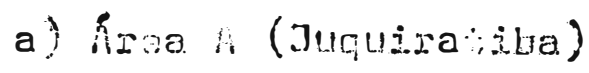

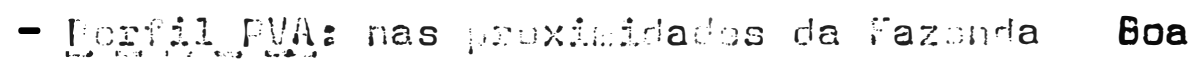
V:ota Cantarallj, a. a trän ejovata do rile-

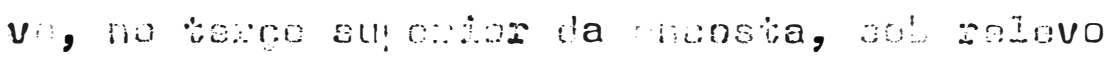
ondulado.

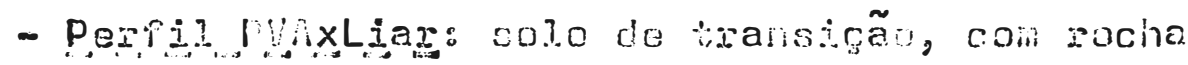
a cerca de $100 \mathrm{~cm}$ da surexifcse, próxino ao

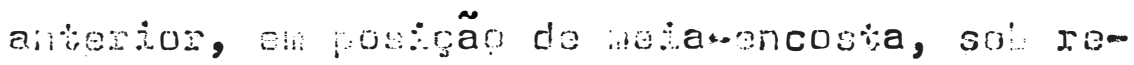
levo fortemondulado.

- Eerpir Liar/l: stulado en posigẽo de topo, ac lado da estrada de linecano de Tuquiratiha ao anci o urecino ascaltado do roduvia para con.. ciras, so'. relevo local chintude.

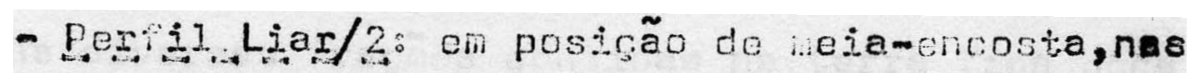
proxinidades de Juquiretita, antes da I reja llossa Seniora de Fádsina, sol rojovo furtomondurado.

b) Áaa $D$ (Finambóia)

- Perifil RLV/LIa posicão de neia-micosta, sob zelevo sueve, ao lado da estrada de livação $P \dot{z}$

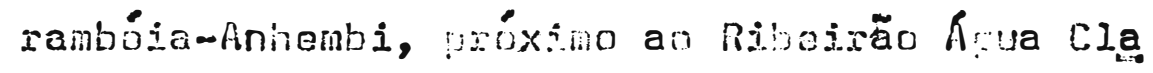
ra.

- Pexts RLV/2: situado em uma meia-encosta de relevo ondulado, ao lado da liesma estrada anterior, após atravessar a Cóncro brejão. 
c) Area C (finhomis)

- Porf j. PVIs: nas proximidados do Córrepo Lajea do, ar sibue ão de berco tinal da encosta, sob rejavo ondujede, a lado da ostrada tus liga os Cairros lajeado a Mibetrão ronito (região de conteto untro as Fonacoues lirambía e Estrada fiova).

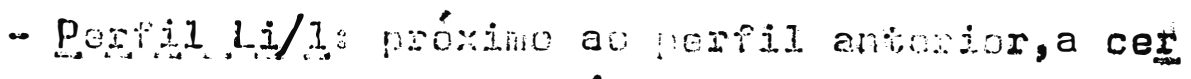
ca de 100 wotros do Córrego Lajoado, con expo. sị̂̃o do su strato wais ou honos arenuso, con

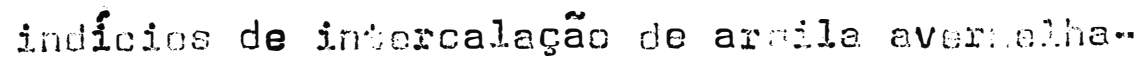
da.

- Pex II Li/2: tan śn daposto en sthuação seme Thanta, a cerca de 40 netros do Cómrego lajea do, con sulstrato iejs fino e consojidado,pos sivalunte de ratureza síltica.

\subsubsection{Análise granulonétrța}

As diversas praponos contitas na teria fina icca ao a: Poram detowinadas pelo nétodo da pipta (KILLER e AlE-

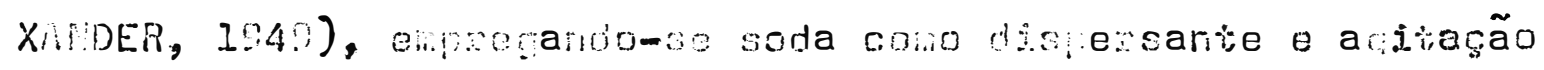
lenta dumento 20 horas; polo cesno nocesso dotentnou-se a

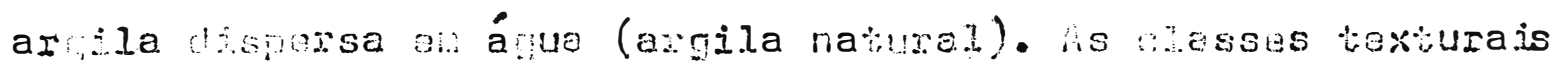

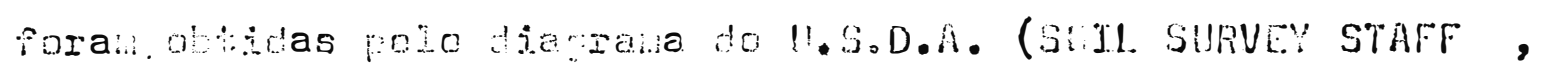
1.51).

\subsubsection{Análisa quínica do solo}

As deteninacoenes de cálcrio e ilarnésio trocáveis Poram efetuadas pelo nétodo do EDTA, sentrido as reconendasões de GLÉRIA et aJi: (1.96).

Os valores de potássio, hidrogênio, alumínio e fósforo trocáveis, ben cuno os de na téria orrânica (\% C × 1,72h 
foran obtidos através da netodolo ia preconizada ei. CATAil et alii (1005).

A capacjade de troca cationica foi determinada velo nétodo do EDTí, proposto por GlónIn et alij. (1950).

Os valores de phl rorali o tidos i.edionte una ren lação solo:á ua a solo:KCI de $1: 2$, .

\subsubsection{Análises ninesalógicas}

Ne separarão da tracão ar ha Mitirounse a thetodoloria exposta an Jnckson! (1005), cujas mincipaio atamas foran resuidanente as se uintes:

- remogão de sais solúvels e cátions tivalntes trucáveis com acetato de sitio:

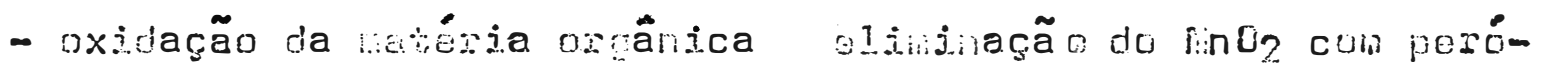
xide de hiszorêrijo:

- renosão dos ákidos de pexro livies con dibionito-icartoneto-cjitrato de sódio;

- dispersão con cartonato de sódio e strona da hacão argi la.

As ar las assim obtidas e secas a $40-60^{\circ} \mathrm{C}$ fom ram levaclas aos la aratórios da Opfice de Ja Recherche Scientifinue of Technirue Gutre lier (O.R.S.T.0.R.t), na Franga, na Seção de Espectrocra L̇a, col a responsabilidade do Di. haurice fina, unde foram analisadas mediante as técnicas explícitas a se! vis.

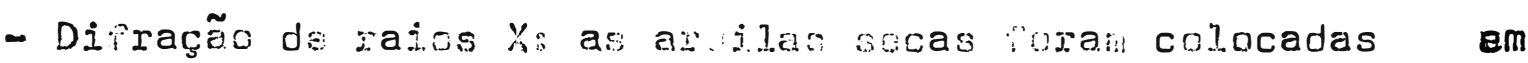
placas de plástico, munidas de ui.a reentóncia retianular (ja

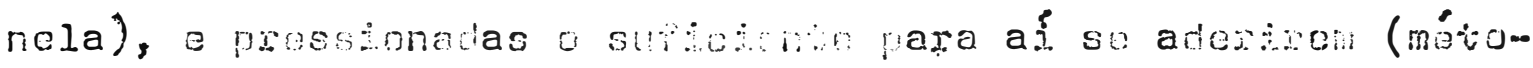

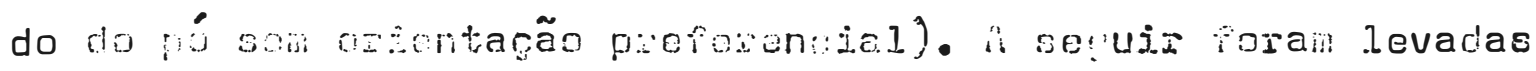
a apazelno de deracão autonévico C.C.R. (Cie. Sénérale de Radiologie), equjpado con espectrogonionetro e registrador grá, fico, enmerandomse como anicatodo o tuho de colalto. 
I nesma amostra foi colocada en disporsãu, $\theta$ suspensũes onan Jevadas a lâminas de vidiro, oltendomse: aroj la orientiada natural, glicerolada e aquecida a $490^{\circ} \mathrm{C}$. nuando juldado convenionto, aqueinentos a outras temisatuas ioram

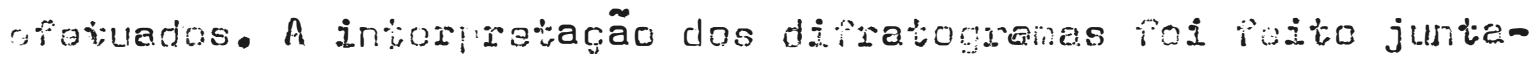

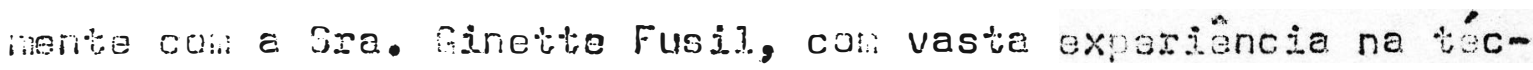
nica, por ser a responsévej. por osto tipo de soviga a trodo

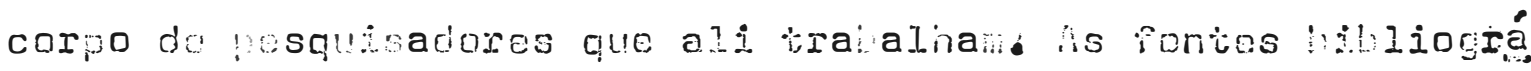

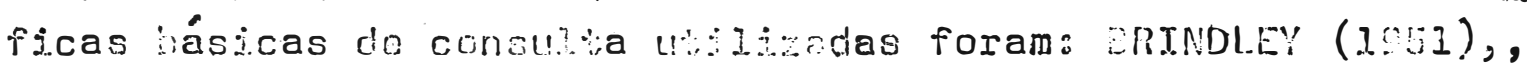

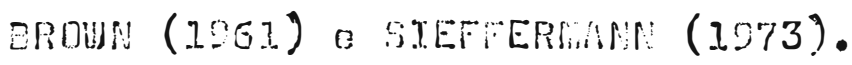

- Análíe téxnica diferencial: a anosira de argila foi coloca ra en un cadinho apropriado e acuplada ao aparelho SETARAfim -hicro AID rít, Lyon, acoplado a un nanovoltinetro e rejistrador SEPVIRRCE, operando-se a una intersidade de lou mv e com

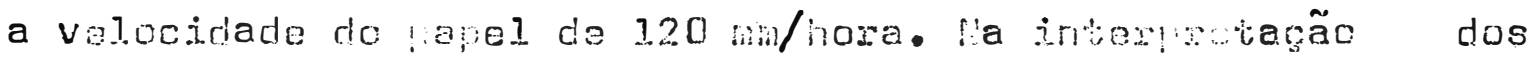

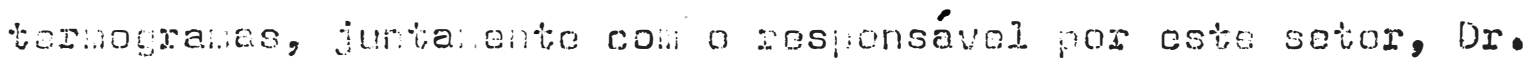

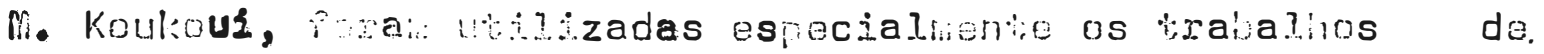

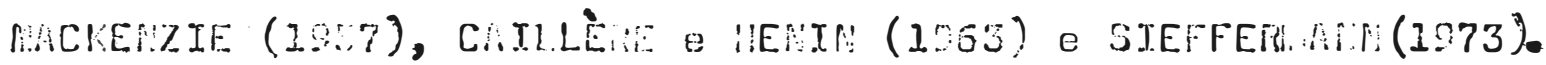

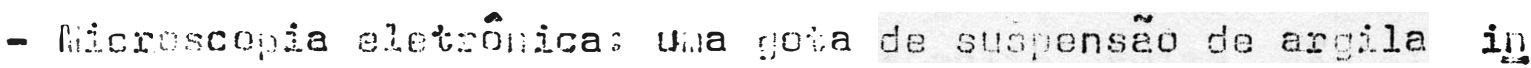

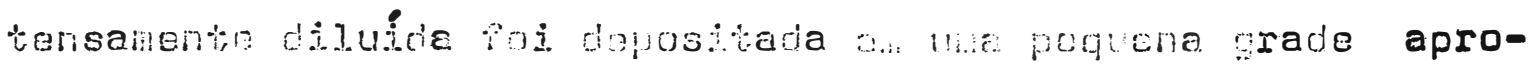

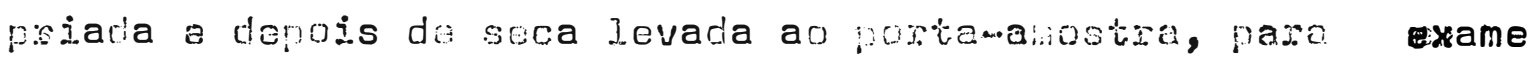

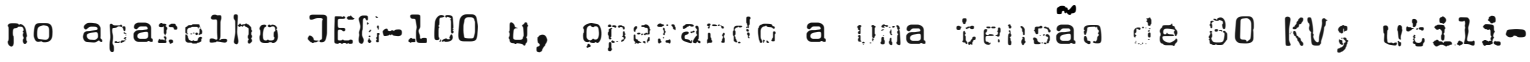

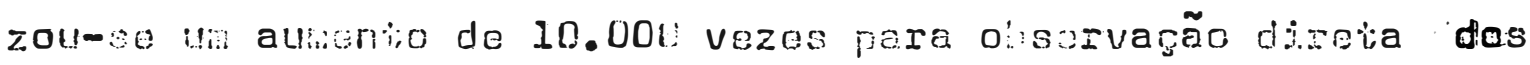

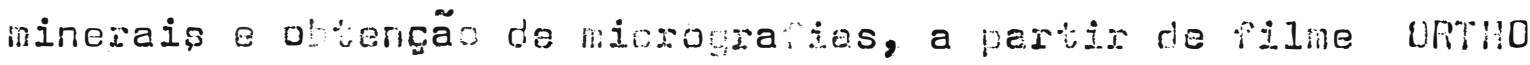

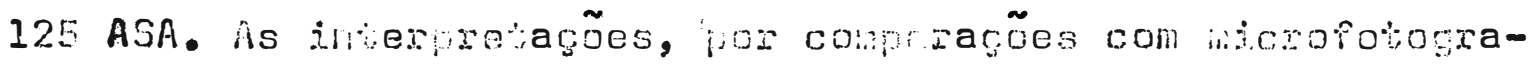

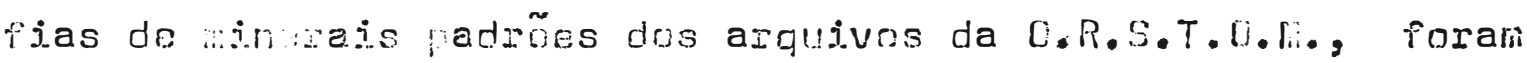
enornentric facilitadas pelo auxilio do geólogo Dr. Douinique Rainiaud, responsável por esso setos de análise. 
5. RESILLTADUS E DISCUSSÃO

Análíses norfológjeas, franul onétricas a gúmicas

5.1.1. Descriçẽes morôlógicas doo persis.

a) Pasis PUA

Al O- 25 cing cinza escuro (5YR $4 / 1$ Úlitio), cinze (5YR 5/1 seco); arejag comosta cranular, nutto pequena, Praca e pãos szmplesi sollto, solto, nãu plásti co, não pegajosog. raíles rinas, a' undantes; linite suave, claro.

A2 25 - $80 \mathrm{~cm}$; pardo averibelinado ( sado (E\%R E/2 seco); araja mectça que se rome en crãus simples; nacico, mujto friével, não plás tico, não pocajosog rajzos finas, nito slave, abrupto. lisesenca das distrioufidas hais ou menos horizontalnente, com toxiura nais tine do que a massa do horizon te, a de cos jardo avernelhada (2, GYR $4 / 4)$.

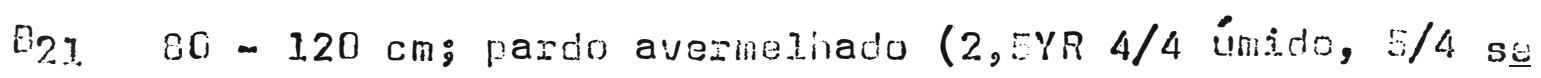
co) : harro arenuso; maciça que se rompe en blocos sulantulakes, nequenos, fraco; cezosidade -moderada, comung revestinentos de naténia oz râ- 
nica comus e intiensa atividade liolólca; duro,

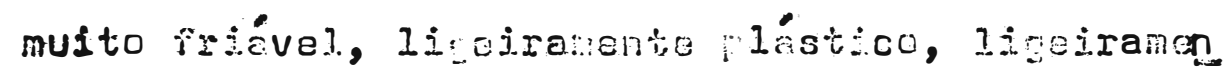

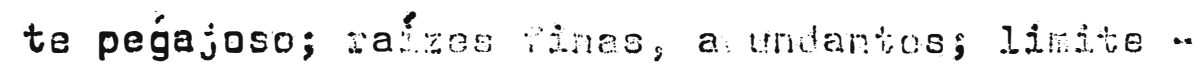
suave, gradual.

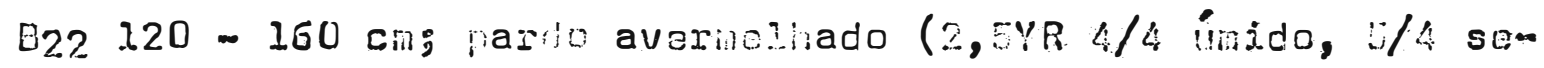
co): harre arenoso; hasiça rus so rompe en blom cos sutanculases, pequenos, pracos cerobidade -

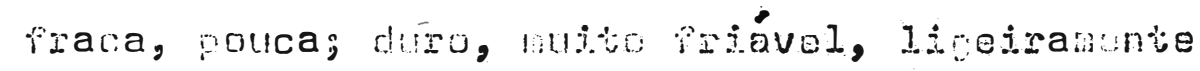
plástoco, ljetramonto porajosog raḱzes nhas,a bundantes.

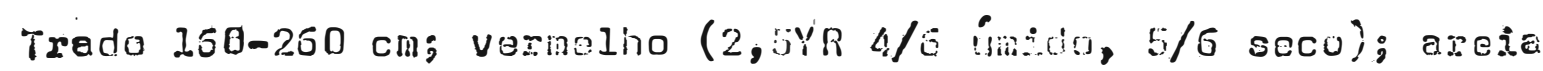
barrenita: não plástisco, não peçajoso.

\section{b) PerfiI PVA $\times$ L. Liar.}

AI 0 - $30 \mathrm{~cm}$; pordu acinzentado musto escuzo (loy $3 / 2$ ú mido), cinza (1OYR G/I seco); areias lacjça; ma cío, muito friável, não plástico, não peģajosọ; raizes finas, abundantes; limite suave, claro.

A2 30 - 65 cn; cinza perdaconto claro (lo y $6 / 2$ Ĺmido), . branco (10 YR o/1 seco); eroiad maciça que se rompe en rã̃os siniples; solto, solto, não plás.. tìco, não regajoso: raizes finas, abundantes li mite slave, abrupto.

8/C 65 - $110 \mathrm{~cm}$ : pardo escuro ( $10 \% \mathrm{r}$ 4/3 ímido), con mosquea. do abundente perdo forte $(7,5 \% \pi 5 / 3)$; barro arm gilo aronoso; hacsça; fróvol, lícirakenteplás tico, litejranente pegajoso: raf...es rinas, cow muns: limile slave, abruptu. Presença de produm tos nats ou menos decompostos do arentito subjam cente e. de arjile translocada das caladas super. ficiais. 
R $110-170 \mathrm{~cm}(+)$; arenitu vartegacio a váríos fraus de der composição, com jmpedinento de drenagen.

\section{c) Perfil Lias/l}

A, $\quad 0$ - $20 \mathrm{~cm}$ p pasdo acinzontada mutco escuro (loyr $3 / 2$ úm njolo, cinze ( $10 \% R$ 6/I seco); arro aronoso: na c.jça que se rompe on manułas: pequena, fraco; lígejuanence duso, muitio friáve?, não hástico,

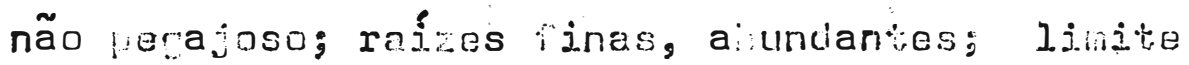
ondulado, abrupto, disotanonto con o arenito.

Rocha - arenitio a vásioe graus de decomposição.

\section{d) Pesfil Liar/2}

A $\quad 0$ - 25 chj cin\%a mojo escuro (loýa $3 / 1$ úmido), cinza (IOYR 5/I seco); araia iarenta: granular, pegiena, Praco: liceiranonto diro, lujito Prível, não plástico, não pogajosoj rǻżes finas, abundantes: lintie ondu?ado, atruto, disetamente solire a rocina.

Rocha - arenjito variegado, prodoninando cures amarelades e amaronomernomedas, cun mirior rau do decomposição a $25-75 \mathrm{~cm}$.

\section{e) Eexf}

Ap $\quad 0$ - $20 \mathrm{~cm}$; pardo avermelhado (5YR 4/3 6 thiclo, $/ 3$ sem co): areias composta cranuter, auto reguena, -

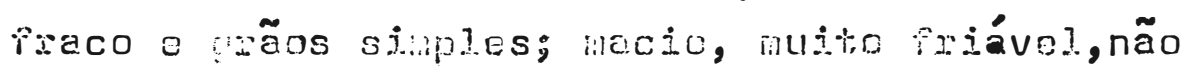
plástico, não pegajoso rajues finas, abundantes; linite slave, gradual.

A3 20 - $50 \mathrm{cmi}$ pardo avermelinado ( $5 Y \mathrm{R} 4 / 4$ Úmirle, $/ 4 \mathrm{sem}$ co); areia; haciça; nacio, muito friável, não plástijco, não pegajosoj rajzes finas, abundan- 
tes: linitue suave, difuso..

(BI) 50 - $125 \mathrm{~cm}$; alaranjado (5/R $5 / 6$ Émido), vardo avernoIhado claro (GYR 6/4 seco); aroia; haciça; macio, muito friável, não plásitico, não verajoso, rafizos finas, conuns: linitie suavo, difuso.

(B2) $125-230$ cin; alaranjado (cyR $4 / 0$ imjio), fardo averneling

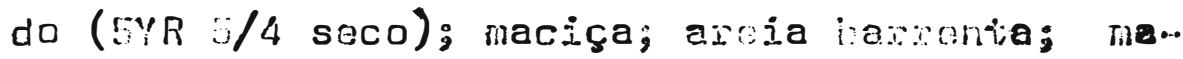
c:o, nuito friável, nẽo lástico, não perajoso. ra?zes finas, raras.

Trado $180-300 \mathrm{~cm}$; alaranjado ( $54 R \mathrm{O} / 3$ úmido); areja barrenta: não plásitico, não pegajoso.

Observaçoses:- pontuacõos de areia lavada ao longo do poríl.

f) $\operatorname{Per} I 1$ RLV $V=2$

$A_{j j} \quad 0$ - $18 \mathrm{~cm} ;$ pardo avermolihado $(2,5 \% R 4 / 4$ kimido, $5 / 4 \mathrm{sc-}$ co); areia; maciça que se ro,npo an gräos $\cdot$ sim ples; solto, solto, não plástíco, não porajosoj raizos rinas, abundantes; linitie suve, claro.

$A_{3} 18$ - $50 \mathrm{~cm}$; pardo avernolhado $(2,5 \times k 4 / 4$ únion), verme. tho claro (2,5YR 6/6 seco); areiag hociças tha. cío, nutito friável, não plástico, não iegajoso: raizos fines, a'undantes; likite suave, difuso.

(BI) 50 - $110 \mathrm{~cm}$; vernelho $(2,5 \gamma R$ 4/6 únicio, $5 / 6$ seco); areia barrenta; i.reciça; nacio, nuito friável, :" não plástico, não pegajoso; raizes finas, conunsili inite suave, difuso.

$\left(B_{2}\right) 110$ - $200 \mathrm{~cm}$; vernelho escuro $(2,5 Y \beta$ 3/6 úmjdo), vvermetho ( $2.5 Y P 4 / 6$ seco); ar ia barrenta; maciça;ma cio, wuito frível, não plástíco, nãu peçajoso; raízes finas, raras. 


\section{g.) Perfin pyls}

$n_{9} \quad 0$ - $30 \mathrm{~cm}$ p pordo acinzentado husto escuro (10\%R $3 / 2$ úm mido), cinza (IDYR 6/I seco); areia; granular, roquona, fraco; nacio, muito frí̂́vel, não plás tico, não pegajoso; raizes finas, áundantes $I$ i mitie suave, claro.

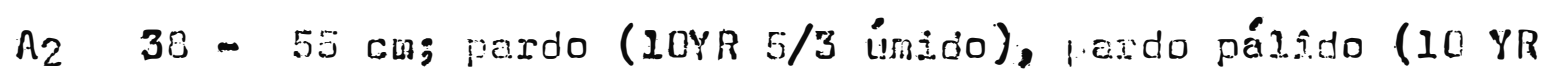
б/3 seco); areia; maciça que se romle en irãos simples; necio, nuito friável, não pístico, não pegajosog. rå̊zed finas, alundantes: linitie suam ve, claiso.

B21 55 - $88 \mathrm{~cm}$; pardo avermelnado (ive $4 / 4$ úmido, $5 / 3$ seco); barro argijo arenoso: hocos suhangulares, mém dios, noderado; cerostidade noderada, comlmo dum ro, finte, plástico, pegajosos raßzes finas, am itmdantes; linite suave, claro.

322 80 - $120 \mathrm{~cm}$; pardo avori..elhade (SYR 5/4 únjdo), pordo á verneliado claro (5YR 6/4 seco); barro arsilo a renoso; hlocos subangulares, pequenos, frocojce rositade rraca, pouca; duro, fíável, plástico, pegajoso; raizes tinas, pollcas; Ilnitie suave, .. gradual.

B3 120 - 180 cin; alaranjado ( $5 Y R 5 / 0$ únido), anarelo avermeIhado (s\% $6 / 6$ seco); basro arenoso; mojge; ma cio, muito fríluel, lineiraiverite plásitico, li.. geiramento pegajosa; raj.es finas, rasas; limim te ondulado, abxupto, en coniato coll material parcialmente decomposto.

Trado 100-200 cm; pardo amarelado (10Y月 5/8 Limo): barro argilo arenoso; plástico, egajoso. héterial .rochoso parcialnente deconposto juntanente com u matorial edarjzado. 


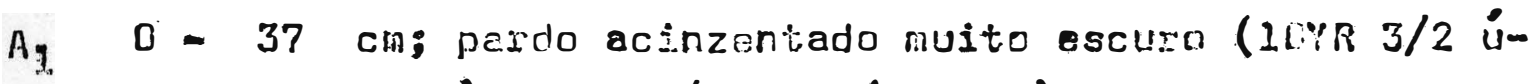
inido), cinza (10\%R J/I seco); arsia barionta;ma ciça cue so rompo en granular. peguna, freco e grãos stmbies; lireiramente duro, mesito iriável, não pléstico, não peg̣ajoso: rajues i inas, abundantes; linite suave, alrupto con a rocira, ein -. descuritinuidade evidericinda pro una linha do soixos da quartzo.

Rocha - arenito apresen ando hatis suerijcialinerite al cum matierial decomposto.

\section{j) $\operatorname{Per} i 1 / i / 2$}

A 0 - $30 \mathrm{~cm}$; pardo acinzentado nuito escuro (10\%R $3 / 2$ trnido), pardo acinzentiado ( $10 \mathrm{~V} R 5 / 2$ seco); harro arenoso; liacsca que se rowpo en cranular, peque na, iraco a grãos simies a li cijanente duro, .-

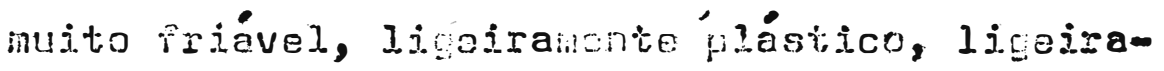
mente pegajoso; rậzes finas, abundantes; linim te suavo, radual.

B/C 30 - 45 cia pardo sscuro (10\%n 4/3 únido), pardo (IoyR $0 / 3$ seco); barro argilo arenuso; hacico que se rome on blocos stiantularns, fenvenus, fraco: cerosidade fraca, pouca; duso, firme, plástico, regajoso; rajizes flnas, al undantes; linjte com a rocina alterada an descon inuidade, fuidenciada por una linha de seixos quartzozos.

Rocina - (arjilio) Iitoiranente decomposto.

5.1.2. Análises granulométricas e químicas dos perfis Os resultados das análỉises necânicas são apreseniados ne TrEeLn $l$ e os de análises quílaicas de rotina cons 


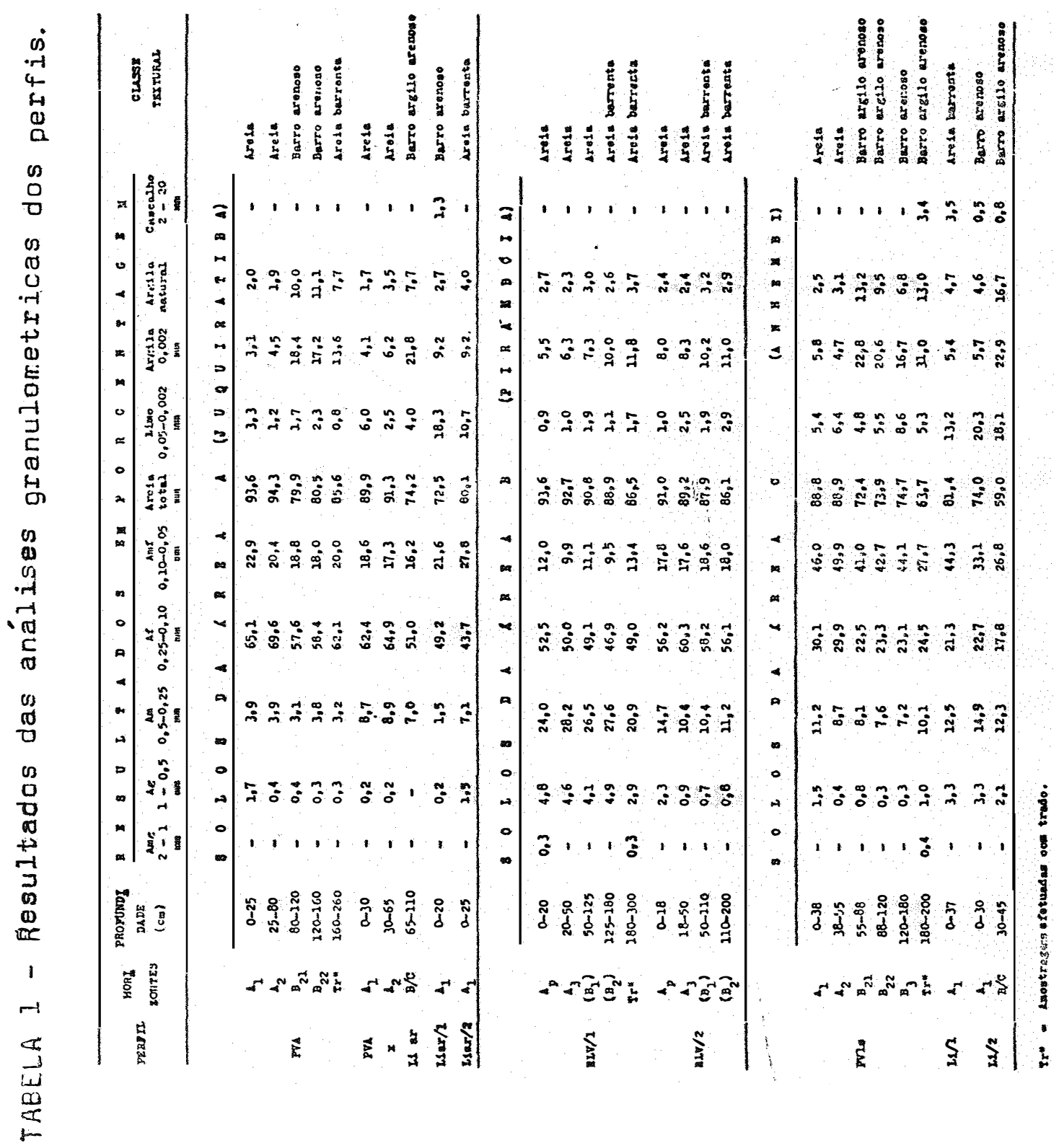


TABELA 2 Resultados das analises quimicas dos perfis.

\begin{tabular}{|c|c|c|c|c|c|c|c|c|c|c|c|c|c|c|}
\hline \multirow{2}{*}{ F8RPII } & \multirow{2}{*}{$\begin{array}{l}\text { HORI } \\
\text { ZONEES }\end{array}$} & \multirow{2}{*}{$\begin{array}{l}\text { PROYUNDI } \\
\text { DADB } \\
\text { (cD) }\end{array}$} & \multicolumn{2}{|l|}{ pH } & \multirow{2}{*}{$\begin{array}{c}\text { MATERIA } \\
\text { ORGANICA } \\
\qquad\end{array}$} & \multicolumn{2}{|c|}{ COUPLEXO } & \multicolumn{2}{|c|}{ TROCKVEZ - 0} & $\mathrm{~m} 3 / 200$ & \multicolumn{2}{|c|}{ O \& DE SOLO } & \multicolumn{2}{|c|}{$\begin{array}{l}\text { S SAR. } \\
\text { DS BASS3 }\end{array}$} \\
\hline & & & $\begin{array}{r}\text { RGUA } \\
2: 2,5\end{array}$ & $\begin{array}{l}x \subset 2 \\
282,5\end{array}$ & & $\mathrm{Ca}^{2+}$ & $u_{\delta}^{2+}$ & $x^{+}$ & $\mathrm{H}^{+}$ & $\mathrm{Al}^{3+}$ & $\mathrm{PO}_{4}^{3-}$ & CTC & $y^{*}$ & $y^{* n}$ \\
\hline \multirow{6}{*}{ PUA } & & s 0 & 03 & $D$ & \& & a & 1 & A & (J) $U$ & 8 & I $R$ & A & $B$ & d: \\
\hline & $A_{1}$ & $a_{25}$ & 5,8 & 4,8 & 0,52 & 1,04 & 0,08 & 0,06 & 1,60 & 0,32 & 0,010 & 2,00 & 59,0 & 38,1 \\
\hline & $\lambda_{2}$ & $25-80$ & 5,8 & 5,0 & 0,21 & 0,40 & 0,16 & 0,04 & 0,72 & 0,32 & 0,005 & 1,40 & 42,9 & 36.6 \\
\hline & $B_{21}$ & $80-120$ & 5,7 & 4,8 & 0,41 & 1,36 & 0,36 & 0,02 & 1,12 & 0,32 & 0,005 & 1,60 & 96,2 & 51,7 \\
\hline & $B_{22}$ & $120-160$ & 6,1 & 5,0 & 0,26 & 1,20 & $\mathrm{~T}$ & 0,04 & 0,80 & 0,32 & 0,005 & 1,60 & 77,6 & 52,5 \\
\hline & $2 x *$ & $160-260$ & 6,2 & 5,4 & 0,16 & 0,64 & 0,16 & 0,04 & 0,16 & 0,32 & 0,005 & 1,80 & 46,7 & 63,6 \\
\hline PVA & $A_{2}$ & $0-30$ & 5,0 & 4,2 & 0,67 & 1,28 & 0,26 & 0,04 & 2,00 & 0,96 & 0,007 & 4,20 & 35,2 & 33,3 \\
\hline$x$ & $A_{2}$ & $30-65$ & 5,3 & 4,3 & 0,26 & 0,80 & T & 0,02 & 0,56 & 0,56 & 0,003 & 2,00 & 42,0 & 42,3 \\
\hline \multirow[t]{2}{*}{ IL ar } & $B / C$ & $65-110$ & 4,7 & 4,0 & 0,60 & 2,32 & 0,40 & 0,06 & 5,52 & 3,60 & 0,003 & 10,60 & 26,2 & 23,4 \\
\hline & Rocha & alterada & 4,5 & 3,9 & 0,21 & 0,96 & 0,24 & 0,04 & 8,64 & 8,24 & 0,005 & 10,40 & $u, g$ & 6,8 \\
\hline $\mathrm{Ltax} / 1$ & $A_{1}$ & 0.20 & 4,8 & 4,2 & 1,71 & 4,64 & 1,20 & 0,10 & 4,88 & 1,92 & 0,040 & 14,00 & 42,4 & 46,6 \\
\hline \multirow[t]{4}{*}{ Ltar/2 } & $A_{1}$ & $0-25$ & 5,2 & 4,6 & 1,96 & 6,32 & 1,04 & 0,16 & 2,40 & 0,32 & 0,093 & 16,20 & 46,4 & 13.4 \\
\hline & & S 0 I & $0 \mathrm{~s}$ & $D$ & $\&$ & $8 \mathrm{~B}$ & $A$ & B & & (P) I & R A & B & 0.11 & A) \\
\hline & $A_{p}$ & $0-20$ & 5,5 & 4,8 & 0,67 & 0,88 & 0,64 & 0,04 & 0,64 & 0,40 & 0,163 & 2,80 & 55,7 & 60,0 \\
\hline & $A_{3}$ & $20-50$ & 4,5 & 4,2 & 0,41 & 0,08 & 0,08 & 0,03 & 1,44 & 0,80 & 0,023 & 1,60 & 11,9 & 7,8 \\
\hline \multirow[t]{5}{*}{ RIV $/ 2$} & $\left(B_{1}\right)$ & $50-125$ & 4,5 & 4,1 & 0,36 & 0,16 & $T$ & 0,04 & 1,68 & 0,96 & 0,012 & 2,20 & 9,1 & 7,0 \\
\hline & $\left(B_{2}\right)$ & $125-180$ & 4,5 & 4,2 & 0,26 & 0,08 & $\mathbf{I}$ & 0,02 & 1,44 & 0,88 & 0,018 & 2,00 & 5,0 & 4,1 \\
\hline & $T r *$ & $180-300$ & 4,3 & 4,2 & 0,41 & 0,24 & I & 0,01 & 1,28 & 0,96 & 0,012 & 2,00 & 12,5 & 10,0 \\
\hline & $A_{p}$ & $0-28$ & 4,5 & 4,2 & 0,41 & 0,16 & 0,08 & 0,04 & 2,68 & 0,56 & 0,014 & 2,20 & 12,7 & 9,6 \\
\hline & $a_{3}$ & $18-50$ & 4,5 & 4,2 & 0,47 & 0,08 & 0,08 & 0,01 & 1,68 & 0,96 & 0,010 & 2,40 & 7,1 & 6,0 \\
\hline \multirow[t]{5}{*}{ RLV /2 } & $\left(B_{1}\right)$ & $50-110$ & 4,6 & 4,1 & 0,36 & 0,08 & 0,08 & 0,01 & 1,52 & 1,12 & 0,007 & 2,20 & 7,7 & 6,0 \\
\hline & $\left(B_{2}\right)$ & $110-200$ & 4,6 & 4,2 & 0,21 & 0,08 & 0,08 & 0,01 & 1,44 & 1,04 & 0,006 & 2,20 & 7,7 & 6,4 \\
\hline & & $S O I$ & $0 \mathrm{~s}$ & $D$ & 4 & B $B$ & 1 & $c$ & & & (A) & H B & $\mathrm{B}$ & I) \\
\hline & $A_{1}$ & $0-38$ & 5,1 & 4,4 & 0,83 & 2,20 & 0,24 & 0,03 & 1,76 & 0,48 & 0,009 & 3.60 & 40,8 & 39,6 \\
\hline & $A_{2}$ & $38-55$ & 5,5 & 4,8 & 0,41 & 0,80 & 0,32 & 0,02 & 0,80 & 0,32 & 0,005 & 2,00 & 57,0 & 50,4 \\
\hline \multirow[t]{5}{*}{$P V_{1}$} & $B_{2 I}$ & $55-88$ & 5,5 & 4,7 & 1,09 & 2,72 & 0.72 & 0,16 & 1,76 & 0,40 & 0,005 & 6,80 & 52,9 & 62,5 \\
\hline & $B_{22}$ & $88-120$ & 4,7 & 4,0 & 0,16 & 0,56 & 0,32 & 0,22 & 3,52 & 2,40 & 0,007 & 6,00 & $16, ?$ & 24,4 \\
\hline & $\mathrm{B}_{3}$ & $120-180$ & 4,7 & 4,0 & 0,26 & 0,32 & 0,24 & 0,17 & 3,12 & 2,72 & 0,006 & 4,20 & 17.4 & 11,1 \\
\hline & $\mathrm{Tr}$ & $18-200$ & 4.5 & 3,8 & 0,36 & 0,88 & 0,64 & 0,18 & 5,04 & 3,92 & 0,010 & 8,50 & 19,8 & 15,3 \\
\hline & $A_{1}$ & $0-37$ & 5,3 & 4,5 & 1,14 & 2,80 & 0,56 & 0,36 & 2,40 & 0,32 & 0,010 & 6,80 & 54,7 & 57,8 \\
\hline \multirow{2}{*}{$\mathrm{LI} / \mathrm{s}$} & Rocha & alterada & 4,8 & 3,9 & 0,41 & 2,56 & 0,96 & 0,10 & 7,20 & 6,88 & 0,010 & 14,60 & 24,8 & 20,4 \\
\hline & $A_{1}$ & $0-30$ & 6,1 & 5,7 & 2,03 & 4,08 & 0,32 & 0,31 & 0,80 & 0,24 & 0,012 & 6,40 & 73,6 & 81,9 \\
\hline \multirow[t]{2}{*}{$51 / 2$} & $B / C$ & $30-45$ & 6,5 & 5,7 & 0,72 & 4,16 & 0,36 & 0,79 & 0,96 & 0,32 & 0,009 & 9,60 & 61,6 & 82,2 \\
\hline & Foche & slterada & 5,2 & $4 \times 0$ & $-0,52$ & 4,16 & $\mathrm{O}_{2} 96$ & 0,29 & 3412 & 2,36 & 0,009 & 14,00 & 35,5 & 54,7 \\
\hline
\end{tabular}


tam da TAEELA 2.

5.1.3. Comentários sobre os resultados norfolá icos, î́sicos e químicos

Além da caracterizarão, om si, de cada perfil, com relação aos seus principais atributos morrológicos, as des criçốs morpoló icas possibilitaram o estabolecinento de determinadas constatações, que, juntamentie con as análises fís cas e quínicas, são apresentadas a seruir.

No peril PVA o horizonte $A$ arenoso é bastante espesso (30 cm), jazendo er contato abrupto com o $\theta$, onde o teor de argila sopre brusca elevaçöo; na camada amostrada com - trado o valor dessa rração decresce novamonte, porém com um ma dininuicão nonos sonsivel do que no $A$. A presenga de cero sidade nos horizontes $E_{2}$ ] e $B_{22}$ é indicativa de processos de eluviação-iluviação, temín rếeida cono aruiluviação (BARTELLI, 1973); entretanto, esse incromento nas partis intermediárias do perfil nom sempre pode ser explicado apenas por es se processo (SIfIOSSON, 1949; ficCALLEE, 1959), de tal sorteque tal empolrecimento do A pode ser devido a un arrastamento oblíguo ao longo das vertentes, como é usual en solos con dom minância arenosa (LAmouroux, 1072; SEGALEN, 1974), pincipalmente ao se vexificar o carbiter de disporsibilidade das argilas en solos dessa netr reza, indicado prlos valores de aroila natural (TABELA 1).

Alén desses mecanismos, a presença de bandas on duladas no porfil PVA é indjcativa de processos de coluviamen to ao Iongo das vertentes (QUEIROZ NETO, 1973), a promover o espessanento do horizonte $A$, o qual, no entender de CARUALHO (1975) e lEATEADO e RAVZRII (1973), pode ser considerado como un colúvio moderno repousando sobre un E fóssil: porém, nas encostas nais ínrrenes, como é o caso do perfil fVAx Liar, a quolo camada se torna menos espessa, acentuando os processos erosivos, de modo semelhante ao observado por QUETRUZ NEfO e 
Esse contato abrúptico é tamién observado no oy tro solo cor elato de Anhombi, (PVIs), onde o rodiunte textum ral é asnda has elovado, cou concontraróos néxinas de arrila nos horjzontios B2s e B22, dininuindo na cankda sul jacante(B3) pera sofrer novamentio uma elevarão brusca en souida, onde o materiel é de naturoza sensivelmente diferente, a ruvelar uma descontinuivade líroló ica entre tais metoriais, corroborada pola presanca do cascalinos juntamente con o meterial pedogenelsado (UUETRIL IETO, 1975 ).

Certanente, a erande diferença textural entre o $A$ e 0 Q é un caráur de extrona inportâncie na interpretacõo dos fenómenos exocivos de una área, pela diuinuicão da taxa de infiltração de áqua no perfil e consequente incremonto do deflúvio, con novjunto lateral da água ao lonro das verten tes, a favorecer os itocessos de coluvionamento. E nítida a saturação con árua na zona de contato onire aqueles horizon tes, quando da sua doscrição norfolófica. Tonón KOFFler(1976) relacione radiente texurel ao major sulcanento de una área, indicado pela sue meior densidade do drenacon e frouchcia de

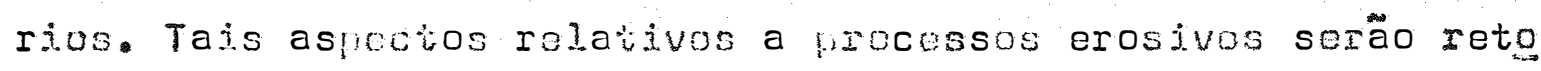
nados posteriormonte, no decorrer do brabalno.

Nos perfis RLV/I e RLV/2, de firambóia, as vam riacöes texiurais são i. enores, e a arpjla notural (arpila dis persa en á irua), froquntemente tomada cono uni indício da mobi. lidade dessa iraçé, wentén-se senpro bajxe, fincincipalnenteem comparacóo con os outros perpis (TAEELA 1), a indicar o seu caráter plucliedo nesses solos, caracteristica essa nats gene ralizada na cateroria dos "solos con 0 latossólico" (CUI.ISSÃo DE SOLOS, 1960), que QUEIROZ NETO (I975) relaciona com o as pecto de "envelhecimento" da rracão asgila, e sua consequente estabjlidade major, aspecto esse encontrado por excelêncitem superficios geonorfolódicas hais antigas; essa estabilidade da fração, au lado do estágio geomórfico senil da pajsạn. 
contribui efetivamente para o amedurecimento do solo. A essa característica associa-se a maior profundidade dos porfis,que onitidamente mais elevada nesses solos RLV, tomada tanbém co mo un indício do seu estágio de maturidade.

Mesmo en perfis menos espessos, portanto menos evoluífos, como é o FUAXLiar, essa brusca elevaça no teor de argila do $A_{2}$ para $O B / C$ e argila netural correlativamente mais elevada são observadas, a reapirmar a constatação de QUEIROZ NETO (2975), a raspeito da relativa rapidez para a formação de horizontes argílicos (s textural), podendomse con cluir, por autro lado, que camadas dessa natuieza podem ser encontradas en nateriais relativanonte recentes. Tal fato é bastante expressivo en perfis ainda majs jovens, como se verj fica pola presença de cerosidade no perfil Li/2 de Antembi.

Frequentemente tomada como um índice da evolum ção atin ida por un solo é a sua saturação em bases - V\%, cujos baixos valores em superfícies jovens, GARELE e DANIELS (1974) atribuem a um rápido intemperismo, ou a um material de origem con baixo teor en bases, com pouco ou nenhum material alterável.

Os dados apresentiados na TADELA 2 confirnam o maior grau de evolução atinjido pelos perîis da área $B$ (piram bóia) - RLV/I e RLV/2, cujos valores $V$ são nitidamente inferiores aos dos oubros solos. Como é de se esmerar, a maior ri queza en bases é enc nirada nos solos 1itólicos, onde o cálcio é o cátion doninante por exceléncia entretanto, sue mobilidade é patentie nos horizonves de lixiviação nais intensa, como é o caso dos $A_{2}$ dos solos podzólicos (f VA e PVis). . Nos solos RLV o complexo sortivo é dominado felo hidrogénio, elemento que. substitui as bascs, num processo de alte-agäo mais initenso.

O magnésio assume maior importância nos solos litólicos, bern como o poțássio, dininuindo sobremaneira nes solos mais desenvolvidos. De modo análogo comportam-se os vam 
Lores de CTC, a indicar a naior riqueza em bases e maior atividade das argilas nos solos menos evoluł́dos. Também relacionados aos níveis de atividade do solo, estão as quantidadesde carbono, ou de matéria orgânica, cono observou QUEIROZ NETO (1075), pelos mejores valores en Litossolos e solos com $\mathrm{E}$ tex tural, quondo comparados aps solos com b latossólico, para se melhantes teores de arjila. No presente caso, mesino em amosm tras com teores de arfila sensivelmente baixos, os Litossolos são os que apresentam valores mais elevados de netéria orgån ca (TAEELA 2), Ievando-se a supor tamín uma major força de sua liçação aos colóides do solo, wequerendomse un número muj to grande de tratemontos com prróxido de hidrogênio, para a sua parcial destruição, cono gue a corrotorar a ałirnação de MARCOS e KINJO (1967), a respeito de os elevados teores constituiren una caracteristica diagnóstica desses solos.

Ds valores de saturação en hases dos podzólicos das duas áreas (A e C) são astante djoferentes entre si (TABE LA 2), coni nuito maior dessaturação do complexo trocável no PVIs (Antrembi), principalmente nas camades mais propundas; so los com baixos valores $V \%$, orifinários de arenitos, foram acrupados na unidade de mapeamento Podzólico Vermelho Amarelo- variação Laras - PVIs (COmISSÃo DE SOLOS, 1960). ao passo que não há menção a solos da Depressão periférica, oxiginários de aronitos, com valores $V \%$ mais elevados, razão pela qual op tou-se pela desicnação PVA ao perfil em tais condições.

Dutra caracterisiica adicional indicativa de pe queno grau de evolução aringido pelos litossolos são os teores relativamente elevados de silte (VAN WHABEKE, 1967), sendo que ao tecer comentários a esse respeitio, a COrISSÃO DE SO LOS (1962) coloca tais unidades como componenties de uma rase de um único processo de iritempoismo tropical: "elevados teores de silte são nomalmente una indicação de que o intempeIismo lacossólico não se acha em fase bastante avançada" . Nos perris de firambóia (RLV/l e RLV/2) os toores de siltie são 
bastante bajkos, conirimando o seu estágio avançado de altera ção (SEGALEN, 1074), a par das outras características discutij das.

Ainda con relação aos dados apresentados, assume especial destaque a presença de "stone-lines" en determina dos perfis ( $\mathrm{Li} / \mathrm{l}$ e $\mathrm{Li} / \mathrm{L}$ ), a indicar descontinuidades entre os materiais situados acima das mesmas e o subjacento (RUHE, 1956), constatação essa à qual SEGRLEN (1974) atribuiu crande inpor tância no ostudo dos solos de regiões tropicais, permitindo melhor estabolecimento das relações entre solos e relevo, a subcituir o caráter "veriticalista" iradicional dos estudos pedológicos.

Entretanto, cono visto anteriormente, outros as pectos são tam él indicativos da natureza transportada dos ma teriais (bandas onduladas no PVA, natureza sensivelmente diversa do substrato, no (PUls), a revelar a natureza pobre em produtos detríticos da massa coluvial (BIGARELLA et alii,1965), sen a ocorrência de "stone-lines" entre as camadas descontinuas.

À exemplo da região de furnas (Cohisstio DE SOLOS, 1962), nem mesmo os solos litólicos, de seções de erosão geológica atual, oú de rejuvenescimento hais recente do relevo, estão inteiramente isentas dé descontinuidades entre - solo e a rocha inediatamente subjacente, e, por vezes ocorre apenas como que una aconodação da capa superícial sobre a rocha, idéia cue parece perfeita para o perfil Li/l, en que o horizonte superficial, com apenas $5,7 \%$ de argila (TAEELA 1), estó disposto sobre um substrato de textura sensivelmente mais fina.

Os colívios pedo enejzados sohrepondo as "stone - Innes" são interpretados cono testemunhos de fases clináticas mais úmidas, subsequentes a fases mais secas, responsáveis pe 10 estabelecinento de tais nateriais detrificos (ABREU, 1976). Também AB'SABER (1969b) e fiCDENESI (1974) admitiem que as "sto 
nemines" que, en geral se estabelecem sob neterieis de veitentes pouco espessos, acompanhando superficialmente a topografia atual, estão relacionadas à últina grande expansão dos paleopavimentos, correspondentes ao derradeiro estégio seco regional.

Desse modo, é provável que os solos das áreas $A$ (Juquiratiba) e C (Anhembi), originários de processos colum viais, associados ou não a "stone-lines", ou desenvolvidos di retanente sobre a roche oricinal fcomo parecem ser os Litosso los da área $A$ : ben cono as camadas nais profundas dos demais solos dessa área), estarian distribuídos en una superfície elaborada en tempos mais próxinos dos atuais, quendo comparam dos aos da área B (firambóia).

Tais constatações vão de encontro às de VILLIERS (1065), ao verificar que o pré-intemperisuo e o arrastamento do solo poden provocar mistura de materiais de diferentes pro veniêncjos, con a ocorrência de nais espécies de materiais de orifen do que diferentes tipos de rochas, o quo, certanente, não é tão usual em zonas temperadas. A par de diversas áreas tropicais que vendo caractexizadas pormenorizadaronto, é muito pertinonte, ne ranjão prosontenentue estudada, a idéia de QUEIROZ NETO (1976), qua cada peril representa una história particulai, sujeito a episódios comuns aos outros vizinhos, de les recebendo inîluenncias, mas tendo pontos de partida em épo cas diversas.

Tal tipo de análise será abordado ao longo de toda a discussão, pelo apoio que as demais determinarõos ofe recem, cujas explicargões vão ser frequentemente, encontradas nos processos valeoclináticos envolvidos, utilizados por CHRICTUFCLETTI e FENTEADU (1970) para explicar a hacromcompar timentação da Depressão Periférica, com períodos de pediplana ção e erosão, cujas mudanças clínéticas ao longo do quaternám rio re: orcubiram por toda a paisa fem, como ben atestam as "stone-lines" separando camadas coluviais. 
A evidência de que as interpretações não podem ser baseadas unicamentie em processos "Iineares" ou tradiciow nais (QUEIROZ NETO, 1976) é con rirmada mediante miltiplos aspectos, como no perill PVA de Juquiratila, revelando a presen ça de bandas onduladas (processos de vertente - coluvionamento) e de cerosidade (processo que pode ser puramente pedológi co), ao lado de perfís litólicos (Liar/l e Liar/2), provavelmonte desenvolvidos diretamento sobre a roche oricinal, não se excluindo tanbén possibilidades de coluvionai:ento, típicas nos Litossolos da árca C (Anhembi). Nẽo muito distante, na á. rea $E$ (Pirambóia), ocorren materiais de natureza nitidamente diversa, muito provavelmente correlacionedos a una superfície mais antiga.

Assim, o comentário de PELLERIN (1974) $\dot{e}$ de real importância, ao afimar que na cartografia das formações superficiais das áreas tropicais deve-se levar en conta os ti pos de argilas nas diferentes posições da paisagem,a permitir: a definição do grau de alteração das diversaş formações que puderam compor o perfil e suas distribuições. Esse tipo de análise é efetuedo a seguir.

\subsection{Análises mineralógicas}

As interpretacões mincralócicas aqui apresenta. das visan tão somente elucidar quais são os ninerais mais caracteristicamente ocorrentes, a frequencia relativa de suas presenças, ben como determinadas evidencias a respeito de suas origens, no cumpinento dos objetivos propostos, sem outro aprofundamento que a mineralogia pode ensejar.
5.2.1. Difração de raios $x$ e análise térnica dîeren- cial

a) Pexfiz PUA

Ds difratorranas de amostras desse perfil (Figu 
ra 5) demonstram a ampla ocorrência de caulinite, que nas lê.. minas de pó sen orientação preferencial - "fó" (Figura 5 e,f, g) é perfoilanente caracterizada pelos picos correspondentes aos semintes espaçenentos (en anstrom): 7,2 - 4,37 - 3,57- 2,57-2,51 - 2,38 - 2,34 - 2,29. D ternograma correspondente (Ficura 6a) revala o intenso pico encolérílco culminando a $590^{\circ} \mathrm{C}$, relativo àquele mineral.

A gibusita ocor en quantidades pecucnas, a jul rar pelos sous pequenos picos caracteristicos, par vezes de má contormexão, sonilo iè evidente na amostra B2l (picos a 4,06 e 4,37), conforme ficura 5\%: essa mesha anoctra aquecida a $500^{\circ} \mathrm{C}$ mostra a destruicão da caulinita e gibloita (Figura 5d). A ATD conirma a pequena expressão desie mineral, pelo pequeno pico endotérnico a $305^{\circ} \mathrm{C}$ (Firura $6 \mathrm{G}$ ).

Ds diversos difratopramas apresentados desse per fil denuncian ainda as presences também secundíries, en ocor rência, de outros ninerais, como a monthorilonita (10,9), ver miculita e/ou minerais interestratiricados (corca de 14 na amostra natural ou con alicerol, reduzindo pora $12,5 \mathrm{sol}$ aquecimentc a $490^{\circ} \mathrm{C}$, na porna de banda ( $F$ i ura $5 \mathrm{a}, \mathrm{b}, \mathrm{c}$ ), ilita incipiente $(10 \AA)$, quartzo $(3,34 \AA)$ e un hineval caractozizado pelo pico a 3,00 $\mathrm{A}$, típico do diésporo, has quo pode ser confundido con reflexão residual da hetahaloistite (entre 3,3 e 4,4), mencionoda por SIEFFerhiann (1973), contorne os difra torramas de pó (Ficura 5 e, $\hat{i}, 0$ ).

\section{b) Perfil pUA - Liar}

Nesse perfil hal drenedo, de transiço, a mont-

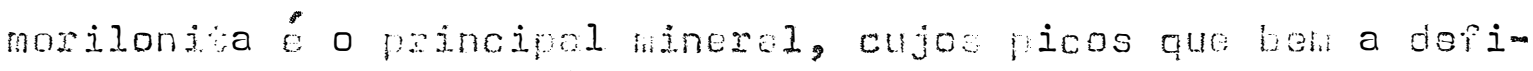
nem contesponden aos es evamentos $12,5-6,27$ e 3,13, relativos às diversas ordens; os picos de caulinita são nitidenente inferiores aos do lerizl anterior $(7,2-3,57$ e 2,39), apesar de hen definidos, cono mostra o difratorama da ficura 5 h. 
51.
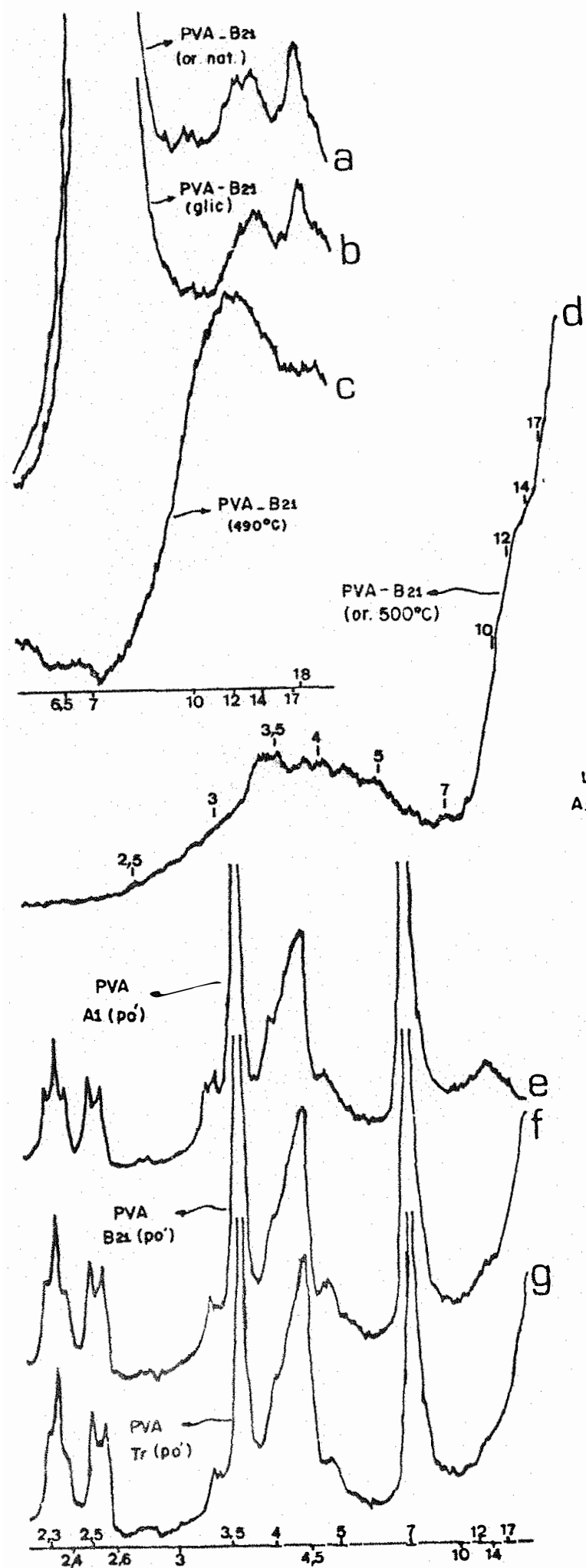

FIG. 5 - Difratogramas de amostras da área A (JUQUIRATIBA) (valores das escalas en angstrons).
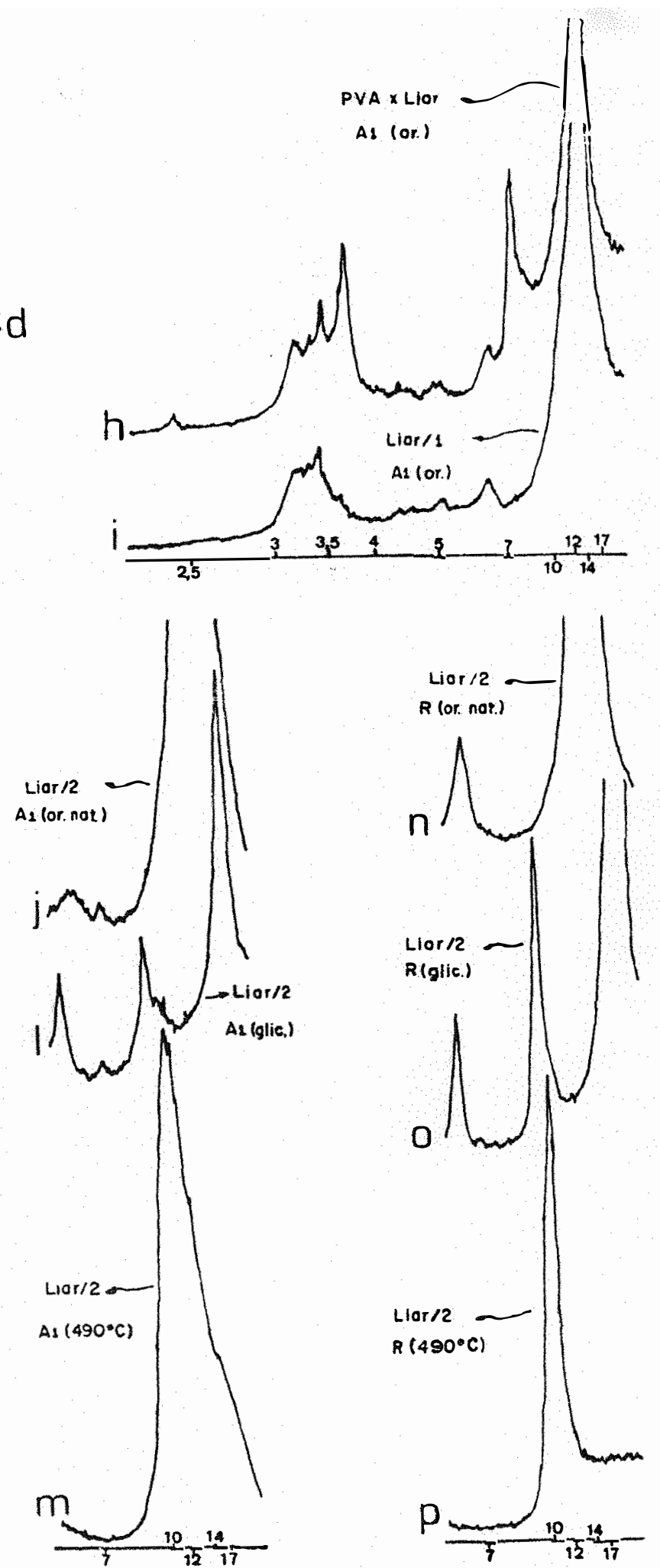
52.

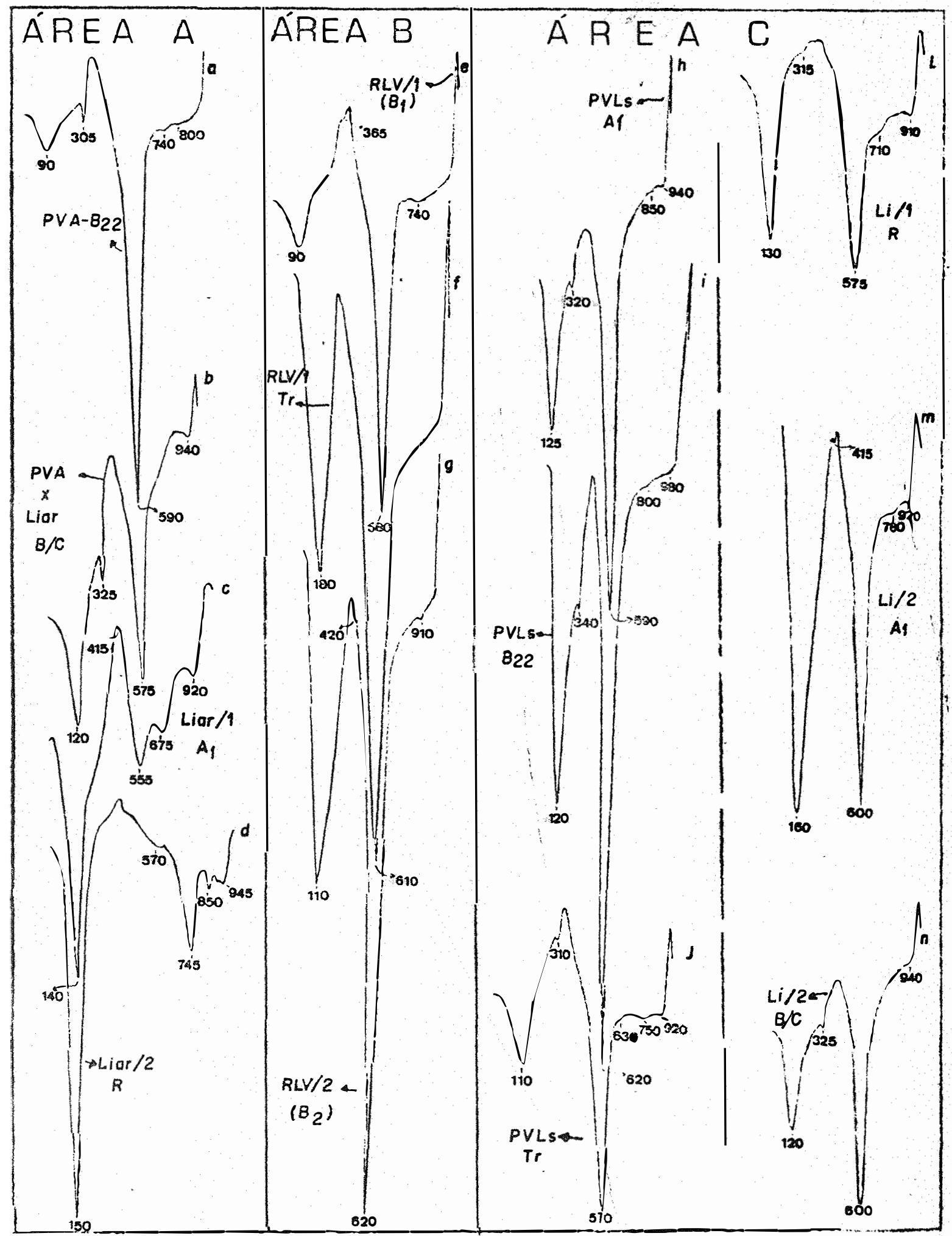

FIG. 6 - Termogramas de argilas dos perfis estudados. (valores numéricos em ${ }^{\circ} \mathrm{C}$ ). 
O termograma da Fi: ura Go commova a ocoriencia de caulinitra on quantidade visivelnento inferior à do perfil antoriormente analisado, cujo pico culinina a tompcratura tam bém inforior, podendo ser indicativo de sua menor cristalinidede. D hosino diegrama ovidencia a gibbsita $\left(325^{\circ} \mathrm{C}\right)$, en frequene quantidade e a influência da métria orgânica (reação xotérmica con máximo a cerca de $400^{\circ} \mathrm{C}$ ). A importante perda de árua hicroscópica a $120^{\circ} \mathrm{C}$ é atriluida rincipelnonte à nontrio rilonita. o pequeno pico ondórérico a $940^{\circ} \mathrm{C}$ é was usual da ilita, deventomse hencionar tambén que o pico a $575^{\circ} \mathrm{C}$, alén .. da caulinite, pode ser atribuído a outros minaris, como à

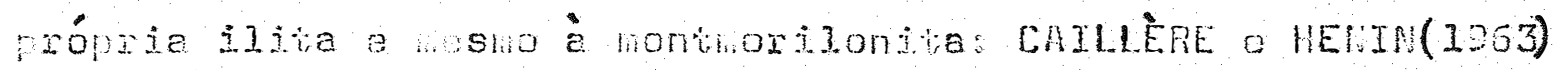
referen-so a pico desse ineral a $650^{\circ} \mathrm{C}$, e thouet (1070) a $500^{\circ} \mathrm{C}$.

\section{c) $\operatorname{EegtiL} \mathrm{Liag} / \mathrm{I}$}

Seri qualquer dúvida, o princifal minercl é a nonthoritontia, confor e denonstra a Fsura 5i, roferente à anostra ocientada, cujos licos pincipeis sãos $12,5-6,27$ e 3,30. Fegueno pico a 3,34 tento pode ser aribuido à ilita (3a. ordem), line vez que ocorre outro ben fraco a 5 \& (2a. or dem), como ao quartzo, en quantidace fraca, ou ainda a ambos.

O termorrana da ficura fo ten de fancipel a re velar, a grande quantidade de ácue rerdida a $140^{\circ} \mathrm{C}$, certamente devirio à montioxilonita, sh esprcial. Tan ém a reaço exom

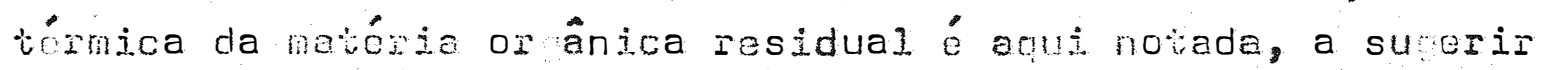
sua forto líação aos colóides do solo, hesho após vérios tra tamentos cm ánua oxifenada (FrrUUET, 1970: LARDunoux, 1972).0 incipionte pico endotérnico a $410^{\circ} \mathrm{C}$ pote indicar a mencionada prosenga de guartzo (SIEFFERMANn, 1973), assin cono a $555^{\circ} \mathrm{C}$ pode ses da ilita, on hesto do quartzo (finCKENZIE, 1057), com no taliém minerais da farilia da monthorilonita (Haver, 1970); a caulinita parece oxcluída, pela não ocorrência no difrato- 
rrama cor:espondente (Figura 5i). Finalmento, os ficos ondovid nicos a 675 e $920^{\circ} \mathrm{C}$ são nojs yovavelnento airibuídos a nontmorilonita. A prosonge de quartzo on peril coridato é tan bém rofenido la comissño DE SOLOS (1950).

\section{d) $\operatorname{fert} \operatorname{Liar} / 2$}

$\mathrm{Na}$ rração ar jlila extraída da rucha (Firura 7b) a ocorroncia é quese quo exclusiva do montionilonita $(12,4$ $6,27-3,13)$, alén do pico muto pequono $(3,33)$, rue pode ser devido ao cuarizo e/ou ilita. Na ATD o nico ondodénico a $945^{\circ} \mathrm{C}$ pode ser atriluído à ilita (Figura Gd), hosocendo espem cial destaque o pico endotérmico a $150^{\circ} \mathrm{C}$, glo, juntamente com os ocorrentes a 745 e $850^{\circ} \mathrm{C}$, deven ser atribuidos à montmorilonita.

En ovira Jânina dessa nesha anoctia (Firura $5 n$, o, p), a nonivorilonita mostra seus picos 12,4 o 6,2 (argila oriontrada natural), que, após tratamento com olicorol sofre expansão $\left(17-9\right.$ e 6) e contração para 9,8, a $400^{\circ} \mathrm{C}$.

Na Finusa 7a é a resentado o dinseto rama pó de socha, coletada a 75-100 ch da superficie do perfil, a revelar a montiorilonita cono maticanente o único ninoral de arvila (secundário); os picos a 3,60 e 2,71 são provavelneniceda hometita. Obuiamente, pela natuieze do metoxiol, os pincipais picos são referenties ao quartzo (4,30-3,69-3,33-2,46-2,28 $-2,13)$; os feldsiatos nostram os vicos $6,42-4,30-3,73-3,24-2,91$ e os piroxenjos: $4,73-4,50-2,09-2,1-2,51-2,28$.

Na anostra do horizonte $A_{\text {? }}$ ainda esse mineral é quase que exclusivo, nostrando, ontrotanto, pogteno pico de

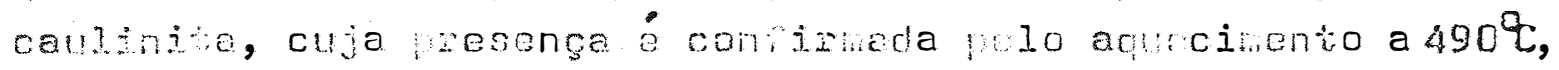
pola sue costrujõo (Fimura $5 j, 1, m$ ).

e) Perfin RUV/L

Na anostre porunda, colotoda con o vado 
55.

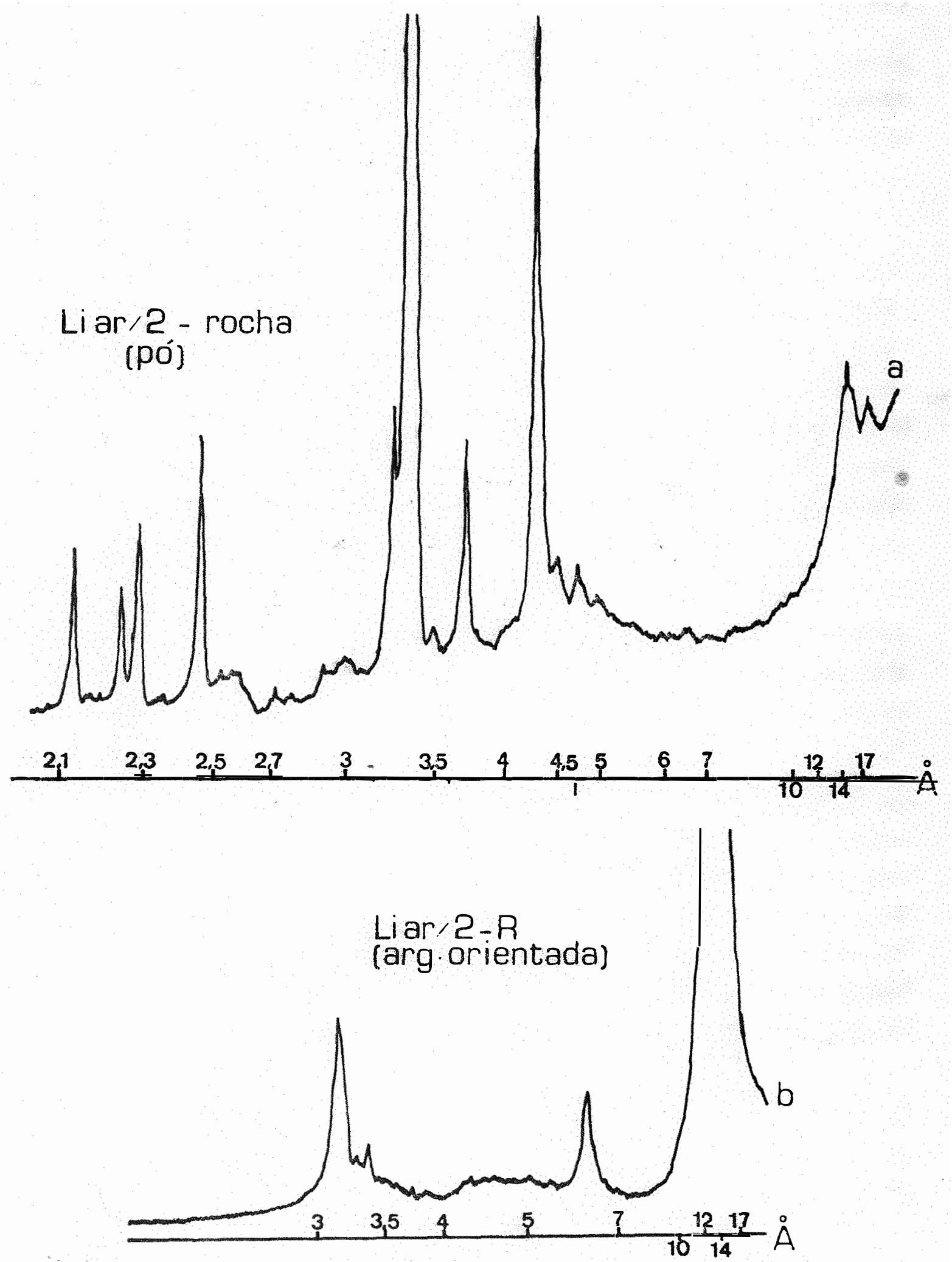

FIG. 7 - Difratogramas da rocha integral e da argila dela extraida (Perfil li ar/2). 
diagroma do pó (Fi gura Ba) indica o amplo predomínio da caulí nita, con o mesmo sistena de picos referitos pora as amostras do perfil PVA, aparecendo um tanto nelhor individualizada a cibbsita, apesar da pequena quantidade (pico 4,06 típico desse mineral e 4,37, juntaiente com a caulinita).

For volia de 14,2 há taribém elevação do "back-ground", na forma de banda, cuja interpretação é facilitada pelo exane do difiratograma da Firura $8 b$, obtido en outra fai.. xa de sensibilidade do aparetho, a indicar a presença de un pico a $10,08 R$, en cuja região BRINDLEY (1951) coloca apenas os montrorilonóides, e outro a 14,2, atribuido à verniculita e/ou ningrais interestratificados, uma vez que a $490^{\circ} \mathrm{C}$ aparece uma banda na região entre 10 e 14 品 (Firura $8 c$ ).

A outra amostra onalisada ( $\mathbb{A}_{1}$ ) apresenta praticamente os nesnoe aspectos observados, con a redução do pico 13,03 pera una banda na região de 14 h sob aquecinento a $490^{\circ} \mathrm{C}$ (Ficura 8d, e, g), a mascarar o da vermiculita $(14,2)$, antes evidenciado; entretanto, aquecinento menos forte $\left(400^{\circ} \mathrm{C}\right)$ demonsira a ocorrência de pico a 12,5, atribuído provavelmente à redução da verniculita e/ou honthorilonita (Figura of).

Os ternorranas revelan a ínína ocorrência de gibbsita (Firura $6 e, f$ ), polo pico a $36 l^{\circ} \mathrm{C}$, sensivelmente pre judicado pela natéria or cânjica, na amostra $B_{1}$ na anostra de trado o inncral. preticamente desaparece. Lireira insinuacão a cerca de $740^{\circ} \mathrm{C}$ deve ser atribuida à pequena quamidade de mon morilonita, anteriornente diernosticada polo raio $X$. Fato que chana heis etenção é o pico endotérnico de á:ua higroscópjica, que na anostra $B_{3}$ é pouco pronunciado, a $90^{\circ} \mathrm{C}$, e na oltira anostra vai a $180^{\circ} \mathrm{C}$, com intensidade bei. haior, pocsiveluente en função da maios quantidade de montmorilonita.

$$
\text { f) Restid RLV/2. }
$$

De una haneira reral, há bastanto sinjlaridade 
57.
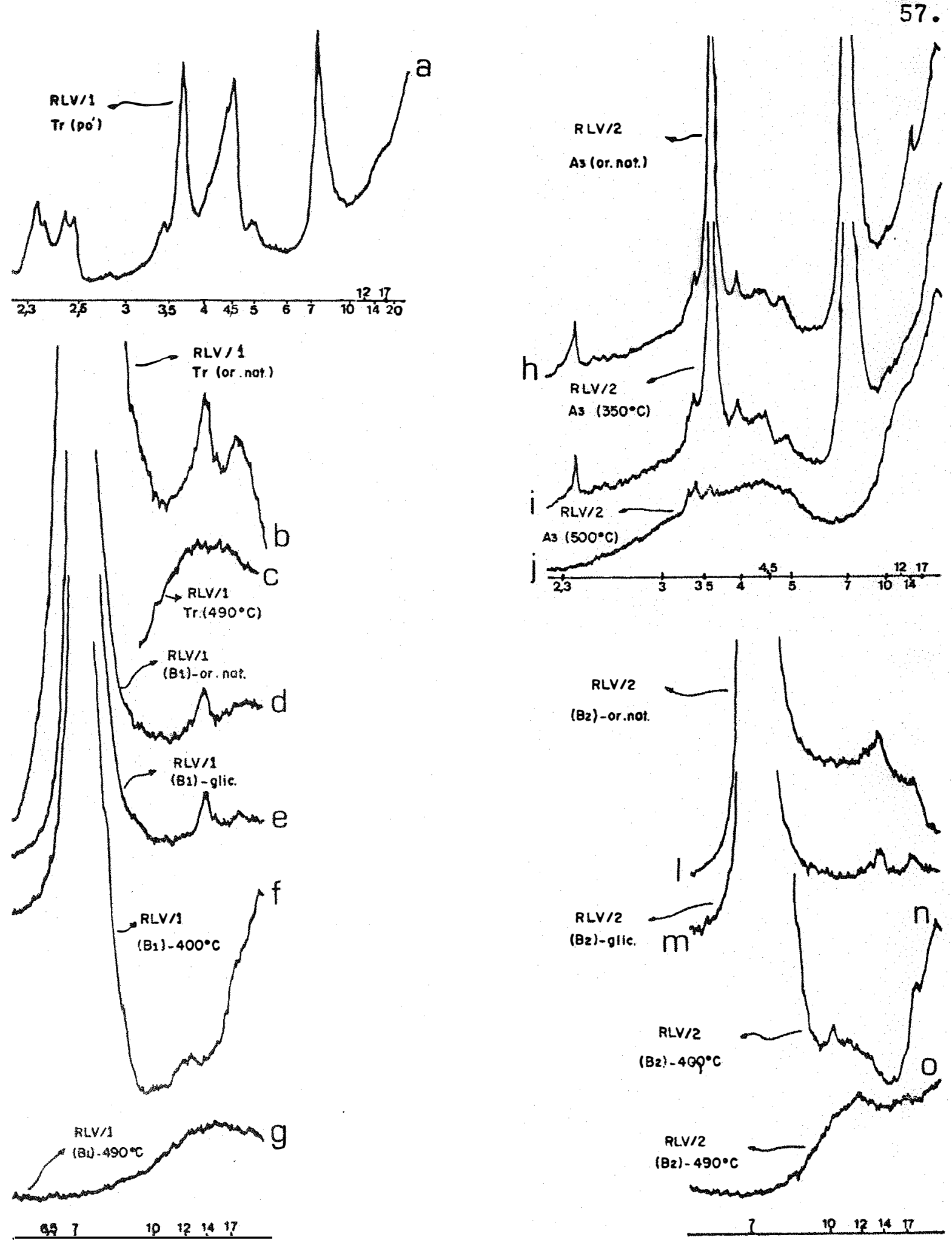

FIG. 8 - Difratogramas de amostras da area 3 (Pirambóia) (yalores das escalas em angstrons). 
com relação a peril anterior, no tocanto à minuralogia da fração ar ila, cono atesta a Figura sh. Aparece pico poguno

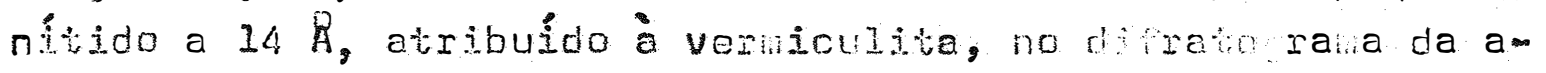
mostra A3 (argila orientada natural), cujos aqucoinontas a 350 a $550^{\circ} \mathrm{C}$ neda mostran do espocial, con rulacẽo a esse mine raI ( $F i$ lia Bi, j).

Na anostra E2 (Figura $81, m$ ) podemese caracteri zor helibor a vernioultia, que de 14,2 passa a $10 \AA$, sot aquecinento a $400^{\circ} \mathrm{C}$ (Figura $5 n$ ); o seu tarmorama (Fi ura $\sigma_{\mathrm{S}}$ ) é muito senelhante ao da amostra RLV/J - Tr, e mostra ainda pico pequeno encotónico a $910^{\circ} \mathrm{C}$, atribuido à nontiorilonita.

\section{g) $\operatorname{ter} i 1$ DUIs}

Nas amostras A1 a B22 (Firura 9a, b) o difratom rama do pó aprosenta a caulinitua con seus picos até certo pon to seme Ihentes aos difratogramas dessa natureza anteriormente aprescntados. Entretanto, o sistena de picos 2,38-2,34 e 2,29 praticanonte se reduz ao 2,34, cuja interpretação pode estar na sua baixa cristalinidado, bon como na presenca da metahaloisita, ou anbos os aspectos. A gibbsita aprosento pico pequeno, assin como a ilitra, e por volta de 34 o ocoris una ban da.

Nas amostias orientacias do horizonive B22 (Figura 9d, o, $\hat{\text { ) }}$ mais una voz se comprova a ampla doninância de minereis da fanjisa da caulintia, a pecendo ainda pico a 28,96 pequono, porón nítido, referente à montroxitontio,e ain da a 14,2, mal conformado e liequeno: no difratorrama a $490^{\circ} \mathrm{C}$ aparece apenas una banda nessa renjão (Firura 9f).

A ATD das amostras $A I$ e B22 dononstra, em espem cial, os Érimos valores de gibbsita, e a $800-350$ e $940-980^{\circ} \mathrm{C}$ pequenos vicos de ilitia e montmorilonita (Firura $6 h, i$ ).

A amostra profunda revela bastante diforençacom 

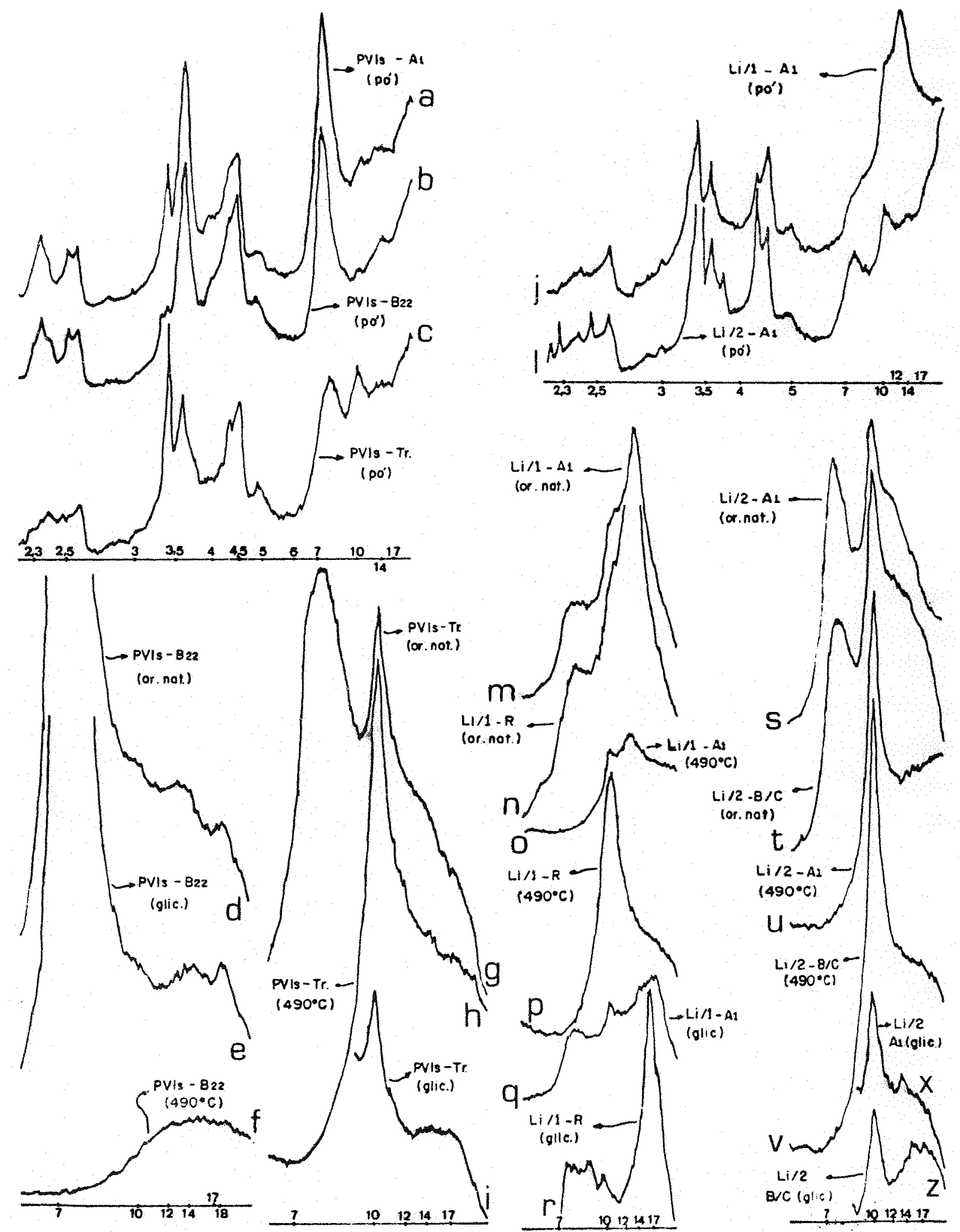

FIG. 9 - Difratogramas de amostras da área C (Anhemísi) (valores das escaias em angstrons). 
as anteriores, polo intenso pico 10 h, caracteristico da ilita (Ficura 9c), o na região da caulinita o pico aparece em po sição hois deslocada, por volta de 7,6, não ocorrendo o siste ma de $3 p$ os a 2,38-2,34-2,29, wis apenas line bonda nessa re gião, caractierísticas essas tipicas da metrahaloisita. A 3,34 ocorre pico hets intenso que a $10 \AA$, quo pode ser devido a ocorrência simlthâna de ilì a a quartzo, e há ainda ligeira banda a 14 . Na anostra orjentiada (Figura $9 g, h, i$ ) a metaha loisita aparece melhor, a a $490^{\circ} \mathrm{C}$ ela dosaparece, rstando un único pico a $10 \AA$, muito intenco, a sugerir a lresença de binerais que sorxem contraça sol ofotios bémicos (montnorilonita e/ou verniculita), cono tambén interestratificados $14 \mathrm{R}$, pela banda que permence nessa recião.

0 tormograma dossa ariostra (Firura $6 j$ ) demonstra os infinos valores de gibbsita e temperatura mais baixa de destruição dos wincrais da família da caulinita, novanente a surerir a mitaloistiva cono importente componento (SIEFFER fiANN, 1973), podundo ela coixistis con a coulinita. Fico a $630^{\circ} \mathrm{C}$ pode ser dritúlo ao ruartzo, a 750 e a $920^{\circ} \mathrm{C}$ à montmo rilonita a ilitia; cossalbo-so ainda gre o pico a $570^{\circ} \mathrm{C}$ pode

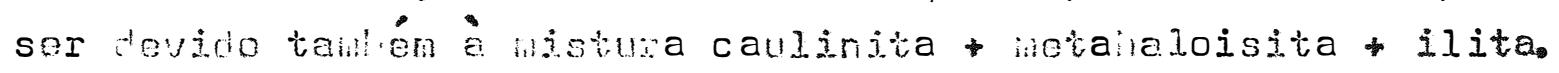

\section{h) Perfis $L I / 1$}

O hinoxal hets impotanto, ela sua ocorrência, é a nonthoritonitia, colio se evilencia atri vés da fi ura $9 j$, il, $n$, com sou pjoco en torno de 12,5 , ch sento quase a hascarar a ilita ( 10 月). No difrato rane do pó, a 7,34 ocorre une banda, atribuida espocialmonto à metahaloisita (ou à sue ristusa com a. caulinita), que na ar ila oxientada aparece en torno de 7,7 R. 1 ico intenso a 3,35 é atríbuído ao quartzo, juntanento com a ilitia (3a. ordan).

Nos difrato ranas da Fi ura $97, r$, ohserva-se 0 ereito do nicerol na uxpansão da hontriarilonita, e a 7,55 o 
pico da rauilia da coulinita epresenta-se nítido, porón mal conformado, desaparecendo a $490^{\circ} \mathrm{C}$ (Finura 90,0 ); a essa tempe ratura aperece vico a 12,5, a suceris a resenco de interestratificados (possivelnente montiorilonita-vejtollita), e a $10 R$ (ilita).

0 termo: rame (Finura 6 l) revela a menor expres são dos ninerois da farỉlí de couliniva, con releção aos pes fis, mais des nuvolvilos, cono ande picos fracos a 315,710 e $930^{\circ} \mathrm{C}$, da gibbsita, honthorizonita e montmorilonita.

\section{i) $\operatorname{teg} i \operatorname{Li} L / 2$}

Os difrato ranas de pó ser orientacão preferon cial da amostra $A_{1}$ (Figura 91) e dela nesio ortentada, como tambén da $B / C$ (Fifura os,t) revelam a ilita como imporianie ni neral (pico $10 \mathrm{R}$ ), acomanhada pelo quartzo, que no diagrama de pó pode ser caracterizado los seus diversos picos: 4,23$-3,34-2,45-2,28.2,23-2,12$, senco que aquele a 3,34 coincide con o de 3a. orden da ilita. Outro mineral inportante é da fanilia da couninita, as provavelmente a hetohaloisita, pe10 espacanonto 7,66. Aléli desses, ocorie pico nerueno e nitido de minerais $14 \%$, boh cono outras roflexóes anteriormente não ancontradas, que poden ser atrituádas à fresença de minerais priḱxios, provavelnente aos piroxônios $(2,57)$ e aos feldspatos $(2,97)$, a reveler a comploxidade da irarão argilo desse solo.

Folos difratoramas das firuras $9 x, z \dot{e}$ posoível diagnosticar as presonças de montmorilonita o vermiculita em ambas as anosiras, principalmente na forma de interestrati ficados.

A análise témica difesenciel revela na anostre Al (Firura $6 \mathrm{~m}$ ) a inportante quantidade de áfue de hidratacão das artirs, mejs popiawonte atrinuida à hontworilonita, aj caracterizada olo poquono pica a $780^{\circ} \mathrm{C}$, secuido pela reaço 
a $920^{\circ} \mathrm{C}$ da ilita. Fico a $415^{\circ} \mathrm{C}$ precedendo a caulinita é referido ao quartzo (SIEFFERhane, 2073). Na anostra $D / C$ a constam tação especial é a prosença tamén de gibbsita $\left(325^{\circ} \mathrm{C}\right.$ ), que a sensibilidade da difraço de raios $X$ nõo pernite dianosticar, pela poquena quanticado dessa mineral (Ficura $6 n$ ).

\subsubsection{Microscopia eletrônica}

As 4 mícrografies eletrônicas selecionadas sẽo apresentadas nas Fifuras 10, 11, 12 e 13. Na Ficura 10 eviden cia-se tificanente a montronilonita, quace que exclusiva, na - ila exirajida da rocha pouco alterada do perfil Liar/2 ( área A - Juquiratiba)" raras placas de coulinitia poeudo-hoxaro nal. aperocen associadas, de tamenho bastante roduzido.

Na Firura 11 do perfil PVAxLiar (amostra B/C), de mosha ároa, porén hais dosonvolvido, jé se percebe claramente maior ocorrência de caulinita, em placas de camanhos va riados, associacla à nontinorilonita, e tanbóm a outros ninercis de romes alon adas, provavelnonte haloisiticos.

Na Firura 12, referente à anostra Bl do perfil RLV/l (área 0 - Pirambóia) a caulinía é, por excolóncia, o mineral bificamente caracterizado, redoninendo as placas de tamanho muito reduzido; quanio estas apresentam tamanhos mais elevados, as formas poljédricas se tornom na is evidentos, cono tantón vesificado por CERBI e ALOISI (1975).

Na Figura 13, rolativa à argila extraída da rom cha do perfil Lj/l (área C - Anhembi), apenas a montrorilonita podo sex identificada, pelo seu aspecto nebuloso, un dos característicos desse mineral.

5.2.3. Confronto entre os resultados mineraló jicos

Com base ns incerpretacões mineralócicas afe- 
63.

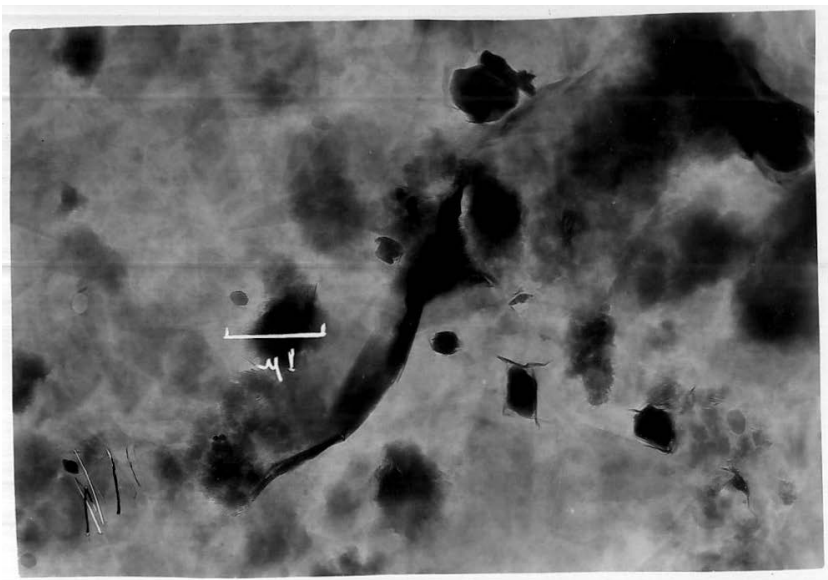

FIG. 10 - Micrografia eletrónica da argila extraída da rocha do perfil Liar/2 (10.000 x).

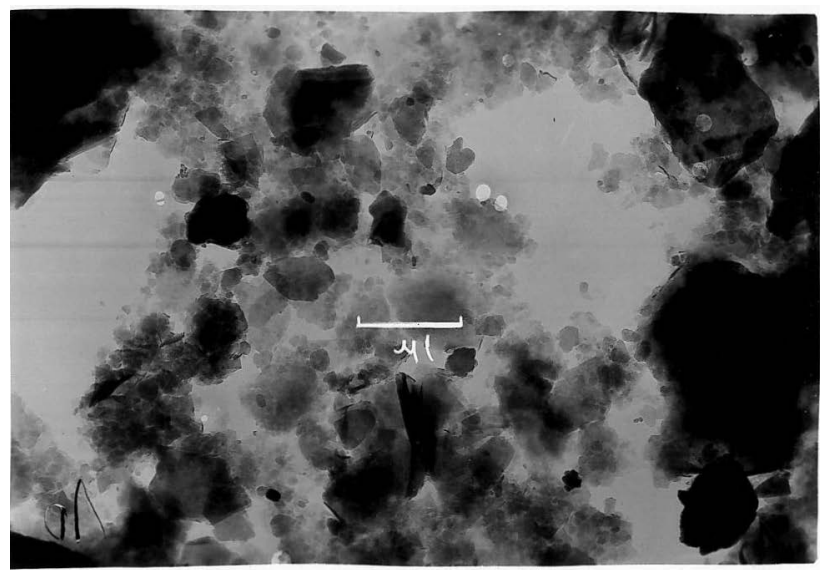

FIG. II - Nilicrografia eletrônica da argila da amostra PVA $\times$ Liar - B/C (10.000 x) 


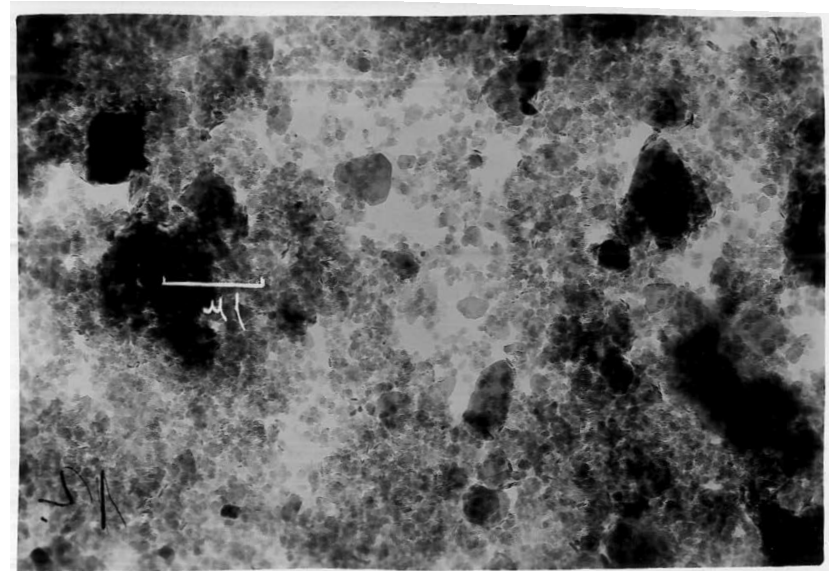

FIG. 12 - Micrografia eletrônica da argila da amostra $R L V / 1$ - $B_{1}(10.000 x)$.

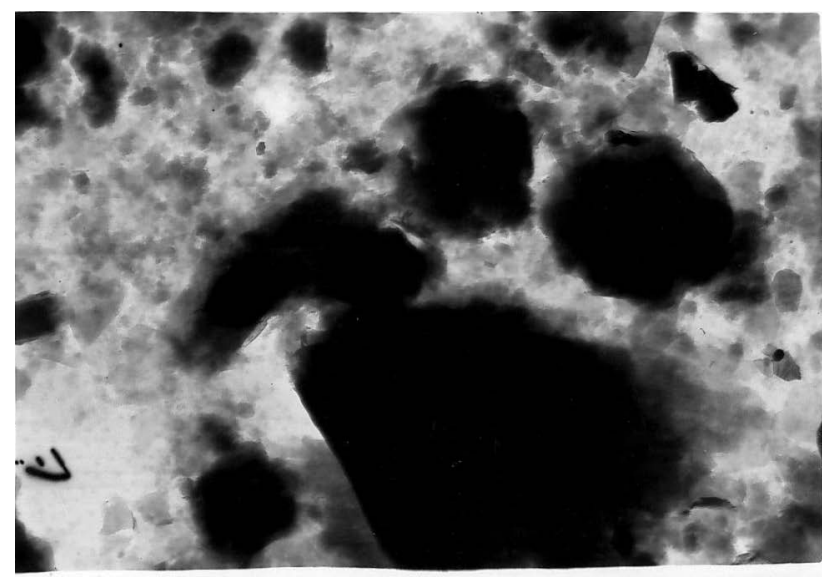

FIG. 13 - Micrografia eletrônica da argila extraída da rocha do perfil Li/l (10.000 x). 
tuadas, são apresentadas, a seruir, considevoröes a raspelto do rau de ovolução âintalos pulos direrentes perpis, nas distinias éroas consideradas, tundo-se verificado nuito clara mente que, a exentlo de DELVIGHE (2065), nere vine wosha preci pitacã livionótrica, a dreneneh incerna pedo vaxicr com a posicõo na ajsaren, êtento a velonidade do alteração o a natureza dos produtos formados.

A ampla ocorrencia de inontiorilonita em solos brasilojros, aqui verificada winciplucnte nos perfis de Litossolos das áreas A e C, bon cono no perril de uransição f $\times$ Liar, ton sido rejatada cono decorrente do condiços ospe-

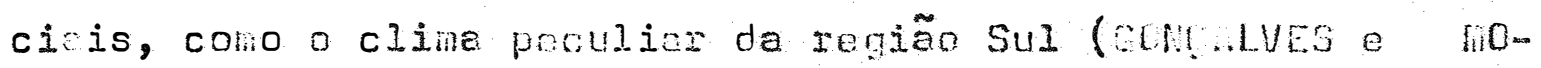
NIZ, 1975), ou do pedo-clime do pantonal matomroesense (fionIz ei alii, 1975b); na rahia, on runcão de solus jovens e/ou pa. leoclines (COREICño ot alii, 1974; RIBEIRO, 1974); na refião de firacicaba, por efotito de herença da rochamão associada a mudancas climáticos (DESATTÊ et alii, 1972).

No caso particular dos Ljtossolos e do FVAxLiar, presentumento analicados, é lezítuanonte justiricável o predomínio daquale mineral, deda às condiços de drenagen defici tária ocorrentes, com pequene lixivieção de asos, como foi visto anterionnto e, certanento, weruna rougão de silica, a manter elevada rolacão Si.⿲I (KELLER, IC64), a caracterizar, portento, un noio coninanio (eocouter ot alii, 1970).

Entretanto, a composiça do hateriai de origem é outro favor bastianło importante ne individuelização dos mi. nerais (fiELFI e LEVI, 1971; CERRI e ALOISI, 1975), podendomse aqui confirliar a verificacẽo de DEhimTE et alii (1972), que o natericl por cles denoninato arenito Botucatu fácies fluvial e lacustro, con cinoniseâa calcéria, da revião de firacicaba, contén elevados teores de montmorilonitia.

Porém, a natureza desse inineral é transitória (FAOUET, 1970), pola sua tendência à alteração em caulinita,e, 
como afirnam HANTJERS e BLEEKER (1970), mesmo sob má drenam cen, en solos pouco espessos sobre calcério, meio rico en sílica e bases, alouna nontroritonita é transforneda en argila caulinítica. Isso pode ser claramente evidenciado no perfil FVA $\times$ Liar, auer pelos difratogramas o termanes (Figuras $5 \mathrm{~h}$ e 6b), como pela micrograria eletrônica (Ficura 11).

Em perifis has espessos, como o PVA de Juquiratiba, a caulinita assume predonínio absoluto, a a hontmorilonita apenes aparece de maneira pouco oronunciada (Ficura $5 a$, b), en certa analo ia com a constatarão de conculues e monIz (1975), que, hesmo naquelas condicões de clina do Rio Grande do Sul, propício à individualizaça da montiorilonita, nas zo nas geomorfológicas mais propicias à lixiviacão a caulinita é fomeda, en dotrimonio daquele outro mineral.

Evidentenenta, sob condicães extrenas de drenagen excessiva, cono ocorre nos perfis RLV de firenbóia, é de se esporar a ocorrência de minerais estáveis cono a caulinita, ao lado de óxidos e hidróxidos, considerados como produtos fi nais do intemperisno lateritico (VILLIERS, 1965), ou da alteracão ferralílica (DELUTGNE, 1965), ou do intempentsino latossólico (Colisssio DE SOLCS, 2062), expressão que se presta à desinnação do hesmo processo, ou conjunto do complexos, que g corre sol condições de intenperismo elevado, caracteríctico de reviões tropicais.

Assim é, que om tajo perîs us resultedos maneraló jcos controvan o amplo preculúnio da caulinita, ovidencia do especialmente na microurarie da Ficura 12. A elevada ocorSoncia de montmorilonita no perit de Rerossolo "interyrade" para fodzólico Vernelho Amarelo, dessaburado en hases, profun do a con ótimas condicões de drenagem (DEmATTE et alii, 1972) é, do certa rorma, inexplicével, à luz das impormacõos coloca das pelos autores: herdada do material de criven en outras épocas favoráveis à cônese desse mineral (clina senimárido,com 
a presença de $\mathrm{Ca}, \mathrm{Mg}, \mathrm{Na}$, ou ainda clima mais úmido e fraca drenagem). Até certo ponto as verificações de CONCEIÇRo et al1i (1974) poderiam corroborar aquelas constatações, pela se melhante explicação oferecida à existência de monínorilonita, sendo a caulinita atribuída à pedogennse em condições atuais; porém esses solos da Bahia são caracteristicamento jovens e pouco espessos, diferindo sobremaneira daquele antexiormente mencionado.

Apesar da natureza calcária do arenito Pirambóia (COMISSR̃o DE SOLOS, 1960), as condiçōes do meio não são suricientes à sintese da atapulgita, encontrada no arenito Bay ru, também de cimento calcário, por PAIVA NETO e NASCIMENTO (1957) e por LEPSCH et alii (1977). Também a mica, importante mineral do erenito Bauru, que se altera para caulinita (MONIZ e CARVALHO, 1973; (ARVALHO, 1976), não assume especial importância no material do Pirambóia, ora em estudo, que se moetra também do natureza mineralógica diferente do arenito Botucatu e seus produtos de alteração "in situ", analisados por DIAS FERREIRA e QUEIROZ NETO (1974), no tocante à importância da mica, acompanhada pela vermiculita, de modo análogo ao relata do por ALOISI et alii (1975), em um Litossolo derivado de are nito na região de Jaboticabal (SP); nos perfis R/LVa, bastan te alterados, dispostos nas superfícies Neogênica e Rio Claro, DIAS FERREIRA e QUEIROZ NETO (1974) verificaram que, assim como nos RLV de Pirambóia, a caulinita é mineral quase que exclusivo, acompanhada de pequenas quantidades de gibbsita, mica e vermiculita, havendo uma certa concordância entre os resultados.

Embora as condições gerais para maior expressividade da gibbsita sejam aparentemente ótimes na área $B$ ( ranícia), a exemplo do que ocorre em solo correlato da região de Rio Claro (ANDRADE, 1971), a explicação para a sua pequena expressão pode ser a mesma invocada por LEPSCH (1975), a respeito da atividade dos íons na solução do solo, num estado de 
elevada atividade do ácido silícico, dentro do campo de estabilidade da caulinita, garaniida pela dissolução do quartzo, mineral abundante nos materiais dessa área, e que ocorre também na fração argila dos perfis anteriormente analisados, ain da que geralmente em teores reduzidos. Explicação de semelhan te natureza é apresentada por GOEDERT et alii (1975), ao rela tar as relaç̃es caulinita - quartzo - gibbsita, em consonência com a verificação de FAUCK (1972), que a riqueza om quart zo nas rochas $̇$ un importante caráter: ciugndo os seus teores descem abaixo do um certo limilie, a gibbitização aparece brus camente.

A respeito da origen da gibbsita via caulinita- pela dessilicificação, a literatura é farta (JACKSON e SHER MAN, 1953; MONIZ e JACKSON, 1967; CARVALHO, 1970), a despeito de sua estabilidade, e, logo, resistência (mIGNIEN, 1956). En tretanto, ela pode irovir tambén diretamentie da alteração de minerais primários, sendo um dos rimeiros a se individualizas na fração argila (KELLER, 1964; RIELFI e LEVI, 1971); cono pare ce ocorrer mais claramente na camada $B / C$ do perfil $L i / 2$ da á. rea de Anhembi, apesar das quantidades diminutas, juntamente com minerais primários e/ou alteráveis. O que parece definiti vo é que a sua permanência no perril, seja pela altaração da caulinita, ou nos primeiros estágios de alteracão dos minerais primários, é altamente dependente de boas condições de drenagem (MOHR e VAN BAREN, 1954; SEGALEN, 1974; CERRI e RLUI SI, 1975 ).

Com relação à vermiculita, apesar de sua pequena expressão, revelada pelós difratogramas, ela ocorre quase seilpre, sendo facilmente observada nos perfis mais evoluidos da área B (Pirambóia), por vezes com características de minerais interestratificados. Frequentemente ela tem sido relatada como um produto intermediário da transformação de mica em caulinita (RICH, 1960; fiDNI\% e JACKSON, 1967; RUELLAN, 1971). Poseivelmente a sua estrutura deve apresentar alumínio nas in 
tercamadas, confe:indo-lhe maior resistência face ao intemperismo, como relatado por MATSUI (1969). Essas evidências pare cem corroborar a menção de VILLIERS (1965), relatando a relativa estabilidade de certos minerais vermiculíticos como produtos do intemperismo laterítico, que parecen ser mais resistentes do que o sistema caulin-haloisita.

No tocante à sua ocorrência mais típica em materiais bem drenados (mILLOT, 1964), também esse aspecto pode ser aqui verificado; nos loceis onde a ilita assume maior expressão (área C - Anhembi), pode-se, até certo ponto, estabelecer um paralelo com as constatações de LAMOuroux (1972), com relação à sue alteração em montmorilonita, sob condições de confinamento do meio, e em vermiculita, sob boas condições de drenagem. comportamento da ilita e da vermiculita parece ser de natureza oposta face às condições de drẹaçem (JWHNSON e JEFFRIES, 1957; ESPINDOLA e GALHEGO, 1975).

A ocorrencia mais expressiva de ilita nos solos da área C, principalmente na argila extraída da rocha, eviden cia a diferente natureza mineralógica de ambos os substratos sedimentares presentes nas áreas (arenito Piranbóia e siltitos da Formação Estrada Nova), sendo ela amplamente relatada como importante componente das rochas sedimentares (RIVIËRE, 1952; MILLOT, 1952; LUCAS, 1962). Outra diferença é a ocorrên cia mais intensa de quartzo na referida área, apesar da comis SÃO DE SOLOS (196) considerámlo como o principal mineral no outro tipo de material.

Com relação à metahaloisita, ela aqui ocorre especialmente nos solos cujo embasamento rochoso é da Formação Estrada Nova, sob fraca lixiviação, em condição semelhante à verificada por MELFI e LEVI (1971), a partir da alteração dé faldspatos. CERRI e ALOISI (1975) comentam que há necessidade de soluções com relativa concentração de sillica, condições es sas ocorrentes nos primeiros estágios de alteração, como $\dot{e}$ também o caso da amostra profunda do perîl pVls de Anhembi, 
de natureza nitidamente diferente das camadas superiores, nas quais a metahaloisita praticamente desaparece, a indicar a sua transformação em caulinita.

É de se supor, assim, também um caréter transitó rio para os minerais haloisíticos, nais típicos de materiais pouco desenvoluidos, como os solos jovens derivados de basaltos, estudados por SIEFFERMANN e fiILLOT (1968), ou de superf́l cies recentes (SEGALEN, 1974). Nos solos altamente intemperizodos, a literatura raramente relata a sua presença como importante componente da fração argila, e perfis dessa natureza não mostram uma nítide sequência de intemperismo dos hori zontes inferiores aos superiores, havencio predoninancia de apenas um mineral de argila (CADY, 1960), tal como ocorre tipj camente com os solos da área B (Pirambóia), com relação à cau linita (os demais minereis ocorrem en infinas quantidades).

Em resumo, a natureza das alteracões na região estão estreitamente correlacionadas à constituição do material de origem e às condições de drenagem, aretadas certamente pelo relevo (MITCHELL, 1962; DELUIGNE, 1965), conduzindo à metcorização dos minerais primários no sentido da bissialitização - sob drenagem pobre, ou no da monossialiticação (cay Iinização) - sob boas condições de lixiviação, de acördo com os processos relatados por PEDRD ( 1969 ).

Uma vez que o esiudo do desenvolvimento e expansão das redes de drenagem possibilitam elucidar e explicar as formas de relevo en seu conjunto, e que a morfologia regional pode ser considerada como consequência diretra das adaptaçoses do sistena de drenagem (CHPTSTOFULETTI a ARANA, 1976), a par dos processos de elteraçãa dos solos serão abordados tais ele mentos, no verificação de até que ponto a análise da rede de drenagem pode evidenciar diferentes composições morfomestrutu rais dọs compartimentos existentes, conforme menção de nBREU (1976). 
5.3. Análise da Iede de drenagem a da evolucão do relevo

A observação das fotograpias aéreas da região de estudo revela o desenvolvimento de amplas planícies aluvionais, principalmente ao longo do Rio do Peixe, principal afluente do Tietê nessa área. Também ao longo do Rio Salgado, no Distrito de Juquiratiba, essas planícies são expressịvas, en contato con os terrenos declivosos que af predominam.

Na área de Pirambóia os diversos tributários do Rio do Peixe apresentam também esses aspectos, como os Ribei rões Água clara e Ŕgua do Brejão, ou os Córregos Rancho das Bicas e Caracatu,e as vertentes extensas e pouco inclinadas a terhinari, como que se confundindo.

Em direção a Anhembi há tanbém trechos do Ribeirão dos Remédios com tais áreas sujeitas a inundações, porém nessa área o aspecto não é tão generalizado, revelado pelos vales menos abertos, com una possível influência do material geolócico presente, numa zona de contato dos materiais anteriormente referidos.

Um aspecto frequente na região é a formação de meandros ao longo das planicies aluviais, que pode ser tomado como indicativo do estágio de maturidade do relevo, confor me o entender de ABDALLA (1973); ouira observação feita, por esse autor, aqui também verificada, é a ocorrência de meandros abandonados e a divagação do leito pela planície, a se estabelecer por toda a extensão e a sucerir a evolução para o estágio de senilidade. Tais eventos poden ser verificados em toda a sua magnitude ao lonco dos vales do Rio Salgado, dos Ribeirões Água Clara e Água do Brejão, bem como no Córrego Rancho das Bicas.

Assim, Utilizando-se das idéias de HrCK (1972), tais áreas estarian correlacionadas ao conceito de superfície final, por ele defendido, a significar uma topografia equilibrada, ou com tendência ao equilíbrio, apresentando uma forma 
para eficiente remoção de detritos, com pedimentos ou rede de pedimentos correlativos en posição de sopé das vartentes em retração.

Também PENTEADO (1974) comenta que o meandro de un rio é um elenento indicativo do estado equilíbrio, lem brando o aspecto meandrante em deterninados trechos do Rio Tietê, focilmente observável na érea de estudo, próximo a Anhembi. Fara a autora, tais aspectos podem ser resultado de mudanças climáticas, pela alteração carga/débito dos rios, ou seja, nem sempre os meandros apresentariam relação direta com as carecterísticas hidrodinâmicas atuais, cono bem demonstram os meandxos abandonados, amplamente encontrados na região ora em estudo. Entretanto, o difícil $\dot{\varepsilon}$ antever a magnitude de tem po, ben como das condições climáticas, necessárias elou suficientes pera produzir tais feições. Se houver necessidade de um longo período, en termos geolócicos, acompanhado naturalmente de sucessivos cavamentos e deposições pelo rio, em razão das variações carga/débito, para que tais episódios se mostrem na plenitude que são aqui encontrados, tais eventos po dem ser evidentemente correlacionados às alternâncias climátị cas ocorridas durante o quatornário, em diversas reciões do globo (CHATELIN, 1967; MATSUI, 1969; HERVIEU, 1970), a particularmente na rovíncia da Depressão Periférica paulista ( $A B$ ' SAEER, 1969a; AB'SAEER, 1969b; PENTEADO, 1969; QUEIROZ NETO, 1969 ).

Guardadas as devidas proporções, a área em apreco revela condições que podem ser correlacionadas àquelas men cionadas por frotTI e MOTTI (1975), en que a morfogênesé mais ativa do que a pedogenese nas condiçoos atuais, traduzida a) pela erosão dos solos sobre as encostas niais incremes, b) com remanejamentos em outros setores dos interílúvios e c) depósi tos com reilanejamento nos vales. De fato, como ben demonstram as Figuras 14, 15 e 16 em un espaço de tempo de apenas 10 anos, aspectos da erosão acelerada, sob a forma de sulcos - de nominados "cabeceiras de erosão" por AfMRAL a AUDI, 1972 - PO 
73.

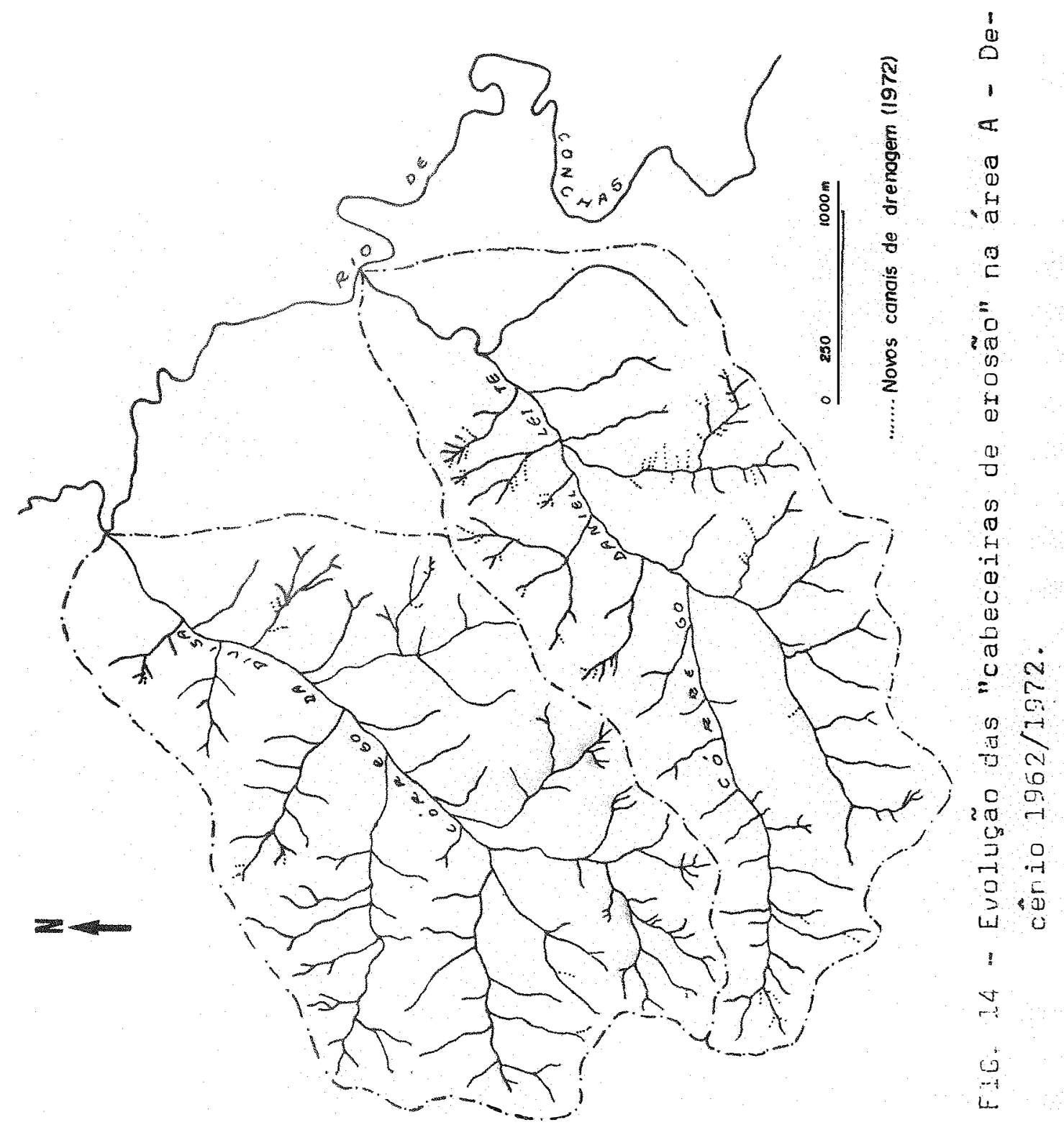




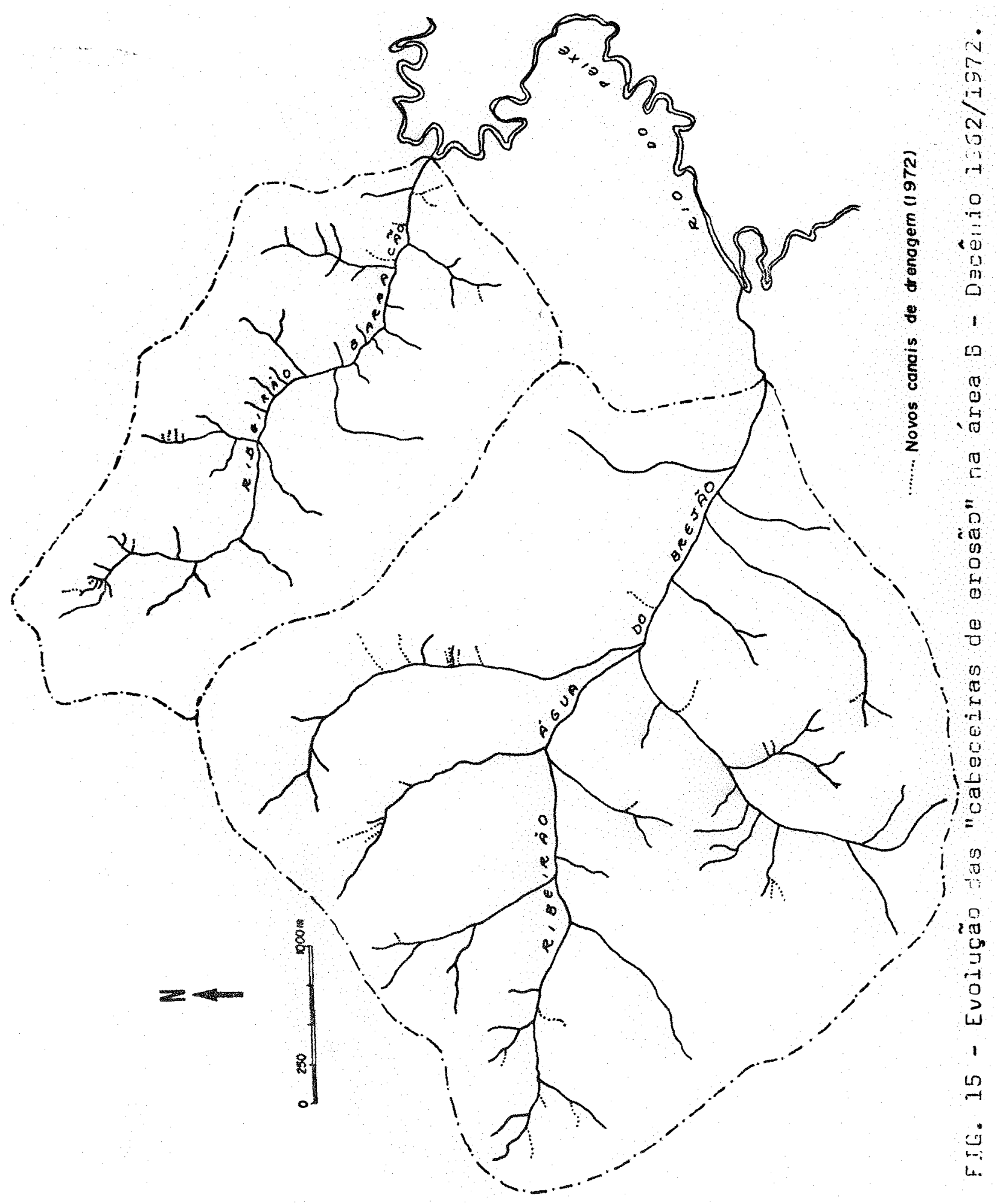




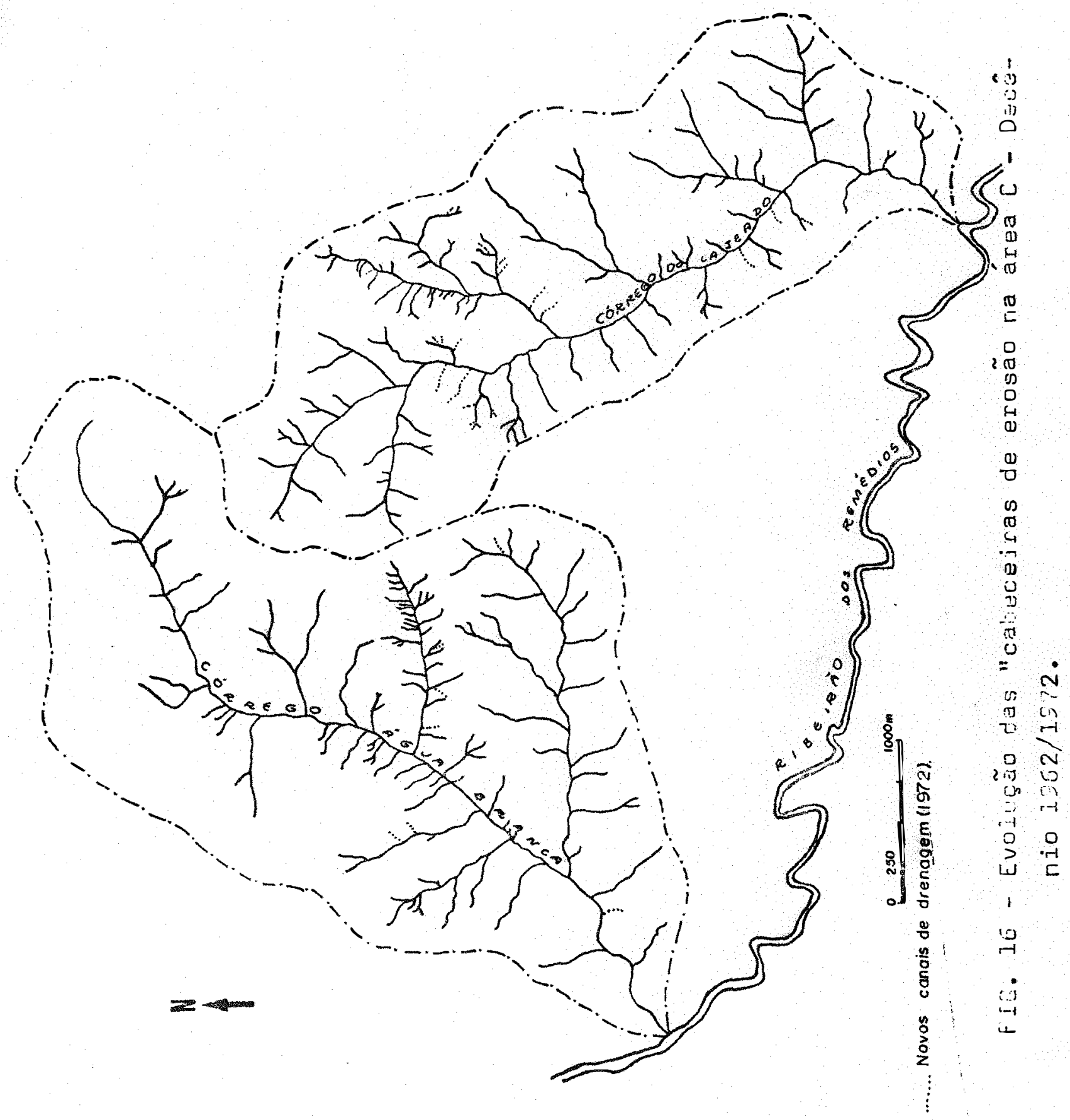


dem ser cartografados, com base nos levantamendos aerofotogra métricos de 1962 e 1972. Para QUEIROZ NETO (1975) essas cabeceiras testemunham açoes erosivas regressivas, cujas partes a vançadas, hinos atacadas pela erosão, conservan, nuithas vezes materiais alterados mais espessos, como é a ceso do PVA de Ju quiratiba. Com relação às vossorocas, a região apresenta abun dância desse tipo de erósão, cujo estudo evolutivo vell merecendo a atenção por parte dos pesquisadores (ROCHA PIEDADE et a1ii, 1976).

No tocante ao remanejamento en outros setores dos interfíúvios, mencionado por motTI e motr I (1975), ele pode ser evidenciado particularmente em determinados locais, como no perfil PVA (área A), apresentando bandas onduladas, e nos demais perfis com "stone-lines", conforme discussão efetuada anteriormente. No que tange aos depósitos de veles, referidos por açueles autores, as planícics de inundação são testemunhos, por excelência, de tais maturiais aluviais/coluviais.

O enriquecimento dessas "caixas eluviois" são,as sim, resultado desses ravinamentos ativos e forte descarnamen to nas vertentes meis vinorosas, que, para ABiSABER (1972), são nais eletivos sob condições de alternâncias climáticas, re lativas principalmento aos perłodos de transição, quando a agressividade é exagerada. Quem percorie o vale do Rio Salgado percebe cleramente a vastidão de sua planície aluvial, que tem recebido contribuições expressivas das vertentes em rejuvenescimonta, a revelar, a natureza policíclica do relevo aludida por ABDALLA (1973). Para PENTEADO (1974) essas retomadas erosivas são determinantes de un reievo policíclico, formado por elementos topográficos distintos, datados de épocas diferentes, tendo como causas principais as modificações do nivel de base e as alternâncias climáticas do quaternário.

A explicação pera tais ocorrências encontra fundamento en SUARES (1973), ao afirmar que muito piovavelmente essa retomada erosiva da atualidade possa estar relacionada a 
um movimento efirogenético posisivo, musto lonto e agindo em impulsos, como mencionam também AZOLIN et alii (1975), Ieferindo-se ao abaixamento do nível de base ou soerguimento da superfície pediplanada e agradada, que condicionou a intensificação dos processos erosivos e doposicionais mais recentes, localizando e implantando a atual rede de drenegem e a indivi dualização das presentes superíicies geomóríicas, assim como a exposiço de diferentes litologias aos processos pedogenéti cos.

O aspecto de nivelamento dos cimos dos principais interflúvios obedece, naturalmente, à tendencia geral dos pro cessos ocorricios na Depressão Periférica, tencio como causas as alternâncias secas e úmjidas ao longo do quatiernário, que PENTEAdo (1969) estabelaceu como tendo siclo nuatorze, a partir de estudos detalhados por ela efetuados na Bacia de Rio Claro. Tal feição pode ser visualizada pela observação da Figura 17, apresentando o perîl topográrico ao longo da rodovia. de acesso principal a Anhembi, a partir da Marechal Rondon.

A análise do aludido perril pernite entrevertrês pincipais colpartinentos topográricos na região: correspondente a niveis en torno de 600 metros, raramente atingindo 630 metros, é encontrada a unidada geomorfolócica que, a sudoeste da área de estuco - na zona da Serra do Limoeiro, corresponde à superficie Neogênica de mRTONNE (1943), elaborada no Terciário Superior (Neoceno), e correspondendo à superfície interplanáltica meis anitiga da Depressão feriférica, conPorne estudos promenorizados eretuados por DIAS FERREIRA e QUEIROZ NETO (1974). Como fornações superíciais tal unidade comporta medominantomente o Regossolo Intergrade Latossolo Vermelho Mmarelo - rase arenosa, sob vegetação de cerrado, re levo. sueve, e a cronoloria relativa é referida o flio-fleisto ceno. Deve haver una correspondincia entre tais hateriais e $a$ rueles referidos cmo Cenozóicos, relatados por SthRES (1975). 
78.
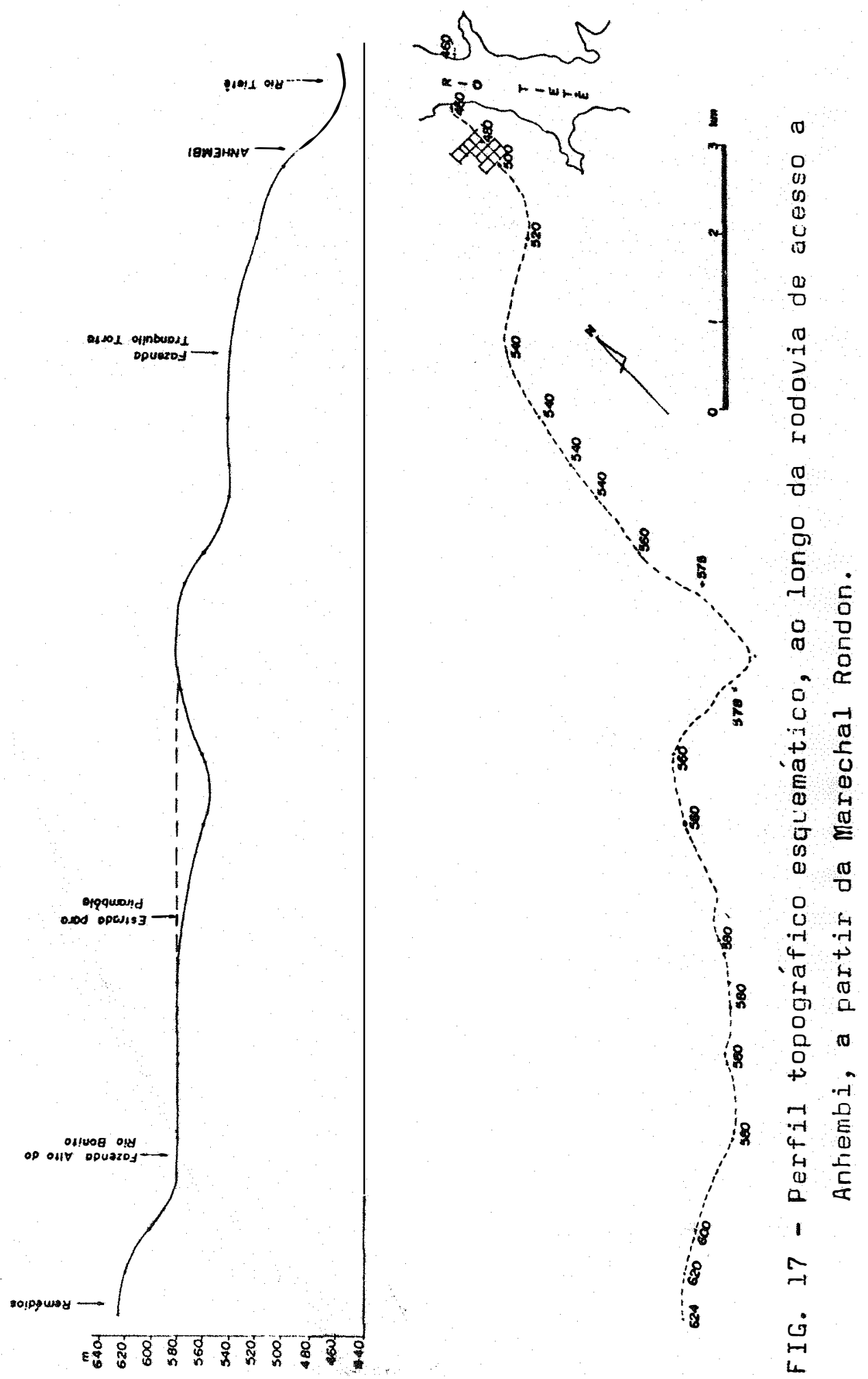
Apenas em determinados locais isolados, cotas atingindo 600 metros são encontradas (çono no Bairro Agua Clara, próximo à Pirambóia, por exemplo). Adentrando cada vez mais na área de estudo, en sequência ao corte topográfico;des taca-se o segundo compartimento, caracterizado por um relevo bastante aplainado, em que as cotas estão entre 580 e 560 metros, em una extensa faixa ao longo da estrada para Anhembi; analogamente à unidade anterior, o solo é da mesma categoria, cujos perfis foram anui designados RLV/I e RLV/2. Também a VE getação original característica é o cerrado, que ver sendo. substituído gradativamente pelo reflorestamento com eucalipto. Esta unidade topográfica identirica-se principalnente com a á rea $B$ (Pirambóia), descrita anteriormente.

Em seguida, surge o outro compartimento menciona do, mais rebaixado, onde as cotes estão usualmente abaixo de 560 metros, e mais frequentemente por volta de 540 metros,com valores diminuindo en direção ao Tietê, e em diversos locais em contato con as planícies de inundacão, que, a rigor, poderiam ser tomadas ainda como outro compartimento característico. Essa terceira unidade comporta uma grande diversidade de solos, quando comparada às antexiores, os quais poderil ser mais convenientemente caracterizados mediante a sua colocação nas áreas A (Juquiratiba) e C (Anhembi), sendo que na primeira o relevo é mais acentuado, com dominância de Litossolos - fase substrato arenito calcário, e na segunda predonina o Podzólico Vermelho Amarelo - variação Laras (CORISSÃ̃O DE SOLOS, 1960)

De forma análoga à observada por DIAS FERREIRA e QUEIROZ NETO (1974), cada parcela apresenta formações superficiais e solos caracterásticos, em diferentes estágios de al teração, e com propriedades pedogenéticas variadas, conforme discussão anteriormente efetuada. Uma vez que a rede de drena gem evidencia diferentes composições morfomestruturais dos compartimentos existentes (ABREU, 1976), assume especial inte resse a sua caracterização anelítica, com o intuito de se ve- 
rificar até que ponto diferentes unidades de solos podem estampar tanibén diversidades em suas redes de drenageii, quernos distinios compartimentos topográricos ( $A$ e $C$ versus $B$ ), como nas diferentes áreas pré-estabelecidas ( $A \times B \times C$ ), de per si.

Nas Figuras 18, 19 e 20 são apresentadas as amos tras circulares de $10 \mathrm{~km}^{2}$, em 7 repetições para cada área, que possibilitaram a obtenção dos índices densidade de drenagem (Dd) e frequência de rios ( $F I$ ), propostos por HORTON (1945)pa ra quantificar a rede de drenageri, cujos valores determinados estão expostos na TABELA 3 ; a análise estatística aplicada a esses resultados é apresentiada na TABELA 4.

Os valores encontrados são sensivelmenite diferen tes nas três áreas consideradas, nitidamente inferiores na ám rea $B$ (Pirambóia), onde ocorre a unidade de solo convencional menie aqui designada RLV. A análise estatística revela que, tanto para a Dd coino para a Fr, os tratamentos foram significativos ao nivel de $1 \%$ de probabilidade.

A comparação de médias polo teste de Tukey demonstra que, para a Dd, os tratamentos $A-B$ e $B-C$ são também estatisticamente diferentes ao nível de $1 \%$; embora $A$ e $C$ não difiram significativarnente, pela sensibilidade do teste, na quase totalidade das repetições os valores daquele índice são superiores na área A (Juquiratiba). Com relação à Fr, há dife renças significativas ao nivel de $1 \%$ entre. $A-E$ e $B-C$, ao passo que $A$ e $C$ diferem apenas ao nível de $5 \%$.

Comparondo os resultados obiidos com aqueles encontrados por FRANCSA (1968), om solos similares - originários de produtos de alteração do arenito Botucatu, há uma concordância no aspecto dos valores crescentés de Dd e Fr, na sequência: RLV - Solos com B textural - Litossolos, em consonân cia com a afirmagão de FROST (1960), que solos semelinentes ocorrem com padrões semelhantes.

$\mathrm{Na}$ comparacão entre cada unidade particularmente, 
81.
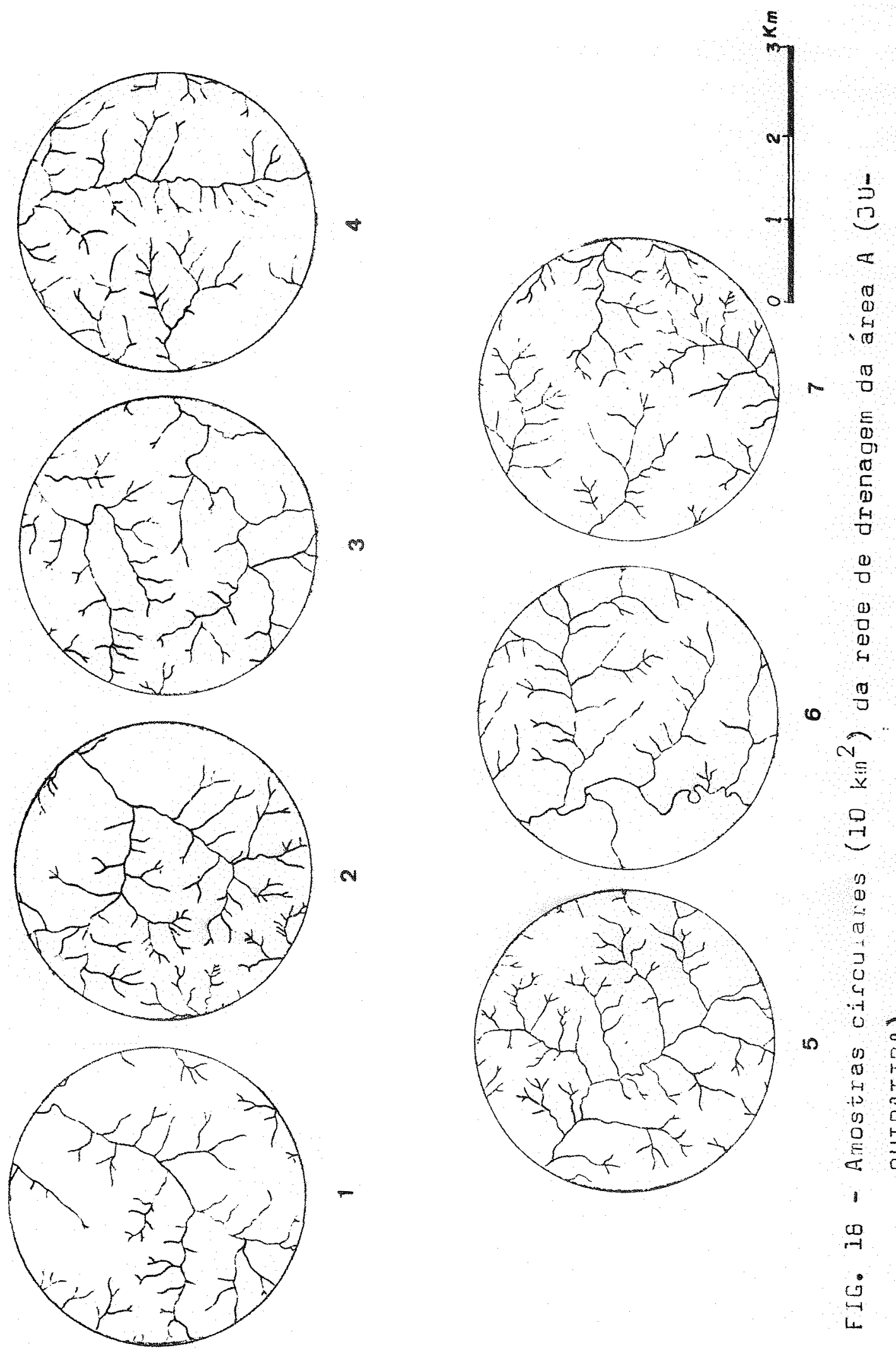

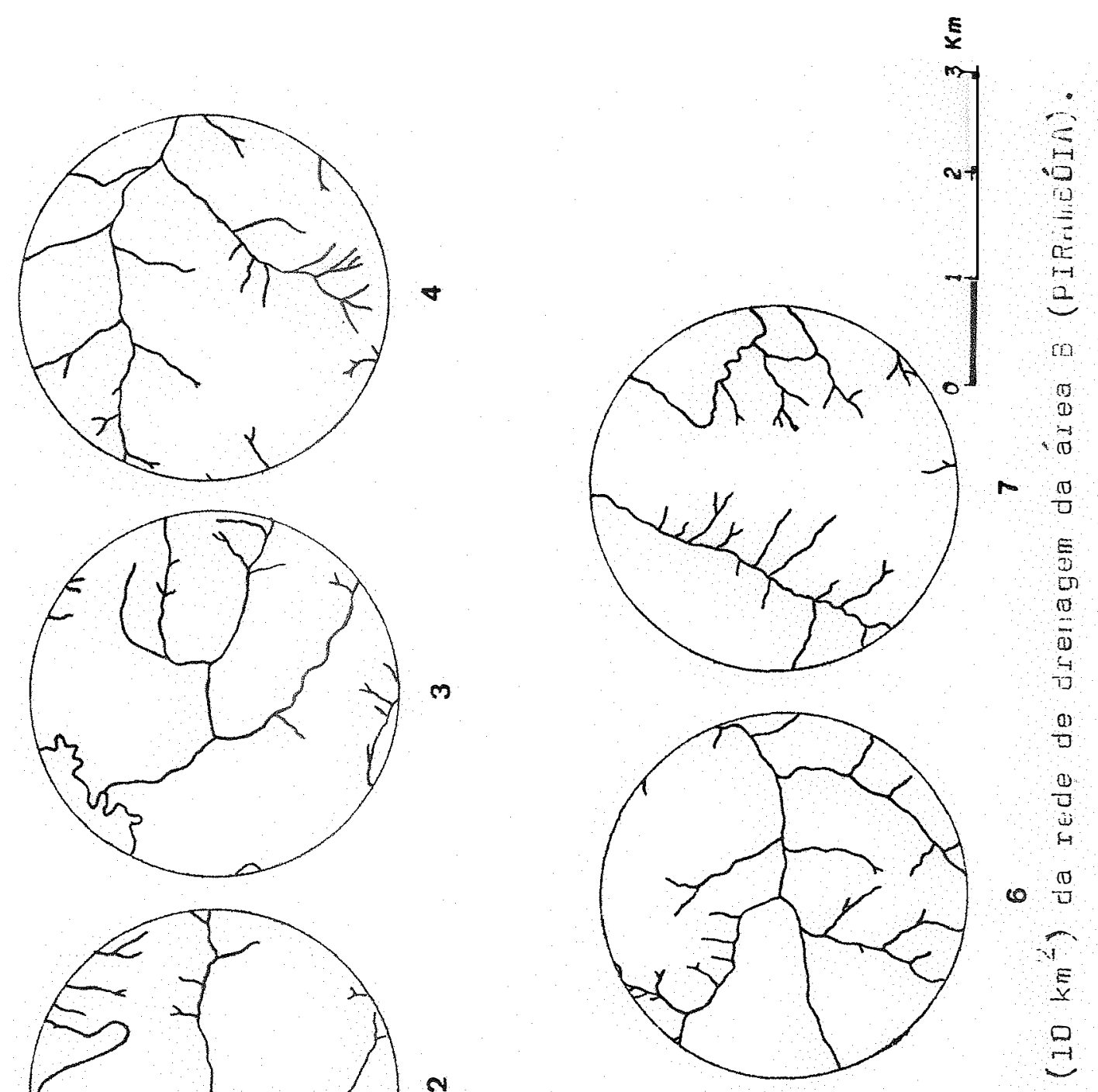

0
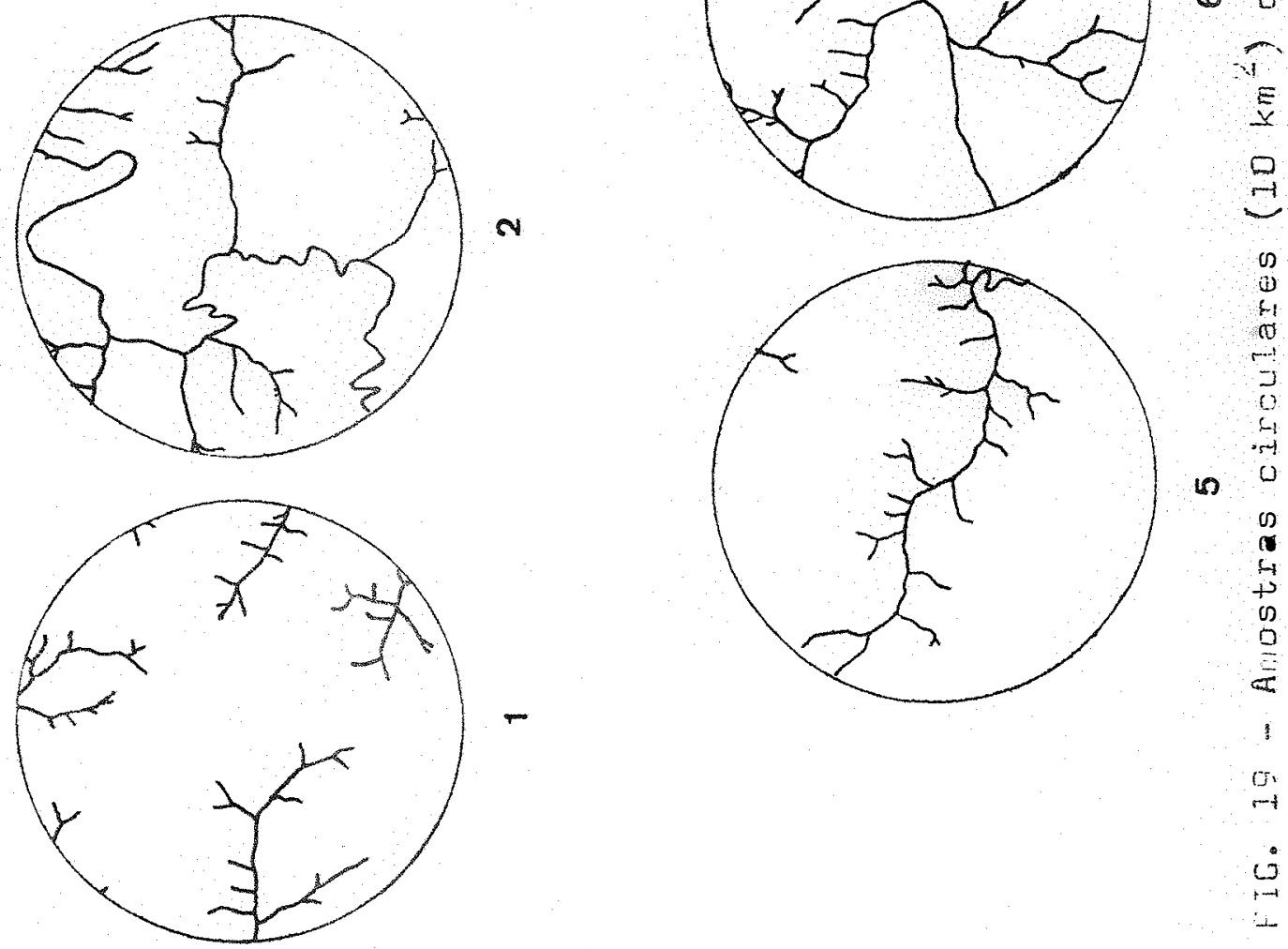

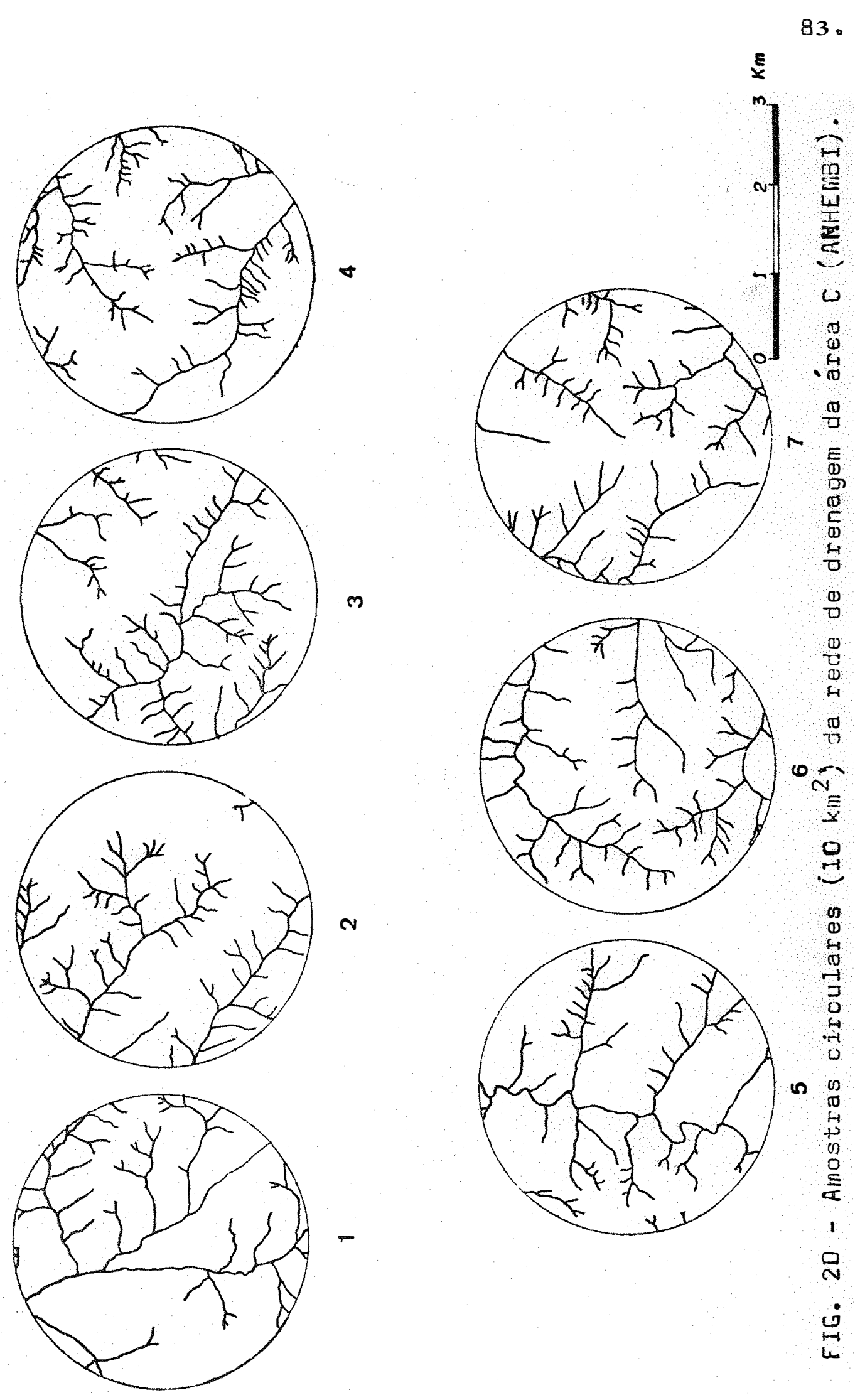
TABELA 3 . Valores de densidade de drenagem (Da) e frequência de rios ( Fr), por repetição.

\begin{tabular}{|c|c|c|c|c|c|c|}
\hline \multirow{2}{*}{$\begin{array}{l}\text { Amostras } \\
\text { Circulares }\end{array}$} & \multicolumn{2}{|c|}{$\begin{array}{c}\text { SRIA A } \\
\text { (Juguiratiba) }\end{array}$} & \multicolumn{2}{|c|}{$\begin{array}{c}\text { AREA B } \\
\text { (Firamboia) }\end{array}$} & \multicolumn{2}{|c|}{$\begin{array}{l}\text { AREA } 0 \\
\text { (Anhembi) }\end{array}$} \\
\hline & $\mathrm{Dd}$ & Fr & $\mathrm{Dd}$ & $\mathrm{Er}$ & $\mathrm{Dd}$ & Fr \\
\hline 1 & 2,75 & 9,80 & 1,40 & 5,70 & 2,75 & 6,50 \\
\hline 2 & 2,90 & 11,50 & 1,95 & 3,50 & 2,40 & 8,90 \\
\hline 3 & 2,80 & 6,50 & 1,20 & 3,90 & 2,75 & 9,40 \\
\hline 4 & 3,45 & 14,50 & 1,55 & 2,70 & 2,85 & 17,90 \\
\hline 5 & 2,55 & 10,40 & 1,65 & 4,30 & 2,35 & 7,50 \\
\hline 6 & 3.35 & 13,90 & 1,85 & 4,00 & 2,65 & 8,50 \\
\hline 7 & 3,35 & 13,90 & 1,75 & 4,40 & 2,50 & 8,60 \\
\hline MÉDIA & 3,02 & 11,50 & 1,62 & 4,10 & 2,63 & 8,76 \\
\hline
\end{tabular}

TABELA 4 . Análise de variância e teste de Tukey.

\begin{tabular}{ccc}
\hline & MEDIAS DAS REPETCCOES \\
\cline { 2 - 3 } Tratamentos & Densidade de Drenagem & Frequência de Rios \\
\hline A & 3,02 & 11,50 \\
B & 1,62 & 4,10 \\
C & 2,61 & 8,76 \\
\hline Frat. & & \\
(1\% probab.) & 46,86 & 24,79 \\
\hline D. M. S. 5\% & & 2,67 \\
(Tukey) 1\% & 0,49 & 3,47 \\
\hline
\end{tabular}


os valores aqui observados são um tanto mais elevados do que os encontrados por aquele autor; tal fato pode ser interpreta do principalmente em função da natureza do substrato rochoso, ou seja, das caracteristicas transmitidas pelos arenitos Boty catu e Pirambóia. Neste último, é frequente a presença de extratos mais argilosos a determinados niveis do depósito sedimentar, que podem provocar maior diriculdade à infiltração de água, com aumentos correlativos na relação infiltração/dếlúvio, mencionada por LUEDER (1959).

Dutro fato que corrobora tais suposições é a relativamente pequena espessura dos arenitos do Pirambóia, situados sobre os siltitos Estrada Nova, menos permeáveis (DIAS FERREIRA e QUEIROZ NETO, 1974), a conferir, por vezes, mosqueamentos em profundidade, reflexo das condições menos favoráveis de drenagem interna, tal como acontece no perfil PVA $x$ Liar. Essas constatações estão em concordância com RICCI e PE TRI (1965), on que a presença de natueriais relativamente impermeáveis (argila, folhelho) a deterninadas profundidades afeta a natureza do padrão de drenagem.

Tais aspectos relacionados à litologia podem ser também utilizados para explicar por que os indices quantitati vos das áreas $A$ (Juquiratiba) e $C$ (Anhembi) não apresentaram diferenças inais sensiveis do que as encontradas. De fato, ape sar do predomínio de Litossolos - fase substrato arenito calcário na área $A$ e de Fodzólico Vermelho Amarelo - variação La ras na área $C$, nesta ocorrem também Litossolos associados, nos cuais o horizonie A jaz em discordância litológica com mate riais do Estrada Nova, como também as camadas mais profundas dos solos com $B$ textural. Tal fato certamente acarreta menor infiltracão e, consequentemente, maior deflúvio, o que vale dizer menor resistência à erosão, e um aumento correlativo da Dd, a demonstrar que as fotugrarias aéreas revelam a drenagem efetiva do perfil (RAY, 1963).

Analisando-se os dados em função do relevo, as- 
pecto esse estreitamente relacionado com a profundidade do perfil, é realmente de se esperar que na área de solos RLV (Firambóia) o padrão seja pouco denso, dada à elevada permea. bilidade do material, com drenagem excessiva, sob um relevo suave; a despeito de sua alta suscetibilidade ¿̀ erosão, caráter esse que vem causando sérios iranstornos na construção da estrada asfaltiada de acesso a Anhembi, aqueles atributos se superimpõem a esse fator, no tocante aos indices quantitativos da rede de drenagem, constituindo-se num dos casos de exceção que o próprio RAY (1963) admite como seren diversos (com respeitio à relação entre Dd e resistência à erosão). Entretan to, são muito expressivos os aumentos de canais de la. ordem nas bacias da área $\theta$ ( $F$ igura 15 ), que na do Ribeirão Barracão $\dot{\theta}$ de 32,4\% (37 canais em 1962 e 49 em 1972) e na do Ribeirão Água do Erejão atinge $52,4 \%$ (de 42 passa a 64 canais, no refe rido decênio): valor da ordem desse último só é encontrado na área A - bacia do Córrego Daniel Leite: 55,6\% (de 81, em 1962, passa a 126, em 1972), conforme a Figura 14, provavelmentepor ser uma zona de contato dos materiais do Pirambóia e do Estra da Nova, segundo o mapa geológico de SOARES (1975), além, 10gicamente, do relevo excessivo e pequena espessura dos solos.

Como tanbém verificou KOFFLER (1976), dentre os solos mais espessos aqui analisados (RLV e Podzólicos), aqueles com naior gradiente textural (solos com 1 textural) são os que apresentam os índices de drenagem mais elevados, a evi denciar a importância dessa característica no estudo da relação infiltração/deflúvio; ao lado da posição topográrica ocupada pelos solos (relação com o relevo), pelas modificações impostas às condições de dinâmica da água (SOUZA, 1975). Tais fatores, aliados à natureza do embasamento rochoso, são us ex plicativos para as principais diferenças nos valores dos pam rânetros das redes de drenagem pera os fodzólicos originários de diferentes arenitos (FRANÇA, 1968; DASQUES FILHD, 1972 ; KOFFLER, 1976). 
Considerações semelhantes poder ser estendidas aos diversos Litossolos, que apresentam, via de regra, elevados valores de Dd e Fr, independentemente da natureza do subs trato rochoso (FRANC, , 1968; hiARCHETTI, 1969; FREIRE, 1977).

A partir dos elementos analisados, verificamse que, à exemplo de AUDI (1972), a drenagem e as caracteristicas erosivas (naturalmente o relevo incluído, como elemento indissociável) são componentes fundamentais nos estudos de fo tointerpretação de solos.

A ação do relevo, relatada por fEMTEndo (1974), influenciando a dinâmica da água nos perfis, e propiciando a diferenciacão dos solos na "catena", aqui evidenciada clara mente nos diversos aspectos tratados, pode ser analisada também de maneira inversa, numa recíproca verdadeira (infiluência dos solos sobre o relevo), a pertir dos mesmos resultados, e da constatação de FRANCA (1968), ao relatar que materiais de texturas semelhantes e depositados pelo mesmo agente de trans porte podem dar origem a solos distintos, cujas direrençasvão se refletir tembém na composição e características do padrão de drencigem. Desta forma, a menção de RUELLAN (1971) é bastan te perínente, ao arirmar que a evolução dos solos e a evolução do relevo estão estreitamente ligadas entre si, influenci ando-se mutuamente a todo o instante.

En função dos valores de Dd e Fr obtidos para as três áreas, cada una com predomínio de ume unidade de solo, a seguinie ordenação decrescence de valores para aqueles parärnetros é observada: Litossolos - Solos com B textural - Solos Recossólicos, cuja sequência coincide com a verificada por Franca (1968), e que é a mesma (em ordem crescente) para o grau de evolução dos solos.

5.4. Quadro analítico da evolucão da paisagen

A partir das discussõos efétuadas, observa-seque 
a região estudada apresenta feições de particuler interesse à elucidação dos processos pedogenéticos envolvidos na evolução do relevo, eri função da instalação e desenvolvimento da rede de drenagem, comandando os processos de erosẽo e sedimentação, com influências narcadas por clternâncias climáticas ocorridas no passado geolócico de diversas regiões do globo, dentre as quais a Depressão Periférica é um característico compartimento topográfico de origem permanentemente denudacional (AB' SAEER, 1969a).

Infelizmente, nos levantamentos pedológicos efetuados pelos órgãos governamentais, posteriormentie á área do Estado de São paulo (COMISSR̃o DE solos, 1960) e à região de Furnas (COKISSÃO DE SOLOS, 1962), não se tem mais levado em conta a distríulição dos solos em função da evolução da paisa gem, preocupação visivelmente demonstrada anteriormente, possibilitando melhor entendimento dos renômenos pedogenéticos.

A existencia dos distintos compartimentos em ám reas conifiguas, a exemplo do que ocorre ao lado leste da região escudada (DINS FERREIRA e QUEIROZ NETD, 1974), ou logo ao nordeste (COUTARD et alii, 1975), possibilita uma interpre tação da evolução da paisagem aos moldes daquela apresentada por BEINROTH et alii (1974), en que uma superfície de solos bastante evoluidos (Oxissolos) sofie entalhanonto, propiciando a individualização de Ultissolos (solos com horizonte arg? lico - E textural) e solos pouco evoluídos em posições de ver tentes, associados a exposições rochosas.

Na região ern estudo, as áreas $A$ e $C$, de redes de drenagem sensivelmente diversas da área $B$, seriam caracieristicamente anuelas rejuvenecidas pela erosão de solos latossólicos antigos (QUEIROZ NETO, 1970a), de velhas superícies de erosão (BENNEmin et alii, 1962), revelando aquelas formações. menos espessas, cono os solos com B textural (PVA e PVls), so los de transição (NVA $\times$ Liar) e Litossolos (Liar/I, Liar/2, . $\mathrm{Li} / \mathrm{I}$ e Li/2), frequentemente de material retrabalinedo, ao lon 
go das vertentes.

Assim sendo, parece generalizar-se a constatação de MARCOS e KINJO (1967), que um Litossolo não representa necessaxiemente un perfil no inicio de sua forraça, pois a ero são em tempos passados promoveu a remoção de camedas de solos romados, e a situarão em que hoje ele ocorre pode ser uma barreira ao acúmulo de materiais edarizados. Nos locais onde há condicõos topográricas para acúmulo de materiais nessas ám reas rejuvenescidas, o kento se espessa, dando origem aos som los com 0 texitural, sendo frequente a natureza mista do materiel oxicinal (autóctone + alóctone), como também verificado pela ConISSRO DE SOLOS (1962) e ANTUNES (1971), com camadas superficiais arenoses resultantes de coluvionamenio en perío. dos recenties (ROTTA, 1975).

De natureza visivelmente diversa $\dot{E}$ a superficie de disposição dos solos da érea B (Pirambóia), bem mais evoluídos, en função principalmente da espessura, pequena expres sãọ dos horizontes, srau de saturação em bases e tipo de argi 1a. Tais solos foren impropriamente caracterizados como "pouco desenvolvidos", em razão dos baixos teores de argila (CDMISSÃO OE SDLOS, 1960), e meis tarde o termo Regossolo ficou reservado pera materieis fracanonte alterados, de natureza in consolidoda, reletivamente rico em ninerais meteorizáveis: pa ra os demais solos arenosos, quartzozos, com ausencia ou muj to baixa proporço de mincke is decomponiveis e baixa satura. ção en bases, CAmRRgo e BENHEmA (1966) Utilizaram a designação Areias Acirlas Vermelhas e fimarelas, no "Delineamento Esw quenático dos Solos do Erasil".

Entretanto, a própria corissÃo DE SLLOS (1960) menciona que tais solos, derivados de moteriais pobres em arm cilas, ou em nineraje primérios que possam ser uransformados em argilas, não mostram numa sequência de alteração nen a fase podzólica bem desenvolvida, nem a litossólica, mantendo-se "regossólicos". 
Realmente, diversos são os pesquisadores que colocam tais perfis de natureza arenosa como componentes de categorias de solos en avançado estágio de alteraçõo: os psamme - ferralíticos de Angola (BOTELHO DA COSTA et alii, 1964) e de outras regiões africanas, cuja evolução se fez no sentido da ferralitização (CHATELIN, 1972), como na Costa do harfim, sobre areias Terciárias e quaternárias (ROOSE e CHEROUX, 1966). Na vizinha região de São redro, COUThRD et alii (1975) consideram-nos como solos com B latossólico arenosos (sedinentos neocenozóicos, sedimentos modernos, Formação Rio (laro).

Assin, essa superfície de donínio dos perfis aqui denoninados RLV apresente analogias con aquelas de solos de senelinante natureza, da região da Serra do Limoeiro (DInS FERREIRA e QUEIROZ NETO, 1974) - a cotas selweIhentes, ou ligeiramente nais elevadas, das Colinas do Sistena feixe-Bonito (final do Neóreno), correlacionados certamente aos materiais arenílicos Cenozóicos, próximos a lirambóia, meveados por sol RES (1975). Talvez essas superfícies possam ser consideradas como contemporâneas, ou, pela posicão que as terras dárea B ocupen, un tanto mais rebaixadas que aquolas, possam ser mais recentes, porér com a grande parcelo de seus materiais de recobrimento delas provenientes, a montanie, quando do desmante lamento da superfício de aplainamento elaboreda por processos de pedimentação extensiva (Superfície Neogênica), pelos cursos d'água, num processo sihilar ao verificado tambérn em áreas hais distantes (ABREU, 1976).

Desta forma, os materieis poderion ter af chegado já com un clevado grau de alteração, desde o início praticamente con aquelas ceracterílicas próprias dos solos com B lotossólico, sen eren caracteristicanente nembros de una sequência do tipo: Li - Solo con B textural - Solo com B latossólico, cono entrevê a COLISST̃o DE SULOS (1960); a própria CO RIISSÑO DE Salos (ISб2) a irma que a latolização expressa em um solo pode ter-se realizado em outro solo primitivo, que 
forneceu os produtos de erosão para a constitutição daquele. Também para BENNELA et alii (1970j, as caracteristicas dos UL tissoios e oxissolos podem ser tomedas coio inciependentes, um tipo de perílz não sendo orjeinário do outro.

Esses solos considerados "velhos", como os latos sólicos, seriam os representantes de processos mais antigos o correntes na área de estuda, fruto de remobilizacão, transpor te e deposição, que a cada episódio, no entender de Guerroz NETO (1976); devem rerder elenentos e degradar-se cada vez neis, onde a floculação e o "onvelhecimento" da fração arcila conferenm line estabilidade, sendo encontrados frequentemente en suparfícies de erosão do Terciário ou do Queterná:io Inrerior (QUEIROZ NETO, 1975). É, portanto, lósico supor que um material sujeito a determinado tipo de intempexismo durante período longo apresente grau de alteração nicior do que aquele sujeitio às mesmas ações durante tempo nenor (QUEIROZ NETO., 1971).

0 Iongo tempo de exposição desses nateriais, sob a ação do uscileções climáticas, tende a abrandar o efeito da suparimposiç̃o de caracteres de pedogêneses sucessivas, dificultando as interpretacões dosse natureze, como veisicicou Fauck (1964) em Solos Fracamente Ferralicicos da Africa Orien tal. Deterninadas ceracterílicicas hoje observadas podem sex devidas a reações irreversiveis que aconteccram no passado (HACK, 1972).

JEGSUl (1960) lembra que peleoclinas relativamen to mais únidos scitom responséveis por una coberture vegetal mais espesso, com diminuição da ação erosiva ao mínino e intensa ação pedogenética; nas fases de clima mais érido haverie rarefação da vecetação, seguida por processos erosivos a. celcrados, frocessos esses ocorrontes en pexíodos mais recen tes do quaternário.

A esse respoito, a interpreteço para a ocoriên- 
cia de cerrado na área B (Pirambóia), eri solos RLV, pode ser correlacionda às observações de CHRISTOFOLETTI (1968), que se baseou nas alternâicias climáticas ao longo do quaternário, culminando na fasc únida atual, a favorecer o desenvolvimento da floreste, en substituição ao corrado, com entalhamenico rilu vial e elaboração de um relevo novimontado, con rorioção de so los antigos e seu consequente rejuvenecinento (áreas $A$ e $C$ ). Onde o relevo não chegou a apresentar un grau de movimentação capaz de promover a perda do capeamento anijigo a a removação das camadas pedológicas, com permanência das antigas formas de relevo sueve (área B), o cerrado continuou a subsistir, Ie cobrindo solos pobres e antigos (RLV), cuja manutenção ainda se encontra favorecida pela alternância de estacões secas o ú midas, enquanto que as florestas foram devastadas pela ocupação humana.

Estas duas feições distintas (áreas $B$ e $A+C$ ), Ie flexo do tempo mais ou henos prolongado durante o cual o mate rial soirreu as eçōes pedogenéticas, correspondem, portanto, a entidades geomorfológicas bem definidas (QUEIROZ NETO, 1970), e cada eśágio na scouencia de alteiação pode ser apropriadamente locado na história do Quaternário, segundo finTSUI(1969), contribuindo para uma representação das mudanças no heio atual. A pediplanacẽo sob clima semi-árido ocorrida no Plioce no serve como ponto de partida para a datarão relativa dos acontecimentos verificados no Quaternário, apás seu entalhamen to pelos cursos d'água (I-ENTERDU, 1974).

Além dos mencionados materiais mais antigos vizi nhos, corzelacionados a superfícies elaboradas no Terciário (DIAS FERRETRA Q QUEIROZ NETO, 1974; SOARES, 1975; COUTARD et alit, 1975), aparecem como testemunhos contemporâneos àqueles as camadas aryilosas, wais ou menos espessas, dos leitos das vossoracas, amplemonte distribuídạs nas regiões cincunvizinhas (PAIVA NETO e PACCOLA, 1972). No extremo opusto, com relação à recenticidade dos materiaiş, aparecem os depósitos de 
várzeas, normalmente sujeitos a processos de hidromorija e Ie feridos ao Holoceno (PInS, 1970), contundo baixos terraços co Iongo dos vales (especialmente ao longo do Rio Salgado), tesm temunhando as ações erosivas e as pulsações climáticas; entre esses duis extrenos estarian situados os sojos presentemente estudados: os RLV da área B (Pirambóia) se eproximando aos ma teriais da superficie nais antira e os das áreas $n$ e C (B tex turais e Litossolos) aos mais recentes.

A ação antrópica nos dias únidos ctuajs vem acelerar os processos erosivos, pela rotirada da veretação florestel, ao lado do intemperismo químico ocorrente, condição essa que difere sobremaneira do outros períodos úmidos anteriores, de entalhamento pelos rios, atividade erosiva em vertenues restringida ao mínimo, pela proteção plosostal, acompa nhada por intenso processo de meteorização química.

As dîferengas observadas com relação à natureza dos solos (em seus múltiplos aspectos) são, de modo similar ao verificado por CARVRLHo (1975), uma função das diferenças nos, wateriais de origeh, idade e posicão topográrica dos perfis. 
6. CONCLUSÕES

- estudo eferuado possibititra constatar uma nitj da associação da distríbuição dos solos (e seus graus de alte ração) com elementos da paisagem, especialmente o rejevo, cujas particularidades são indicadas mediante a caracterização da rede de drenagem, no conjunto da área.

Con base princirolnente na espessura dos perfis, grau de saturação em bases, tipos de argilas, capacidade de troca de cátions e mobilidade da fração arcila, os solos RLV (área B - Firambóia) são os que atingiran maior estado de maturidade, em comparação aos demais existentes. O henor grau de evolução é demonstrado, evidentemente, pelos Litossolosdas áreas $A$ e $C$ (Juquiratiba e Anhembi), e um estágio internediário é epresentado pelos fodzólicos dessas mesmas áreas.

A montmorilonita, principal mineral de argile presente nos Litossolos, alterarse para caulinita, à medida que as condicões de confinamento do meio se atenuam, passando este mineral a ser o tipico de perfis hais evoluidos, como os RLV e os podzólicos espessos. Nos Litossolos da área C (Anhem bi), ao lado da montrorilonía, a ilita assune importância,cy ja ocorrência é atribuída à herchça da rocha-mãe, fornecedora de tois produtos (Fornação Estrada Nova), que, em mistura com materiais da Formação firambóia, vão constituir tais solos; tanbén a métahloloisite parece restrita a eoses meios confina- 
dos de alteração recente, ao lado da ilita.

A naúlureza das alteraçós é, pois, bissialítica nos Litossolos e nos solos de transição pouco esuessos (fVA $x$ Liar), e monossialítica nos demais solos, eril funcão das condj ções de maior ou menor confinamento do meio de alteração.

Processos erosivos ao longo das vertentes revew Iam a Corçe da morfogênese nessas áreas de nantros arenosos (Formação Firamója). recobrindo materiais nais finos (Formação Estrada Nova). Na área A (Juquiratiba), de domínio de solos rasos, o relevo é mais dissecado, con processos erosivos mais intensos, a afetar o desenvolvinento dos mesmos; en locais esparsos, onde o relovo é mais suavizado, eles parecem sofrer espessamento e evoluir para solos fodzólicos, em cond çöes nais estáveịs, recebendo coniribuiçöes coluviajs de mate riais a montantie. Esses processos de coluvionamento são facil hente evidenciados nas áreas mais jovens ( $A$ e $C$ ) marcados ou não por "stone-Iines", a denunciar as alternâncias climáticas ocorridas na érea, ao longo do quaternário.

Nesses solos jovens, mesmo nos pouco espessos $L_{i}$ tossolos, a argiluviação revela ser um mecanismo praticamente atual no desenvolvimento dos perfis, reflexo de certa mobilidade das argilas, que não se verifice nos nais evoluidos RLV, cuja evoluço parece sez independerive dos solos anieriores, “ sendo originários de materiais anticos, pré-alterados, cuja . principal tonte é caracterizada pulas velinas e espessas supe fícies arenosas vizimhas, à mentante (testemunhos da Neogênica): nãu se exclui, ontretantio, a participação de produtos provenientes das vertentes descarnadas, em posições que permi tam tal evontualjdade.

As Iedes de drenagem das éreas $A$, B e $C$ mostraram-se si nîicativanente distintas, por intermédio dos índices densidade de drenagem (Dd) e frequência de rios (Fr), reilevindo as diferenças entre a relacão infiltração/derlúvio de cada área, a indicar certa analogia com as condições de - 
confinamento, ou seja: o grau de evolução atingido pelos solos (nas áreas A, B O C) está numa sequência inversa dos valo res de Dd e Fr: RLV - Podzólicos - Litossolos:

Dois compartimentos topográficos são evidentes : a cotas 580-560 m (área B - Pirambóia; solos RLV) e a cotas inferiores, predominando valores em torno de 540 metros (áreas $A$ e $C$; solos fodzólicos e Litossolos). Os solos arenosos da primeira corresponden a uma superfície mais entiga, na'área de estudo, sofrendo uma evolução latussólica ou ferralítí ca, cuja elaboracão está correlacioneda ao Pliompleistoceno, enquanto que os demais perfís de vertentes serjan os represen tantes de una superficie mais reconte, provavelmente atribuída ao Pleistoceno Superior. Certamente os depósitos de vale, que não se constituíran en objeto de estudo do presente traba lho, correspondem aos processos mais atuais, relativos ao Holoc sno.

Essas diversidades encontradas nos diferentes so los caracterizados são, pois, o resultado das variações. nos materiais de origem, nas idades e posições topográficas dcs perisis. 
7. SUMMARY

A region between Canches and Anhembi (Siate of São Paulo - Brazill is studied in this uork. There are three disinguished areas in relation to soil distribution and relief variations: Lithosol - calcareous sandsione substratum phase is dominant unde: sirongly undulated relief, in area $A$ (Juquiratiba); Regosols intergrading to Red-Yellow Latosols (RLV) occur under lightly undulated relier, in area B (firam bóia) and Red-Yeliow Podzolic Soils - Variation Laras are dis tribuied under undulated relief, in the area c (Anhembi).

Caicareous sandstones (Mesozoic) occur mainly in this region, with secondary occuing of faleozoic naterials (specially sirales).

$n$ drainage pattern foitointerprotative siudy from each area and the profile weathering degrees were made in or der to relate the distribution of soils and the landscape, by using morphology, routine physical, chemical and nineralogical analysis ( $X$-ray diffraction, differential thernal analysis and eletronic microscopy).

A high degree of weatiliering was presented by area $B$ soils, in opposition to area A (Lithosols), and an alterasion intermediate level for the fodzolic Soils from area $C$, based on depth, bases saturation index, CEC, clay mineral types and fine fraction mobility. Montmorilionite is dominant - 
under lightly invernal drainage condtoions (nainly in the shad low soils), wich is altered to Kaolinite in well drained propiles.

$$
\text { Rondonised circular seven samples from each area }
$$
showed stgnificant differances amone "drainage density" and "stream frequency", with the following values: $A=3.02$ and $11.50 ; B=1.62$ and $4.10 ; C=2.61$ and 0.76 , showin different infiltration/runoff ralationships, and therefore different ew rosion resistences.

Erusive processes duin tho quaternary were res ponsible by the ancient erosion surfece dismanting ("Noogenic"), with young soils formation (Lithosols and Podzolic Soils) on a. ceomorphic surface, probably rolated to Superior Pleistg cene. Ancient soils (RLV) renain at the areas where relief did not prosent conditions for producing those occurrencies. Contributions of ancient and poor upside naterials (Neogenic) yould be responsible by "cerrado" ve: etation, related to dry climate from Quaternary (Plio-Fleistocene).

The found differencos are explained based on parent naterial variations, ages and profile topouraphic positions. 


\section{LITERATURA CITADA}

ADREU, h.A.de, 1976. Relevos cuestiformes do leste paulista - extreno do alto vale do Ribejxão dos foxcos. Boletim Ee: Isto de Geogafia, São Paulo, (50):47-55.

ABDALLA, S.L.F., 1973. A evolugão da drenagem conforme a teo ria davisiana. Not. Geonorfol., Campinas, 13:69-77.

AB'SAPER, A.R., 1969a. A depressão perifézica paulista: um se. tor das áreas de circundesnudagão pós-cretácica na lacia. do Paraná. Geomorfologie, Iceog/usp, sỏo raulo, (15):15 p. ABSAEER, A. H., 1969b. Una reysãono do quaternário paulista: do presente para o passado. Rev. Bras. Geogr.s. 31:1-51.

AE'SAEER, A.N., 1072. Farticipacão des depressões pariféricas e surerficies aplainadas na compartimentação do Vlanalto Erosileiro. Goomoriolonia, IGEOG/USF, São paulo, (28):3Bp. ALfiEIDA, F.F.nide, 1964. Fundanentos geológicos do relevo paulista. In: Geolo ia do Estado de S̃̃o lavlo, Eoletim do Instituco Georráfico e Geológico, São faulo, (41):167-263. ALOISI, R.R., G. RANZANI, J.L.I.DERITTE E C.C. CERRI, 1975.Mineralo ia da rraço arjila de aluns solos do fiunicipio de Jaboticabal, SP. In: Anais do XV Congresso Erasileiro de Ciêncie do Solo, Caminas, p. 457-460.

ArinAL, A.Z.do e R. AUDI, 1072. Fotopedoloria. In: Elementos de Podologia, monIz, f.c., ed. Polígono, São laulo. p. 429-442 . 
ANDRADE, 5.S.de, 1971. Gênese e Classificação de Solos de Três Catenas nos fiunicipios de Piracicaba e Rio Claro. Piracicaba, ESALn/USP, 74 p. (Dissertoção de fiestrado).

ANTUIES, F. dos S., A.0. MARTINS, L.L. AMTUIELLD e I. A. GO-

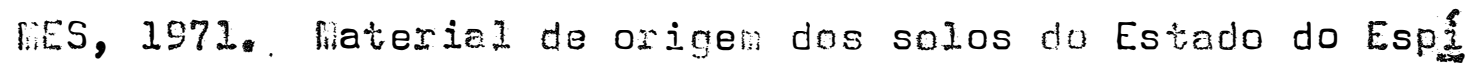
rito Santo. In: Anais do XIII Congresso Erasileiro de Ciân cia do Solo, Vitória, p. 104-105.

nUDI, R., 1972. Fotointerpretaça de Aiributos dos Canais de Drenagem en Solos da Recião Noroeste do Estado de São Pau10. Viracicala, ESnLn/USF., $182 \mathrm{p}$. (Tese de Doutoramento). AZOLIN, m.A.D., E. KLAMT e Ri.C.L.dos SANTOS, 1975. Relaçöes solomsuperfícies geomórficas e naterial de origen a este da Depressão Central e Campanha no Rio Grande do Sul. In: Anais to XV Congresso Erasilejro de Ciencia do Solo, Campj nas, p. 345-350.

BARTELLI, L.J., 1973. Soil developnent in loess in the Southern Mississipi Valley. Soil Scie, New Brunsuick, 115: $254-260$.

BEINRUTH, F.H., G. UEHARA e H. IKAUA, 1974. Goonorphic relationships of pxisols and Ultisols on Kauai, Hawaii. Soil Sci.Soc. Alier. Proc, Rladison, 38: $128-131$.

BENUEMA, J., Ni.N. CAMARGO e A.C.S. URIRHT, 1962. Regional contrast in South fmerican soil formation, in rolation to soil classification and soil fertility. In: International Soil Conference, flew Zealand, Intern. Soc. Soil Sci. p. In -15 .

BENAENA, J., A. JONGERTUS e R.C. LEMOS, 1970. Ritcromorphology of solie oxic and argillic horizons in South erazil in relation to weathering sequences. Geoderina, Ansterdan, 4: $333-355$.

BIGARELLA, J.3., R.R. fiOUSINHO, fi.R. e J.K. SILUA, 1965. Pediplanos, pedinentos e sous depósitos correlativos no Bra- 
sil. Boletim Faranaense de Georaria, Curitiba, (16-17): 117-152.

EOCQUIER, R. G., H. PACUET e G. MILLOT, 1970. Un nouveau type d'accumulation dijlique dans les paysages géochimiques: l'in vasion remontante de la montuoritjonite. C.R. Acad. Sc. Paris, t. 270, série D, p. 460-463,

DOTELHO DA COSTA, J.V., E.I.C. FRARCO e R.P. RICARDO, 1964. Ceneralized soil nap of Angola ( $2^{\text {nd }}$ Aproximation). In: Trans. Bth Intern. Concr. Soil Sci., Bucharest, p. 153-162. ERINDLEY, G.W., 1951. X-Ray Identification and Crystal Structures of Clay minerals. fiiner. Soc. (Clay fineialo ical Group), London, $345 \mathrm{p}$.

BRIfDLEY, G.W., P.de SOUZA SHATOS e H. SOUZA SRMTOS, 1063. Mi neralopical studies of kaolinite - halloysito clays: Part I. Identification prollems. An. Mineral, \$8:397-910.

BRown, G., 1961. The X-Ray Idontification and Crystal Siructures of clay flinerals. fiiner. Soc. (Clay filnoralo ical Group), London, $544 \mathrm{p}$.

CADY, J.G., 1060. Riincral occurrence in relation to soil profile differentiation. In: Trans. 7th Intern. Concr. Soil Sci... Ameterdan, Elsevior, 4:418-424.

CAILLËR, S. e S. HENIN, 1963. Minéralo ie des Areiles. Mas son et Cie, faris, 355 p.

Margo, M.N. e J. EENMEMA, 1956. Delineanento esquenático dos solos do erasil. Pesc. arrug. bras., Rio de Janeiro, l: $47-54$.

CARVALHO, A., 1970. Study of Texra Roxa Estruburada and Latos. solo Roxo on a topographic sequence in Sao Paujo State, Bra zil. Newcastle upon tyne, University Newcastle upon tyne, $93 \mathrm{p}$. (Thesis Master Sci.). 
CARURLHO, A., 1976. Solos da Região de fiarília. Relorões Entre a fedogênese e a Evolução do Relevo: São faulo, Insìtuto de Eeociûncias/USP, $163 \mathrm{p}$. (Tese de Doutoramento).

CATARI, R.A., 3.R. GALLG e H. GRRGANTINI, 195!. Amosiragern de solo. Rétodos de análise. Interpretecão. e indicacões gerais para fins de fertilidade. Bol. Inst. agron. Canj nas, Campinas, (69):1-28.

CERRI, C.C. e R.R. AlOIST, 1975. Altracã̃o do Tranicio de Itu: vênese e alteração dos minerais secundários. In: Anais do XV Congresso Brasileiro de Ciência do Solo; Campinas, D. $451-455$.

CHITELIN, Y., 1967. Influence des conceptions geomorphologiques et paléoclimatiques sur l'interprétation de la cenèse et la classification des sols ferralitiques d'Afrique Centrale et fusuralie. Cah. O.R.S.T.O.M., Gér. Pédol., taris, $5: 243-255$.

CHATELIN, Y., 1972. Les Sols Ferralitiques. Tone I - Hiscori que, Développencht des Connaissances et Fornation des Conconts Actuols. Injciations et Documentations, D.R.S.T.O.R. Paris, (20):98 p.

CHRISTOFOLETTI, A., 1960. O fenômeno morfoçenético no fiunicí pio de.Campinas (SP, Erasi1). No Eeonompols, Campinas, $8: 3-97$.

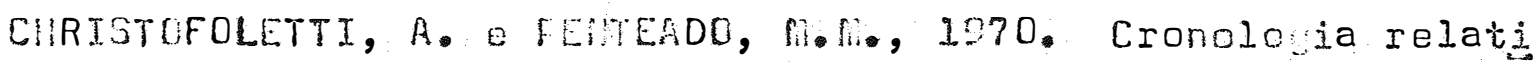
va do Ouaternário na Depressão Periférica Faulista. Not. Geonorifol., Campinas, 10:35-46.

CHRIGTOFOLETTI, A. O J. ARANA, 1076. Estwuração de redes hidrográficas na roctão norto-ociclontal do Estado de São Paulo. Eoletim faulista de Gegrarja, (52):5-27.

CORISSR̃o DE S LOS, 1960. Levantamentio de Reconhecinentio dos Solos do Estado de são faulo. Boletim do Centro Nacional. de Ensino e Fesquisas Agronônicas, Rio de Janoiro, (12): $634 \mathrm{p}$. 
COMTSSÃo DE SCLOS, 1962. Levantonento de Reconhecimento dos Solos da Reuião sob a Influencia do Reservatório de Furnas. Eoletin do Ceniro Nacional de Ensino e fesquisas Agrononicas, Rio de Janeiro, (13):462 p.

CONCEIÇ̃̃̆, T.M.L., A.C. MONIZ, J.J. OLIVEIRA O G. SIEFFEMMNN, 1974. Les sols à nontmorillonite sur cneiss de la zone tropicale humide de l'État de Eahia. Si nificetion paléoclimatirue. Cah. 0.R.S.T.0.M., SéI. Fédol.., Paris, 12:137$-243$.

COUTARD, J.F., R.I. DIAS FERREIRA, J. PELLERIN e J.F.da QUEIRoz UETO, 1975. Étude prelinineire du fuaternaire de la rerion de São fedro (Sf-Brésil). Simpósio do quaternário, Curitibe (no preto).

DELVIGNE, J., 3965. Pédocenése en Zone Tropjcale. La Fornation des finéraux Secondaires en Milieu Ferralitique. O.R. S.T.O.M., Dunod, Faris. $177 \mathrm{~m}$.

DEMATTE, J.L.I., A.C. TETXEIRA RENDES \& L. GERALDI FILHO, 1072. Ocorrência de montmorilonita em alguns solos desenvolvidos do arenito de Botucatu. Anais Esc. sup. Angic. "Luiz de Queiroz", Piracicaba, 20:30-60。

DIA.S FERREIRA, R. F. e J.P.de QUEIROZ NETO, 1074. Sequéncias de altoraçõo na resião da Serra do Limoeiro, SP. In: Anais do XXVIII Congresso Brasileiro de Geologia, Porto Ale gre, $3: 40-50$.

DUNBAR, R.A., 1950. Proiltem of interpretation in tropical regions. In: hexial Photocraphic Intorgretation: Principles and Applications. New York, flc Graw-Hill Book [a. Inc., p. $426-427$.

ESPIIDOLA, C.R. e H.R. CALHEGo, 1075. Estudo mineralógico de solos da rerião Botucatu - São hanuel, SP. II - A fracão argila do lodzólico Vernelho Amerolu da Fazonda Experimental São manuel. In: Anais do XV Conrresso Erasileiro de Ciencie do Solo, Campinas, p. $445-450$. 
FAUCK, R., 1954. Les Sols Rouges Faiblement Ferralitiques d'

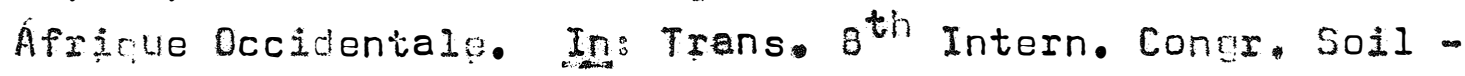
Sci., Eucharest, p. 547-557.

FAuck, R., 1972. Contribution a l'Étude des Sols des Régions Tropicales - Les Sols Rouges sur Sables at sur Gres d'Arri que Dccidentale. Mímoires O.R.S.T.D.m., Veris, (61):257 P.

FRANCA, G.V.de, 1063. Interpretação Fotográíica de Eacias e de Redes de Drenager. Arlicada a Solos de Rerião de Firacicaba. Frecicaba, ESAlq/USt, 151 po (Tese de Doutoramento)

FREIRE, J.C., 1977. Fotointerpretacão de Redes de Drenagen de Três Solos da Região de. Alpiriópolis, Mineras Cerais. Pí racicala, ESnLa/USF, $136 \mathrm{p}$. (Tese de Doutoramenio).

FROST, R.E., 1960. Photointerpretation of soils. In Manual of Photographic Interpretation. Washington, Ai. Soc. of Photogrami., p. 343-402.

FUNDAÇÃu IEGE, 1970. Carta do EIasil. Folha SF-22-R-IV-4-A nhembi (Escala 1:50.000).

GAR:BLE, E.E.e R.8. DANIELS, 1974. Parent naterial of Upper and filddle - Coasial - Plain soils in North Cacolina. Soil Scj. Soc. Amer. Proc... liadison, 38:633-637.

CERASTíV, I.P., 1960. Gloyey Pseudomodzols of Central Euro pe and forration of binary surface deposjis. Soils fertijo Harpenden, 23: $1-7$.

GLoRTA, N.da, R.A. CATANI e T. MATUO, 1964. Método do EDTA no deterbinação do cálcio e nacnésio "irocável" do solo. Anais Esc. sup. Acric. "Luiz de Queiroz", Piracicaba, 21: $220-223$.

GLOMIA, U.da, R.A. CATARI e T. MATU0, 1965. Deteminação da. capacidade de troca de cátions do solo pelo método do EDTA. Revta, Aaric., Piracicaba, 40:193-198.

COEDERT, H.J., J.K. SYERS e R.E. COREY, 1975. Relações caulj ntta-quartzo-gibbsita en solos desenvolvidos de basaltos - 
no Rio Grande do Sul. In: Anajs do KV Congresso Erasileiro de Ciência do Solo, Campinas, p. 495-498.

GONCALVES, A.R. e A.C. MONIZ, 1975. Estudo das argilas de so los das unidades goomorfológicas da bacia da Lagoa firim do terribório brasileiro. In: Anais do. XV Congresso Brasileiro de Ciência do Solo, Campinas, p. 500-516.

HACK, J.T., 1972. Interpretaçõo de topogrâia erodida em regiōes temperadas úmidas. Noi. Geonorfols, Campinas, 12:3-37 .

HilTJENS, H.A. e P. BLEEKER, 1970. Tropical weathering in the Territary of Papua and New Guinea. Aust. J. Soil. Res.. I: $157-177$.

HERUIEU, 7., 1970. Le Ruatiernaire du Nord-Camejoun, schéme devolution geonorphologique et relations avec la pédogene so. Sah. D.R.S.T.D.N...Sér.. Fédol., Paris, 0:295-317.

HORTON, R.E., 1945. Erosional development of streams and their drainage basins: hidrophysical approach to quantitam tive morphology. BuII. Geol. Soc. An.2 Colorado, 56:275-370 .

JACKSON, M.L., 1965. Sold Chemical Analysis: Advaneed Course. madison, Univ. of Ulisconsin, Dept. of Soil Science. 991 p. JACKSON, M.L. e G.D. SHFPhin. Chonical weathering of minerals in soils. Ady. Agron.., New Vork, 5:219-318.

JESSUP, R.W., 1960. Identification and sirnificance of buried soils of Quaternary age in the fouthern Portion of the Aus tralicin and zone. J., Soil Sci., Oxford, 11:198-205.

JomSCH, L.J. e C.D. JEFFRIES, 1957. The effect of drainage on the weathering of the clay minerals in the Allenwood $C_{5}$ tena of l ennsyluanie. So II. Scj. Soc. Anex. Froc., fladisom $21: 539-542$.

KELLER, W.D., 1964. Processes of orilin and alleration of clay minerals. In: Siqia Clay Minoralogy - A Symposium RICH 
c. I. G.W. KUNZE, ed., The Universitity of Norih Caroli na Press - Chape1 Hill, 33* p. p. 3-76.

KILMER, U.J. E L.T. ALEXANDER, 1949. fiethod of nacking mecha nical analysis of soils. Soil Scie, New Erunsuick, 68:15-26 .

KOFFLER, N.F., 1976. Utilização de Imagens Aerofotográricas e Orbitais no Estudo do Padrão da Drenagen en Solos Originados do Arenito Bauru. São José dos Campos, IMfE, $150 \mathrm{p}$. (Tese de flestrado).

LARouroux, he, 1972. Étude des Sols Fornés sur Roches Carbonatées. fédogenèse fersiallitique au Liban. Ménojres . .. R.S.T.O.M., Paris, (56): 266 p.

LEPSCH, I.F., 1975. Soil Landscape Relationships in an Area of the Occidental Plateau of Sao raulo, Brazil. Raleigh, Univ. North Carolina, 163 p. (Tese de Ph.D).

LEFSCH, I.F., R.C. MONIZ e C.L. ROTTA, 1977. Evolução minera ló ica de solos derivados da Forneção Bauru en Echaporã, . São Paulo. R. bras.. Ci. Solo, Carinines, $1: 30-43$.

LUCAS, G., 1962. La transformation des minéraux argileux dens la sedimentation. Étude sur les arciles du Trias. Mém. Serv. Carte gél. A]s. LorI.s, Stransburg, (23):202 p.

LUEDER, D.R., 1959. Aeriaj Photographic Interpretatjon: Ifinciples and Applications. New York, McGraw-Hill Book Co. Inc., $462 \mathrm{p}$.

liACKENZTE, R.C., 1057. The Differential Thermal Invostigation of Clays. finer. Soc. (Clay Mincralo ical Group), London, 456 P.

fAICNIEN, R•, 1966. Conyte Rendu de Recherches sur. Ies latérites. Paris, UNESCO, Rech. Ress. Natur. IV. 154 p. MARCHETTI, D.A.E., 1969. Fotointerpretação de Átrịbutos de Relevo Aplicado a Solos da Região de Piracicaba. Firacica 
ba, ESALQ/USF, 53 p. (Tese de Doutoramento).

kARCOS, Z.Z. e T. KINJ0, 1967. Litosol: suas características e provável gênese. Anais Esc. sur. Acric. "Luiz de Qugiroz", Piracicaba, 24:343-352.

IARTONIE, E.De.,.1943. Problenas morfológicos do Erasil Tropi cal Atiântico. Revista Erasileira de Geograrja, Rio de Ja neiro, $1523-550$.

MatSUI, T., 1969. Two-cycle concept of soil clay genesis and its application to the study of the polycenetic red suils in Japan. In: Proce of the Intern. Clay Conference, Tokyg p. $533-540$.

MicCALLED, 5.0., 1050. The genesis of the Red-Vellow Podzolic soils. Soil Sci. Soc. Aner. Proc., hadison, 23:164-168.

fiELFI, A.J. e F. LEVI, 1971. Geochemical and nineralogical study of the first stages of weathering of basic and Ielat. ed rocks. Part I - hineralocical siudy. Rev. Frasil. Geoc. São Faulo, $1: 22-28$.

MILLOT, G., 1952. Hexitoge et neofornation dans la sedinenta tion argileuse. In: Congres Géolorique International, AlgeI - CIFEA, XIX Session, fasc. XVIII.

filllot, 6., 1964. Géologie des Argiles. Paris, hasson et Cie, $499 \mathrm{p}$.

MITCHELL, B.D., 1962. The instuence of soil forming factors on clay genesis. In: Genese et Synthise des Arriles, Colloques Internationaux du C.H.R.S., Paris, (105):139-147. MODENESI, 1..C., 1974. Coniribuição à Geomorfolo ia da Região Itu-Salto: Estudo de Fornaçnes Superíciais. ECEOH/USP, São Paulo, 90 p. + Apêndice. (Tose de liestrado).

MOHR, E.C.J. e F.A. VAN DAREN, 1954. Tropical Soils. New York, Incerscience Pu! ishers. $498 \mathrm{p}$. 
108.

MoNIZ, A.C. e Mi.L. JACKSON, 1967. Quantitative mineralogical analysis of srazilian soils derived from basic rocks and slates, Madison, Univ. Uisconsin, Soil Sci. Report, (212): $73 \mathrm{p}$.

monIZ, A.C. e A. CARVALHo, 1273. Sequência de evolução de s?. los derivados do arenito Bauru e de rochas básicas da reGião noroeste dọ Estado de São Paulo. Bragantia, Campinas, $32: 309-335$.

fiOHIZ, A,C., P.K. KIYOHARA, A. CARVALHO E F.dE SOUZA SANTOS, 1975a. Notureza mineralógica do fração argila de solos de rivados do arenito Bauru do hunicípio de Pindorama, SP. In: Anais do XV Congresso Brasileiro de Ciência do Solo, Campj nas, p. 509-516.

MONIZ, A.C., S.5. de ANDRADE e H.G. dos SAITUS, 1975b. Inves tịação das relações genéticas do Solonedz solodizado e Planossol do Pantanal de porto murtinho, fiT. In: Anais do XV Congresso Erasileiro de Ciencia do Solo, Campinas, p. $475-400$.

MutTI, C.F. E P. MotTI, 1975. Conentário do mapa narropedoló gico do Setor de Santa Quitéria (BA). Not. Geonorfol., Campinas, 15:65-74.

PAIVA NETTO, J.E.de e A.C. NASC IRENTO, 1957. Minerais de argila do arenito Baury (Cretáceo) do Estado de Sẽo Paulo. Bol. Soc. Bras. Geol. São Paulo, 6:21-35.

PAIVA NETTU, J.E.de e A.A. PACCOLA, 1972. Voçorocas e camadas cenozóicas na. refijão de Botucatu, Pardinho, Águas de São Pedro e Avaré. In: Anais da II Jornada Científica da F.C. M.B.E., Botucatu, Associação dos Docentos de F.C.M.B.B., p. 118.

PAGUET, He, 1070. Évolution Éochimique des hinéraux Argileux dans les Altérations et les Sols des. Clinats mediterranées Trolicaux à Soison Contrastées. Mém. Serv. Carte géol...- 


\section{Als. Lorr, Strasbourg, (30):212 p.}

PEDRC, G., 1969. A alterąão das rochas em condições superf ciajs (perimorîsmo). Caractorização geoquímice dos proces sos fundamentais. Not. Geomorfole, Campinos, 9:3-14.

PELLERIN, 3., 1974. D problema da cartografia das formacõos superficiajs em regionos tropicais - o exemplo do Brasil. Not. Geomorfols, Campinas, 14:105-113.

PENTEADO, M.fi., 1969. Novas informações a respeito dos pavimentos detriticos ("stone-1ines"). Not. Geomorfol., Campi nas, $2: 15-41$.

PENTEADO, M.M., 1974. Fundamentos de Geomorfolocia. Bibliom teca Geográrica Brasileira, Série D, Publicagão no 3, Fundação IEGE, Rio de Janoiro. 163 p.

PENTEADO, fi.fi. e G. RANZANI, 1973. Problemas geonorfológicos relacionados com a gênese dos solos Podzolizados fiarilia. Sedimentologia e Pedologia, IGEOG/USP, São Paulo, (6):23 p.

PIAS, J., 2970. Las Formations Sédimentaires Terciaires et Quaternajires de la Cuvette Tchadienne et les Sols qui en Dérivens. Mémoires D.R.S.T.D.M., Paris, (43):407 P.

PIREUTEL EOfiES, F. 1970. Curso de Estatistica Experinental. Nobel, Såo paulo, 430 p.

QUEIROZ NETD, 3.f. de, 1969. Incervretagâo dos Solos da SerIa de Santana para fins de classificaçoo. Piracicaba, ESALQ/ USF, $335 \mathrm{p}$. (Tese de Dautoramento).

QUEIROZ NETO, 3.P.de, 1970a. Etude sur de degré dialtération. de quelques profils de sols de l'Etat de São paulo, Brésil. Science du Sol, (2):73-85.

QUEIROZ HETO, 3.P.de, 1970b. Les rapports entre les sols dt les. Tomations superficielles de liEtat de. São Paulo, Bré-. sil. État actuel des connaissances. Bull. Ass. sénéd. Et. Guatern. Duest afI., Dakas, (26):57-75. 
QUEzROZ NETo, J.p.de, 1971. Laboratório de Pedologia e Sedimentologia, Instituto de Georraria, UST : seus oijetivos e pronranas de pesquisa. Sedimentolonia e fedoloria, IGEOG/ USP, São Paulo, (I):5 p.

QUEIROZ HETO, J.P.de, 1073. Observações preliminares sobre perís de solo com bandas onduladas no Estedo de São faulo. In: Anais do XIV Congresso Erasileiro de Ciência do Solo, Santa Maria, p. 643.

GUEIROZ NETO, J.F. de e 5.S. de CASTRO, 1974. Formações superficiais e Latossolo Vermelho Amarelo Húmico da áree de Eragança Paulista, Estado de São Paulo, Erasil. In: Anais do XXVIII Congresso Brasileiro de Geologia, Parto Alegre, $3: 65-83$.

OUEIROZ NETO, J.P.de, 1975. Pedogênese no Planalto Atläntico. Contriluicão à Interpretação Paleogeográfica dos Solos da mantiqueira Norte Ocidental. São Paulo, FFLCH/USP, 270 p. (Tese de Livre Docência).

QUEIROZ NETO, J.F.de, 1976. Tendências atuajs das pesquisas de solos em São Faulo. Boletim Paulista de Geografia, São Paulo, $(50): 37-56$.

RANZANI, G., 1969. Manual de Levantamento de Solos. São Pau 10, Edrar Blbcher Ltda. e Editora da Universidade de São Paulo, 2a, ed. $167 \mathrm{p}$.

Y, R. G. 1963. Fotorrafias Aéreas na Interpretacão a Mapeamento Geolóqico. Traducão, do Inst. Googr. Geol., São Pau10. 88 p. e 75 fotogramas.

RAY, R.G. e H.A. FISCHER, 1960. Quantitative photography. A geologic research tool. Photorram. Engng., Washington, $25: 243-150$.

RIEEIRO, L.F., 1974. Caracterização dos Solos de Ibitiara BA. Salvador, Instituto de Geociências/UFBa, $124 \mathrm{p}$. (Tese de Mestrado). 
RICCI, ni. e S. FETRI, 1965. Princípios de Aerorotogrametria E. In turpretacão Geológica. São Paulo, Cia Editora Nacional. $226 \mathrm{p}$.

RICH, C.I., 1960. Ammonium fixation by two Red-Yellow Podzolic soils as influenced by interlayer - Al in clay minerals. In: Trans. $7^{\text {th }}$ Intern. Congr. Soil Sci., Madioon, 4:468-475 .

RIVIÊRE, A., 1952. Sur l'origine des argiles secinentaires. In: Congres feologique Intern., Aleer - CIrEA, (18):177-180. ROCHA PIEDADE, G.C., U.A.CARVALHO TOSIN e G.V.de FRANCA. 1076. Avaliação do desenvolvimento de voçorocamento no munjciplo de botucatu em 10 anos. In: Anais da VI Jornada Cientifica da.FCMBB, Botucatu, Associação dos Docentes da FChiBC, P. 49.

ROTTA, C.L., 1975. Minaralogia de Solos de una Topossequênça de Atibaia, Sp. Sã. Paulo, Instituto de Geociências/uSp. $88 \mathrm{p}$. (Tese de llestrado).

RUELLfN, A., 1971. Contribution a la Connaissance des Sols des Régions héditerranéennes (Marroc Orjental). Mémoires D.R.S.T,O.M., Paris, (54):302 p.

RUHE, R.V.,. 1956. Geomorphic surfaces and the nature of soils. Soil. Sci.e, New Brunswick, 82:441-455.

SECRETARIA DA AGRICULTURA, 1974. Zoneamento Agrícola do Esta: do de São Paulo. Comissão de Zoneamento Agrícola. vol. I, $167 \mathrm{p}$.

SECRETARIA DOS SERVICSOS E OBRAS PÚCLICAS, 1972. AtIas Pluvionétrico do Estado de São Paulo. Centro Tecnológico de Hidráulica, São Paulo. $83 \mathrm{p}$.

SEGALEN, P., 1974. Sols ferralitiques. Surfaces d aplanissem ment et zones de tectonique et volcanisme récents. Pedologie, $24: 147-163$. 
SETZER, J., 1966. Atlas Clinático e Ecológico do Estado do S̃ão Paulo. Comissão Interestadual de Bacia Paraná-Uruguai, São Paulo. $61 \mathrm{pl}$

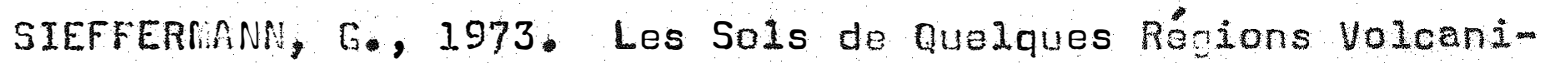
ques du Cemeroun. Variations Pédologicues ot Minéralogiques du hilieu Équatorial au hiliou Tropical. Mómoiros O.R.S. T.D.hig, Paris, (66): $183 \mathrm{p}$.

SIEFFERMANN, G. e G. MILLOT, 1968. Lhalloysiste des sols jeunes sur basaltes recents du Centre Cameroun. Bulleitin. du Groupe Francais des Arciles, Paris, 20:25-30.

SIMONSON, R.W., 1949. Genesis and classification of Red-Yellow Podzolic soils. Soil Sci.Soc.Aner.Proce, ladison, 14: $316-319$.

SOARES, P.C., 1973. Nota sobre a tectônica moderna na Depres são Periférica Paulista. Not. Geonorfol., Campinas, 13: $75-81$.

SOIL SURVEY STAFF, 1951. Sojl Survey fianyal. Uasinjnton, Soil Conservation Service, U.S. Dept. Aric. $502 \mathrm{p}$.

SouzA, hil.de F,, 1975. Fotointerpretação das Redes de Drena geñ de Três Solos com Horizonte B. Latossólico Ocorrentes no Município de Ponta Grossa - PR. Piracicaba, ESALQ/USP, 135 p. (DLssertação de Mestrado).

STRAHLER, A.N., 1957. Quantitative analysis of watershed geo morphology. Irans. Am. Geophys. Union, New Maven, 38:913-920 .

VAN WAREEKE, A., 1967. Recent developnents in the classifica tion of the soils of the tropics. Soil Sci.. New Brunsuick, 104:309-313.

VASTUES FILHO, 3., 1972. Critérios florfométricos Aplicados à Fotoincerpretação de Redes de Drenagem en Três Unidades de Solos no municppio de Piracicaba. Piracicaba, ESALa/ USP, $113 \mathrm{pe}$ (Tese de Doutoramento). 
113.

VILLIERS, J.filde, 1965. Present soil-forming. factors and pro cesses in tropical and subtropical regions. Soil Sci.e, New Brunswick, 29:50-57. 